DOT/FAA/CT-91/11

FAA Technical Center

Atlantic City International Airport

N.J. 08405

\title{
CONTROLLER EVALUATION OF INITIAL \\ DATA LINK EN ROUTE AIR TRAFFIC \\ CONTROL SERVICES: MINI STUDY 3
}

The Data Link Development Team

June 1991

Final Report

This document is available to the U.S. public

through the National Technical Information

Service, Springfield, Virginia 22161

U.S. Department of Transportation

Federal Aviation Administration 

This report documents a Federal Aviation Administration controller evaluation of air traffic control (ATC) Data Link services planned for implementation in the en route ATC system.

The main body of the report includes a detailed description of the objectives of the study and of the technical approach and test methods that were used. In addition, the combined results of the study, conclusions, and recommendations are presented. There are four appendixes to the report. These appendixes are referenced in the main body of the report and include documentation of the controller inputs used to deliver the test services, controller questionnaires, airspace configurations, and controller discussion issues. 


\section{ACKNOWLEDGEMENTS}

The study reported in this document was conducted at the Federal Aviation Administration (FAA) Technical Center by the Airborne Collision Avoidance and Data Link Systems Branch, ACD-320.

The planning and execution of the study were the results of cooperative efforts of several members of the Data Link Development Team. In particular, the following individuals played key roles in this research:

FAA Technical Center, ACD-320

Nicholas Talotta

Thomas Pagano

George Chandler

Ephraim Shochet

Henry Marek

Air Traffic Data Link Validation Team

Sam Bass, ATR-320

Gregg Anderson, Ocean TRACON

Michael Blomquist, Denver ATCT

Edward Brestle, Ft. Worth ARTCC

Michael Bullington, Sacramento TRACON

Barbara Cassada, Denver ARTCC

James Cherry, Miami ARTCC

Greg Colclasure, Kansas City ARTCC

Mona Colclasure, Kansas City ARTCC

Joe Dalessio, New York TRACON

Evan Darby, ACD-320

Dana Jones, Ft. Worth ARTCC

Jerry Karrels, Madison, WI, Tower

David Lister, St Louis ATCT

Charlotte Long, Ontario, CA, TRACON

Tom Ray, Tulsa Tower

Steve Reutepohler, Cleveland ARTCC

Joe Strietzel, Anchorage ARTCC

Universal Automation Leasing, Inc.

John Evans

James Merel

The MITRE Corporation

Frank Buck

Preston Cratch

Robert Lautenschlager

Dave Sweeney

Appreciation is also extended to the staff of the Technical Facilities Division, $A C N-300$, who provided the expertise required to keep the many NAS test systems operating in order to prepare and conduct these tests: George Kupp, Dick Algeo, Dan Warburton, and Hank Smallacombe. 


\section{TABLE OF CONTENTS}

\section{Page}

EXECUTIVE SUMMARY Xi

1. INTRODUCTION 1

1.1 Purpose 1

1.2 Background 1

1.3 Objectives 2

1.4 Test Environment 3

2. METHOD 3

2.1 Participants 3

2.2 Simulation Facilities 3

2.2.1 NSSF and VAX Laboratory 4

2.2.2 En Route System Support Facility (ESSF)

Display Laboratory 5

2.3 Research Design 8

2.4 Procedure 8

2.5 Simulation Runs 8

2.6 Traffic Samples 9

2.7 Data Collection 10

3. TEST RESULTS 11

3.1 Controller Discussion Issues 11

3.2 Post-Experiment Interview (Debriefings) 11

3.2.1 Washington ARTCC Airspace Evaluation 11

3.2.2 Test Bed Software Validation 15

3.2.3 Automatic Transfer of Communication 16

3.2.4 DL/OK With the S Option And DL/OK From Any Sector 19

3.2.5 Held TOC Messages Not Bright 19

3.2.6 Sending Data Link Eligibility 20

3.2.7 Altitude Timeshare 21

3.2.8 Full Data Block Failure Display Options 21

3.2.9 Menu Text Referent in the status List 22

3.2.10 Free Text Recall 22

3.2.11 Communications Backup Downlink 24

3.2.12 D-Position 31

3.2.13 Data Link Procedures 33

3.3 Altitude Timeshare Display: System Impact 34 
$\begin{array}{llr}3.3 .1 \text { Analysis } & 35 \\ 3.3 .2 & 35\end{array}$

3.3.2 System Impact 35

vii

TABLE OF CONTENTS (CONTINUED)

3.4 System Data 36

3.5 En Route-Terminal Joint Airspace Discussion 37

4. CONCLUSIONS 37

4.1 Test Bed Activities 37

4.2 Voice Check-In/Initial Contact 38

4.3 Automatic Transfer of Communications 38

4.4 Sector Data Link Displays 38

4.4.1 Plan View Display (PVD) Information 38

4.4.2 Computer Readout Device (CRD) Information 39

4.5 Data Link Eligibility 39

4.6 Altitude Timeshare 39

4.7 Menu Text Referent in the Status List 39

4.8 Free Text Recall 40

4.9 Communications Backup Downlink 40

4.10 D-Position Operations 41

4.11 Future Testing for Workload Reduction 41

4.12 Data Link Procedures 41

5. RECOMMENDATIONS 41

5.1 Test Bed Activities 41

5.2 Voice Check-In/Initial Contact 42

5.3 Automatic Transfer of Communications 42

5.4 Data Link Failure Displays 42

5.5 Items for Operational Test and Evaluation (OT\&E) 42

5.6 Communications Backup Downlink 43

5.7 Future Testing 43

5.7.1 Training Requirements 43

5.7.2 D-Position Responsibilites 43

5.7.3 Altitude Timeshare Display Impact 43

5.7.4 Data Link Procedures 43

6. REFERENCES

APPENDIXES
A - Controller Questionnaires
B - Controller Discussion Issues
C - Sector Descriptions
D - Controller Chart 
viii

LIST OF ILLUSTRATIONS

Figure

Page

$1 \quad$ ATC Data Link Test Bed

2 CDC ESSF Display Laboratory Configuration

for the Leesburg ARTCC Data Link

Simulation

3 Controller Workload Ratings

4 Controller Scenario Ratings

5 DL Setting, $\mathrm{T}$, Auto or Manual

17

6 TOC Inhibit Feature

$7 \quad$ TOC Status Display

8 Overall TOC Evaluation

9 Held TOC Messages Not Bright

10 FDB Failure Display

11 Input To Uplink Last Free Text Message

12 Free Text Recall Overall Ratings

13 Alerting Mechanisms

14 Downlink Text Display

15 D-CRD Downlink Message Display

16 Flight Strip Printer Output

17 Acknowledgement Input Format

18 Communications Backup Overall Rating 


\section{EXECUTIVE SUMMARY}

\section{INTRODUCTION .}

The Federal Aviation Administration (FAA) is pursuing an initiative to develop and implement a Data Link System intended to enhance communications between ground-based air traffic control (ATC) and airborne systems. By providing digital information transfer with the ability to discretely address individual aircraft, Data Link is expected to relieve frequency congestion on existing voice radio channels while increasing the overall safety and productivity of the ATC system.

To insure that the introduction of Data Link will have a positive impact on ATC, the FAA is conducting research to guide system design efforts and evaluate the benefits of Data Link to the ATC system. The Air Traffic Data Link Validation Team (ATDLVT) has been formed to participate in the research. The team consists of full performance level controllers representing a variety of FAA field ATC facilities.

Mini studies are being conducted under realistic conditions which simulate the essential components of controller tasks associated with the services. The goal of these studies is to identify service delivery methods which optimize the human computer interface. Operational evaluations are also being performed in order to verify the safety and efficiency of Data Link utilizing real ATC systems and operational scenarios.

Two mini studies were conducted at the FAA Technical Center Data Link test bed during 1988 to develop an initial set of en route Data Link services. In April 1989, an operational evaluation of the initial en route Data Link services was performed using Full Performance Level air traffic controllers. As a result of this evaluation and subsequent ATDLVT meetings, specific enhancements and changes were made to the design of the Data Link services. The ATDLVT strongly suggested an enhanced scenario capability in the FAA Technical Center test bed. The Washington Air Route Traffic Control Center (ARTCC) was chosen by the ATDLVT as the airspace for future Data Link test bed evaluations enabling enhanced scenarios. In addition, Data Link service design changes were suggested by the team. The team also expressed their continued desire for the use of Data Link at the DController position and the need for development of Data Link procedures.

This report presents the results of the third FAA controller mini study of en route ATC services developed for implementation on the Data Link system. This study follows two en route mini studies, several smaller studies using the en route Data Link test bed, and an operational evaluation. 
OBJECTIVES.

xi

The objectives of the November en route ATDLVT meeting include the following items:

1. ATDLVT evaluation of the new Washington ARTCC airspace test bed implementation.

2. ATDLVT evaluation of recent refinements to the Data Link service designs.

3. ATDLVT evaluation of the preliminary communications backup downlink design.

4. Preliminary ATDLVT evaluation and determination of the NAS and Data Link functions the D-controller may perform in a Data Link system.

5. Preliminary discussion of formal Data Link operational procedures.

6. Determine how collected data can be used to help develop performance measures for use in Data Link testing.

The results of the meeting and test activities will be used to enhance the current Data Link test bed software and provide test guidelines regarding new airspace usage, D-Controller

responsibilities, Data Link procedures, and performance measures for future testing efforts.

DATA LINK OPERATION.

The en route Data Link test bed consists of the NAS Host Computer System (HCS) used in conjunction with other support computer systems to provide a realistic simulation facility for the development of operational and procedural concepts of the initial en route Data Link services. The following services and functions have been

incorporated into the HCS software in the en route Data Link test bed.

1. Transfer of Communication (TOC). This service provides for handoffs between ATC control sectors. The controller transmits, via Data Link, the necessary handoff data to the pilot.

2. Altitude Assianment. This service allows for the uplink of altitude assignments, and interim altitude assignments.

3. Menu Text. This Data Link function provides the capability to store repetitive ATC instructions in a menu, which are easily uplinked to an aircraft. 
xii

4. Communications Backup. This Data Link service has two functions: controller-to-pilot and pilot-to-controller message processing. This service facilitates free format messages between the ground and air for the purpose of a backup to the voice communication channel.

These capabilities are intended to enhance current ATC operations by relieving congestion on the radio voice channels, providing a more reliable communication channel thus increasing safety, and potentially reducing the controllers workload.

\section{APPROACH .}

The Washington ARTCC airspace was used during the laboratory sessions. Two scenarios have been developed and will be referred to as Scenario 1 and Scenario 2. Scenario 1 consists of actual traffic recordings at the Washington ARTCC. Scenario 2 contains aircraft in addition to the aircraft in Scenario 1. The National Airspace System (NAS) Simulation Support Facility was used for pilot simulation to afford a high level of realism. ATDLVT controllers were used to evaluate the Washington ARTCC airspace and the Data Link services.

The scenarios were used in a series of test runs designed to review and critique the service designs. Questionnaires were administered to controllers after selected test runs. Additional data collection which occurred during debriefing sessions included structured discussions to elaborate on the results obtained in the laboratory and the adequacy of the test scenarios and the operational value of the tested services.

SUMMARY OF RESULTS.

The Washington ARTCC airspace provided adequate realism for the simulation and was approved by the ATDLVT. The ATDLVT suggested minor enhancements for future ATC Data Link simulations.

Recent refinements to the Data Link service designs were reviewed by the ATDLVT. A detailed analysis of the test results is included in the text of the report. These refinements included the automatic Transfer of Communication (TOC) function, voice check-in requirements, generic full data block (FDB) failure displays, plan view display (PVD) settings, status list display states, /OK functions, free text (communications backup) recall, the altitude timeshare function, and menu text referent acceptability.

A brief synopsis of the refinements test results indicates: 50 percent of the ATDLVT preferred the automatic TOC function, voice check-in remains a significant unresolved issue, no acceptable generic FDB fail display was found during the testing, PVD setting displays should be changed to reduce display clutter, the status list should have two display states - full and default, 
xiii

use of /OK to acquire Data Link eligibility should be allowed from any sector, the menu text referent, and the free text recall

functions were approved. The preferred alternation display interval for timesharing the uplinked altitude with the normally displayed altitude in the FDB is 1.5 seconds. Preliminary collected data suggest that altitude timeshare transactions will not significantly impact the display channel interface capacity in the near term.

Although the communications backup downlink service was rated "good," numerous comments and suggestions were submitted by the ATDLVT concerning the design. Future testing will be required in order to evaluate these changes.

Communications backup and handoff/TOC were cited as the most likely candidates for D-controller responsibility. The ATDLVT also suggested that the D-controller could perform Data Link status list maintenance and monitor for Data Link failures.

Discussions on rules for Data Link message transmissions resulted in several recommended procedures related to multiple Data Link uplinks, resolving failed transactions, and pilot check-in. Although many proposed procedures were discussed, no consensus was reached. Further testing is required.

Performance measures were collected and are listed. The data are currently being reviewed.

RECOMMENDATIONS.

The Washington ARTCC adaptation should continue to be used in the en route Data Link test bed. A Data Link test bed capable of interfacing en route and terminal computer systems should be established.

An initial contact procedure should be developed. Discussions and testing with pilots and controllers should be conducted to address the issue of voice check-in, and to define associated operational requirements. The initial contact procedure was identified as a high priority item.

All Data Link functions approved by the ATDLVT should be implemented in the en route test bed software and subjected to future operational test and evaluation.

A generic display technique for alerting the controller to transaction failures should be developed and tested.

The functional design and use of the Communications Backup downlink should be pursued in accordance with the detailed modifications to the design identified herein. Furthermore,

$$
\mathrm{xiv}
$$


pilots and controllers should participate in developing the default response messages, and in developing procedures associated with the function.

Further testing should be conducted to develop the D-controller position capability with Data Link. In support of that requirement, D- position operational responsibilities should be identified and tested, and new traffic scenarios should be developed to increase sector workloads to support these tests.

Additional testing should be conducted to assess the effects of the Data Link altitude timeshare function. The display channel should be tested to verify that the 1.5-second alternation is maintained during peak heavy loads.

Controllers and pilots should jointly develop testable procedures for using Data Link ATC services. The procedures should then be evaluated in the test bed. 
1. INTRODUCTION.

1.1 PURPOSE.

The purpose of this report is to provide a detailed description of the en route Air Traffic Data Link Validation Team (ATDLVT)

activities conducted during Mini study 3. Included are the items and issues the team addressed during the week long session. Test conduct, test items, questionnaires, and results of the testing are included. These materials are intended to provide all the information pertaining to the November 1990 en route ATDLVT Mini Study 3 .

\subsection{BACKGROUND.}

In response to the National Airspace System (NAS) Plan to provide a digital Data Link between ground based operations and aircraft, a Data Link test bed has been constructed at the Federal Aviation Administration (FAA) Technical Center to support the development of en route Air Traffic Control (ATC) Data Link services.

The en route Data Link test bed consists of the NAS Host Computer System (HCS) used in conjunction with other support computer systems to provide a realistic simulation facility for the development of operational and procedural concepts of the initial en route Data Link services. The following services and functions have been incorporated into the HCS software in the en route Data Link test bed.

a. Transfer of Communication (TOC). This service provides for handoffs between ATC control sectors. The controller transmits via Data Link, the necessary handoff data to the pilot.

b. Altitude Assiqnment. This service allows for the uplink of altitude assignments, and interim altitude assignments.

c. Menu Text. This Data Link function provides the capability to store repetitive ATC instructions in a menu, which are easily uplinked to an aircraft.

d. Communications Backup. This Data Link service has two functions: controller-to-pilot and pilot-to-controller message processing. This service facilitates free format messages between the ground and air for the purpose of a backup to the voice communication channel.

These capabilities are intended to enhance current ATC operations by relieving congestion on the radio voice channels, providing a more reliable communication channel, thus, increasing safety, and potentially reducing the controllers workload.

Two Mini Studies were conducted at the FAA Technical Center Data Link test bed during 1988 to develop an initial set of en route Data Link 
services. In April 1989, an operational evaluation of the initial en route Data Link services was performed using Full Performance Level (FPL) air traffic controllers (reference 1). As a result of this evaluation and subsequent ATDLVT meetings, specific enhancements and changes were made to the design of the Data Link services.

During May 1990, a Data Link Service Design Validation Micro Study was held at the FAA Technical Center (reference 2). The purpose of the study was to validate design changes resulting from the operational evaluation and subsequent controller meetings. Many Data Link designs were validated during the study while other design and test conduct issues surfaced. The feedback obtained from the ATDLVT during the Data Link Service Design Validation Micro Study strongly suggested an enhanced scenario capability in the FAA Technical Center test bed. The Washington Air Route Traffic Control Center (ARTCC) was chosen by the ATDLVT as the airspace for future evaluations. In addition, minor Data Link service design changes were suggested by the team. The ATDLVT reviewed the Communications Backup Downlink design and offered suggestions for implementation in the test bed software. The team also expressed their continued concern for the use of Data Link at the D-Controller position and the need for development of Data Link procedures.

\subsection{OBJECTIVES.}

The objectives of the November en route ATDLVT Mini Study 3 include the following items:

a. Establish an operational baseline for testing Data Link in the en route FAA Technical Center test bed. his consists of ATDLVT evaluation of the new Washington ARTCC airspace implementation.

b. ATDLVT evaluation of recent refinements to the Data Link service design. This involves evaluation of the changes made to the Data Link software as a result of the spring ATDLVT meeting.

c. ATDLVT evaluation of the preliminary downlink design. This includes using the en route test bed and the ATDLVT to evaluate the communications backup downlink service design.

d. Preliminary ATDLVT evaluation of the "D-side" effectiveness. Determine what NAS and Data Link functions the D-side can perform in a Data Link system. Gain insight as to how the D-side may increase a sector's effectiveness. Obtain ideas for use in testing the D-side effectiveness in future Data Link evaluations.

e. Preliminary discussion of formal Data Link operational Procedures. Use ATDLVT to draft an initial set of formal Data Link procedures.

f. Collect data from the NAS HCS, the VAX computer, and the NAS Simulation Support Facility (NSSF) computer system to determine how the data can be used to help develop performance measures for use in Data Link testing. (A set of Data Link measures was developed for the 
operational evaluation (see reference 3). The current effort is intended to enhance these measures and develop new measures for upcoming Data Link tests.)

The data collected in items 2, 3, and possibly 4 above will be used as input to the Data Link portion of the En Route Software Development and Support (ERSDS) contract. The requirements for the Data Link portion of the ERSDS contract are detailed in the Functional Specification for ATC Data Link Service Implementation in the HCS (reference 4). In addition, the results of the meeting will be used to enhance the current Data Link test bed software and provide test guidelines (i.e., new airspace usage, D-Controller responsibilities, Data Link procedures, and performance measures) for future testing efforts.

\subsection{TEST ENVIRONMENT.}

The Washington ARTCC airspace was used during the laboratory sessions. Two scenarios have been developed for the Washington ARTCC airspace and will be referred to as Scenario 1, and Scenario 2. Scenario 1 consists of actual traffic recordings at the Washington ARTCC and is somewhat easier than the other scenario. Scenario 2 contains aircraft in addition to the aircraft in scenario 1 and is slightly more difficult than Scenario 1.

The pilot side of the tests was supported by the NSSF. The NSSF provides a better level of realism than does Dynamic Simulation (DYSIM) available on the HCS. With the NSSF, pilots are physically located in a room apart from the controller laboratory and aircraft maneuvers are simulated with greater accuracy than with DYSIM. The NSSF enabled the ATDLVT to better evaluate the realism of the en route test bed and provided an additional data collection and reduction capability.

2. METHOD.

\subsection{PARTICIPANTS.}

The en route members of the ATDLVT were used as the test subjects. These controllers were used due to their expertise with the Data Link service design. In addition, there were four facilitators, one at each sector position, to help with controller questions. The facilitators consisted of engineering staff familiar with the Data Link services and test bed

scenarios. All facilitators were familiar with the purpose and conduct of each test run. The facilitators were also responsible for recording any controller comments or scenario/system problems encountered during the test runs.

\subsection{SIMULATION FACILITIES.}

2.2.1 NSSF and VAX Laboratory. 
In this study the NSSF was the target generator which produced radar targets in the En Route Laboratory. Physically, the NSSF consists of two SEL computers and the Simulator Pilot Complex. The NSSF permits real-time, interactive simulation of en route and terminal airspace. It can be configured to match a facility's current operations by emulating existing traffic densities and mixes, radars, navigational aids, and communications. It has the ability to examine proposed changes: different routes and procedures, additional runways, modification of separation standards, additional traffic demands, and new technology such as Data Link, Microwave Landing System (MLS), etc.

Maps and routes with display information based upon either present or proposed operations are used for simulated sectors and their

displays. Patch-in telephone communications and computer linking serve to simulate sector operation in a realistic fashion. Where available, an analysis of the subject facility's past flight strips serves to ensure an appropriate mix of aircraft, routes, and identifiers.

The Simulator Pilot Complex houses the simulation pilots (operators) and their aircraft control consoles. In this study, the simulator operators communicated via voice and Data Link with the controllers in the en route laboratory and converted their traffic control directives into keyboard entries to initiate the required computer simulation of the desired aircraft response. All aircraft responses are modifiable and are programmed to be consistent with the type of aircraft which is being simulated. The "pilots" also initiated communications to the controllers in the en route laboratory and provided them with any required procedural reports, emergency notifications, etc.

When Data Link is fielded operationally, all Data Link related communications with equipped aircraft will be routed through Ground Data Link Processors (GDLP), located in each of the En Route Air Traffic Control Centers. In this study, the function of the GDLP was simulated by a VAX-11/750 computer, which interfaced to a Host computer INTO/INTI Interfacility port via a custom Motorola VME processor. Aircraft Data Link functions were simulated via VAX "Pilot" cathode ray tube (CRT) terminals, positioned one per simulated sector in the NSSF Simulator Complex, paired with the target generator terminals utilized to simulate aircraft state functions. Each VAX Pilot terminal displayed all Host computer initiated Data Link services for equipped aircraft in its assigned sector, and provided means of generating pilot responses to those services. Additionally, the VAX Pilot terminals were used to generate aircraft initiated Emergency Backup Communications Data Link messages (see figure 1 ).

\subsubsection{En Route System Support Facility (ESSF) Display Laboratory.}

The ESSF Display Laboratory is used to perform testing and analysis to support ARTCC operations and development programs. It consists of two ARTCC configurations, each with 11 radar controller positions. 
One configuration is driven by the Computer Display Channel (CDC) and the other by the Display Channel Complex (DCC).

The Washington ARTCC adaptation was implemented to run in the CDC side of ESSF Display Laboratory. This adaptation was used to configure sector controller positions, adapt airspace, prepare traffic samples, and configure other peripheral devices needed to conduct the Data Link tests. In the Display Laboratory, 4 of the 11 radar controller positions, which included the D-controller positions, were configured as active control positions. These positions are depicted in figure 2. The controller positions \#30 and \#31 were adapted as low altitude control sectors, controller position \#32 was configured as a high altitude control sector, and controller position \#60 was configured as an intermediate control position.

\subsubsection{Support Systems.}

The other systems that were used to support the realism of the Data Link tests were the AMECOM Communication System and Flight Data Input Output (FDIO) System.

\subsection{AMECOM Communication System.}

The AMECOM Communication System is a microprocessor controlled voice communications system that was used to provide the communication link between the controller positions and simulated pilot positions used in the Data Link simulations. The system provided both radio and intercom/interphone capability at the controller positions and only radio (simulated) capability at the simulated pilot positions. The system is programmed for scenarios and can be reconfigured for different assignments.

The AMECOM system also provided the capability for voice recording and data collection for the controller positions.

\subsection{Flight Data Input Output System (FDIO).}

The FDIO system is the NAS hardware that provides flight data entry and printout capability in the ARTCCs. It also distributes flight plan data, weather information, and general information between ATC facilities. The system was used in the ESSF Display Laboratory to provide at each controller position printed flight plan data on flight strips via the flight strip printers. The

\section{FAA TECHNICAL CENTER}




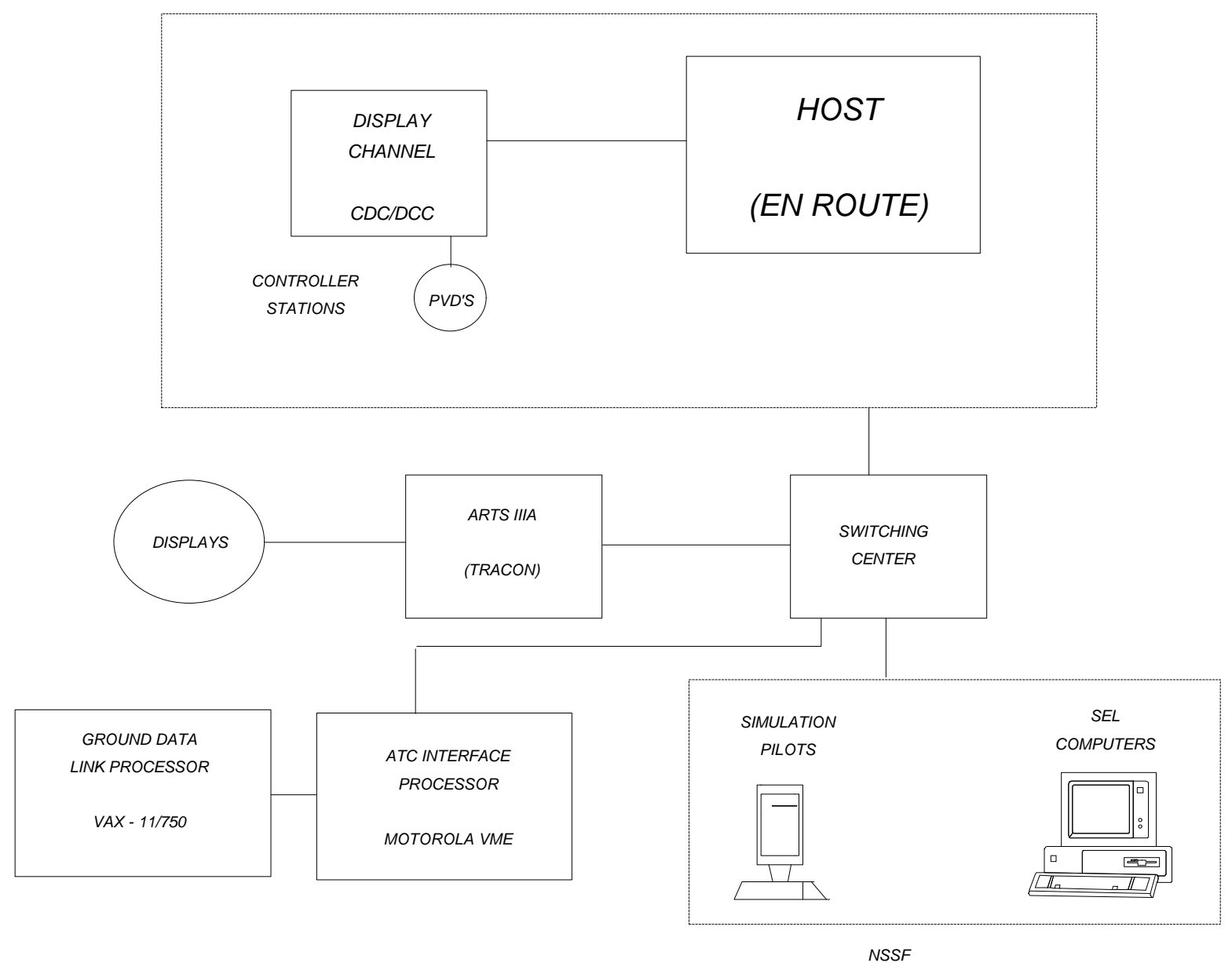

FIGURE 1. DATA LINK TEST BED 


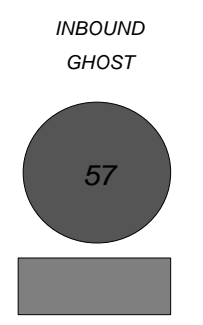

Controller Freq:111.100/ 111.200
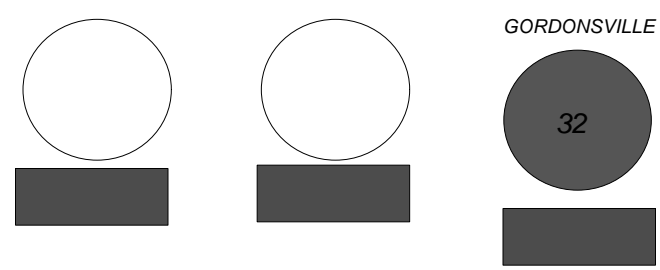

Controller

Freq: 133.720

Controller Freq:133.100

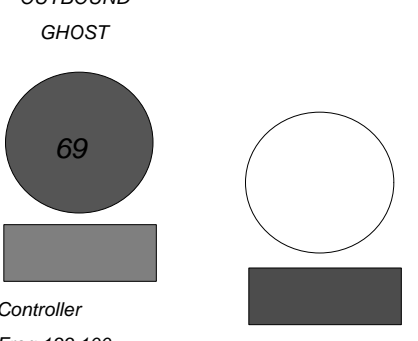

Freq:133.720
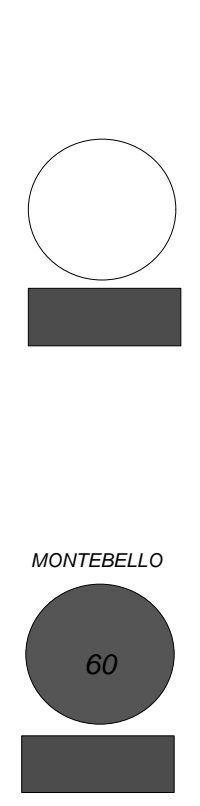

Controller

Freq:135.400

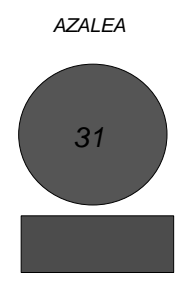

Controller

Freq:124.250

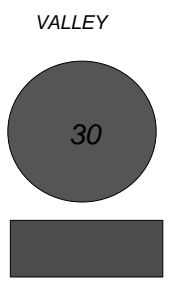

Controller

Freq:125.750
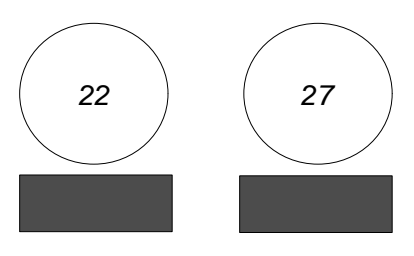

FIGURE 2. CDC ESSF DISPLAY LABORATORY CONFIGURATION FOR THE LEESBURG ARTCC DATA LINK SIMULATION 
FDIO system improved the realism of the Data Link tests by providing the controller with the capability to receive and enter flight plan data on the traffic samples.

\subsection{RESEARCH DESIGN.}

The November 1990 ATDLVT meeting consisted of briefings, group discussions, and laboratory sessions. The laboratory sessions utilized the FAA Technical Center en route Data Link test bed which provided a realistic simulation facility for the ATDLVT to develop the en route Data Link services. Prior to each laboratory session the controller team was briefed on what was to be accomplished during the test session. To ensure that testing was effective, each controller was given material that explained each step of the test. During testing, a facilitator was present at each sector position to answer any controller questions. Each facilitator had a Data Link Laboratory Session Sheet that contained the purpose of each test and the proper conduct that had to be followed to obtain the desired results.

Following the test sessions, a debriefing session took place to discuss the issues raised during the laboratory test session.

\subsection{PROCEDURE.}

The laboratory sessions consisted of three 4-hour sessions. Two controllers were assigned to each of the four controller positions. One acted as the R-controller and the other acted as the Dcontroller. During the tests their positions were switched, as described in the Data Link Laboratory Session Sheets, to enable each controller to play both the $\mathrm{R}$ and $\mathrm{D}$ roles.

\subsection{SIMULATION RUNS.}

\section{Day 1}

Run \# I

Purpose: To familiarize the ATDLVT with Data Link and the sector airspace in the scenarios, and to allow the controller team to observe the timeshare of altitude data in the full data block at a 1second interval.

Run \#2

Purpose: To allow the controller team to evaluate the Automatic Transfer of Communication displays, use the Data Link /OK function with and without the S option, observe Held TOC messages, and Send Data Link Eligibility with and without the new I option. 
Run \#3

Purpose: To familiarize the controller team with the new Leesburg airspace and collect baseline data (i.e., no Data Link timeshare) for the full data block timeshare CDC evaluation.

\section{Day 2 \\ Run \#1 and \#2}

Purpose: To evaluate the Altitude Timeshare interval, the Full Data Block Failure Display Options, the Menu Text Referent in the Status List, and the Free Text Recall (items 5, 6, 7, and 8 on the Testbed Software Validation Questionnaires).

Run \#3

Purpose: To evaluate which Data Link services should, and should not be displayed in the Data Link status list.

\section{Day 3}

Run \# 1

Purpose: To evaluate the Communications Backup Downlink service.

Run \#2

Purpose: To evaluate the D-position Data Link functions.

Run \#3

Purpose: To collect Data Link information for the Full Data Block timeshare CDC evaluation and data for Data Link measures evaluation.

\subsection{TRAFFIC SAMPLES.}

The scenarios used in the Data Link tests were prepared from actual flight plan data collected from the Washington ARTCC. The flight plan data sample originated from air traffic in the western part of the Washington ARTCC airspace. The traffic load of the sample ranges from low to moderate. The sample contained 89 flights and included General Aviation (GA), commercial, and military flight plan data. Two different scenarios were prepared from the sample. This was accomplished by changing some of the flight plans and adding new flight plans. All aircraft in the traffic scenarios were desiqnated as Data Link equipped.

The flight plan data for each scenario was stored on a simulation (SIM) tape. During each test run, the flight plan data were read from the SIM tape to the HCS to display aircraft targets on the four controller position plan view displays. Each traffic scenario was prepared to run a maximum of 90 minutes. 
In the scenarios, the traffic in each of the four controller sectors presented different situations for each controller. The traffic in the two low altitude sectors consisted of a mixture of GA and commercial aircraft. In these two sectors, there were overflights, arrivals and departures to and from airports within the sectors. The traffic in the intermediate and high altitude sectors were composed of military and commercial overflights. The number of aircraft in each of the four scenarios were 89 in the first scenario and 100 in the remaining three scenarios.

The traffic in the low sectors provided interaction between the two low altitude sectors and the intermediate altitude sector. Whereas, the traffic in the intermediate sector provided interaction between the low and high altitude sectors. However, there was no interaction between the low altitude sectors and the high altitude sector.

\subsection{DATA COLLECTION.}

Different methods were used for collection of data from the ATDLVT members. The first was the use of questionnaires immediately following every test run. Each controller answered specific questions and provided comments about the issues raised during the test run. The questionnaires were completed in the laboratory at the sector position. The controller questionnaires used in the Mini study are provided in appendix A of this document.

After the test runs, the ATDLVT members were taken to a debriefing room where the test items were discussed among the group members and engineering staff. During these discussions the individual

questionnaire results collected during the test runs were presented to the team for discussion among all group members. Upon mutual agreement between the team members and engineering staff, issues were resolved.

In addition to the data collected from the controller team, the test bed computer systems record large amounts of data. Certain data collected will be reduced and used to develop measures of Data Link performance. The purpose of the data collection during these tests was to determine which data can be collected and successfully reduced. Special emphasis was placed on data collected by the NSSF since most of the data collection on the HCS and voice systems in the test bed are already being utilized (see reference 3). The NSSF can provide a wide range of data, therefore, specific NSSF data collection requirements have been defined. 
3. TEST RESULTS.

3.1 CONTROLLER DISCUSSION ISSUES.

In order for the Data Link Development Team to present issues to the ATDLVT which require discussion, the controller discussion issue (CDI) format was initiated. A CDI permits the controller team to address a specific problem with the benefit of a suggested solution from the Development Team. The ATDLVT may elect to concur with the suggested solution or dictate one of their own. Typically, the ATDLVT will discuss approximately 10 of these CDI's in addition to formal test runs and debriefings. The CDI's presented to the ATDLVT are included in appendix B. The CDI's contain the resolutions obtained by group consensus. A brief review of the resolutions indicates that the ATDLVT feels that increased design and development time should be assigned to the majority of these issues in the near future.

\subsection{POST-EXPERIMENT INTERVIEW (DEBRIEFINGS).}

3.2.1 Washington ARTCC Airspace Evaluation.

During previous ATDLVT evaluations of the en route test bed, the Universal Data set (UDS) airspace used for Data Link simulations was cited by the controller team as not being sufficiently realistic. As a result of this inadequacy, the FAA Technical Center en route Data Link test bed scenarios and airspace adaptation were changed from UDS to the Washington ARTCC airspace. The Washington ARTCC airspace is taken from the ARTCC and is identical to that used in the field. As a result of the new airspace, new traffic patterns, or scenarios, were developed. Scenario 1 contains air traffic taken from actual tapes of traffic recorded in Washington ARTCC. The other scenario uses the same aircraft appearing at different times, and some new aircraft to increase the level of difficultly providing the controllers slightly different traffic patterns.

The Data Link test bed uses four sectors from the Washington ARTCC adaptation. In addition to these sectors, one ghost sector is used to initiate air traffic into the active sectors and another is used to receive traffic that is leaving the four active sectors. During the study, the controllers evaluated the new airspace and scenario implementation in the Data Link test bed and found it to be a very realistic environment to test the Data Link services. All the controllers were in agreement that the en route test bed provided the level of realism needed for future testing efforts.

One problem arose with the implementation of the Washington ARTCC airspace. The controllers found that with the increased complexity of the sector airspace came a proportionate increase in the time it took to learn the specifics of the airspace. The controller team suggested that during future test sessions sufficient training time be allocated to teaching the subject controllers the airspace.

In addition to the airspace evaluation, the scenarios, or traffic patterns, were also assessed by the controller team. The controller 
ratings on Scenarios 1 and 2 are given in figure 3 . Scenario 1 was rated as a low workload scenario, while scenario 2 was rated more difficult with a moderate to high workload rating. The controllers felt more workload, stress, and were generally busier with Scenario 2 than Scenario 1 (see figure 4). In addition, the controllers felt they performed better in Scenario 1 than Scenario 2. From these data it was concluded that Scenario 1 would be used for controller training and Scenario 2 would be used for actual testing during future evaluations.

In addition to the ratings, the controllers were asked: What suggestions would you make to improve this scenario? Their comments for Scenario 1 and Scenario 2 were as follows:

Scenario 1 Controller Comments:

a. "Not being familiar with the area, it was hard going back and forth to get the proper fixes when the aircraft needed to be put in trail."

b. "For this particular sector, there could have been more crossing traffic similar to Scenario 3."

c. "N733A departed DCA, yet it came to us descending from FL310 to FL210 when it should have been climbing to FL210 from approximately $160 . "$

d. "When the problem is all voice more aircraft are needed than this problem generated to increase controller workload."

Scenario 2 Controller Comments:

a. "Good scenario."

b. "Successive departures should not increase in speed."

c. "Some non-Data Link equipped aircraft should be included."

d. "Get the pilots to acknowledge frequency (voice). Make the controllers run it as an actual situation (grading on counting error would help, no controllers like to admit mistakes). Establish track history on limited data blocks before entering sector. Voice checkon! I like the warm fuzzy."

e. "Eliminate the dropping of data blocks while in sector. The pilots need to be on frequency when the Data Link symbol indicates they are. When using the "R" feature, the climb arrow 


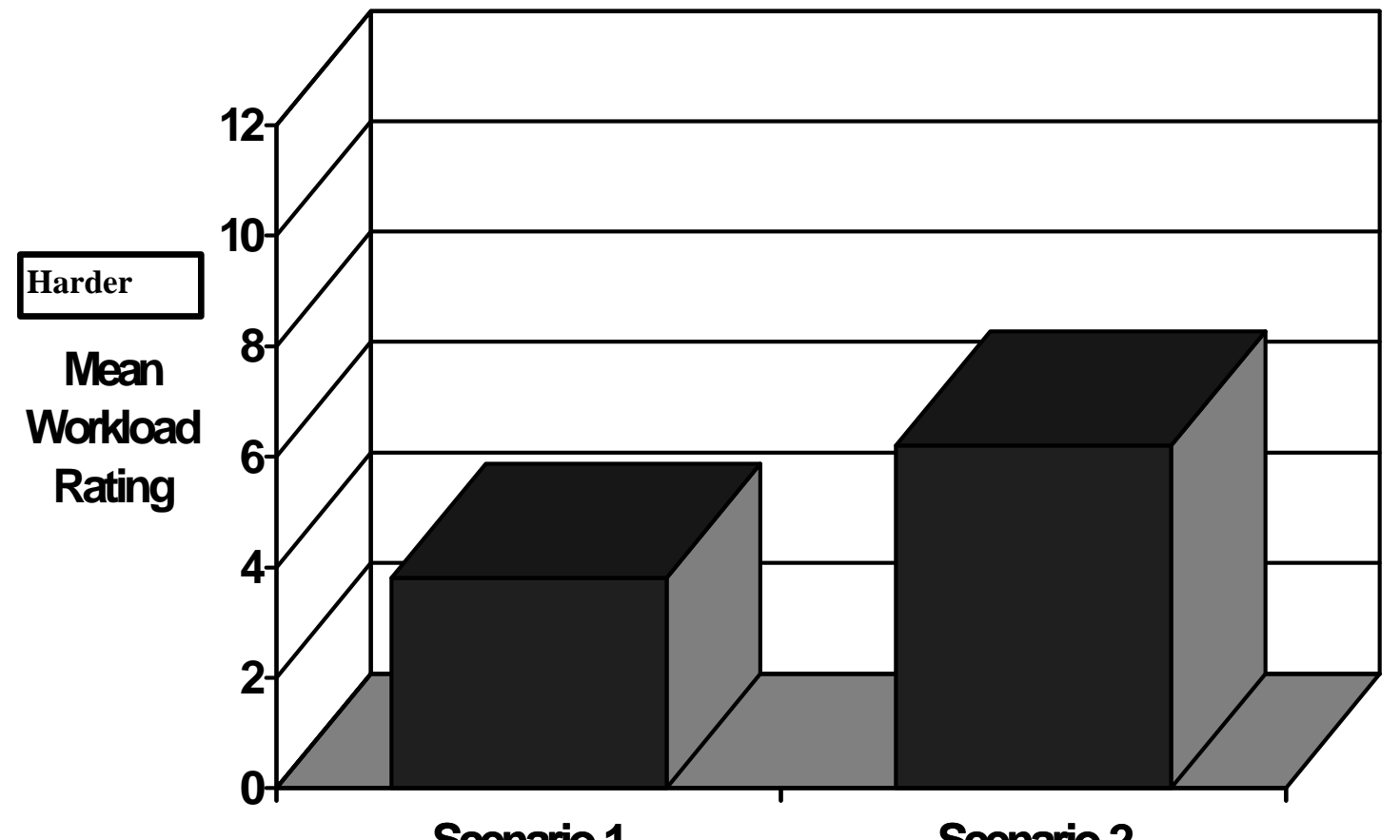

Scenario 1

Scenario 2

Easier

FIGURE 3. CONTROLLER WORKLOAD RATINGS 


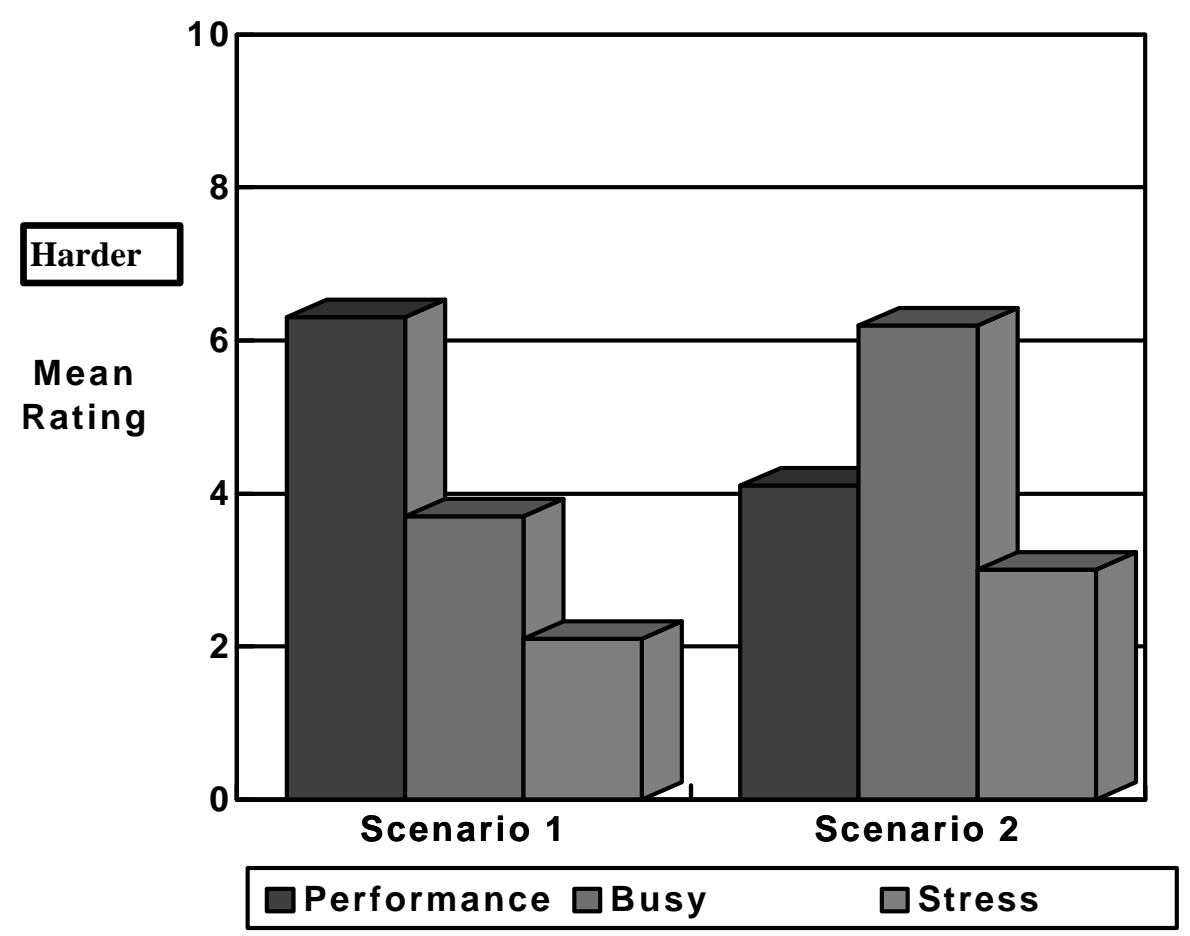

Easier

FIGURE 4. CONTROLLER SCENARIO RATINGS

needs to appear when the WILCO times out. The failure indication in the data block is needed, but I would like to look at other methods."

Most of the controllers comments addressed scenario problems, which were fixed after the testing was complete. One comment addresses the 
lack of traffic in scenario one. This supports the controller ratings of scenario one and reinforces its use as a training scenario. Another comment addresses including non-Data Link aircraft in the scenarios, which will be done as test cases warrant in the future.

Scenario 2, comment "d" addresses a voice check-on procedure for TOC. This is an on-going issue that the controller team felt must be addressed. They came to the conclusion that the voice check-on, or initial contact, should be the subject of the next en route ATDLVT meeting. They decided that a 2 or 3 day meeting should be established to design the en route initial contact. The engineering staff agreed, and it is generally felt that a voiceless TOC under current procedures cannot be realized without an initial contact service.

More can be said concerning an en route initial contact service. Some controllers would like to see a voiceless TOC, while others feel that a voice check-on is necessary for both the pilot and controller. The voice check-on provides both parties confidence that the aircraft is on frequency.

The en route controllers agreed that the initial implementation of a Data Link TOC service would require a voice check-on. But, they felt that after enough experience with Data Link, both controllers and pilots would build enough confidence in the reliability of Data Link and voice check-ins could be phased-out. If this were the case, there is currently no mechanism included in the TOC design for verifying an aircraft's currently assigned altitude on check-in via automation. (The controllers felt that the current procedure which requires the verification of an aircraft's currently assigned altitude would not be eliminated with Data Link.) For this reason, the ATDLVT felt that an en route initial contact service should be developed. Its primary purpose would be to verify the aircraft's altitude, via automation, when the aircraft enters a sector's airspace.

\subsubsection{Test Bed Software Validation.}

During the ATDLVT meeting, the en route controller team validated design changes and commented on Data Link functionality. Their comments and ratings of the Data Link designs are included in the following sections.

\subsubsection{Automatic Transfer of Communication.}

During the May 1990 testing, the ATDLVT suggested that automatic TOC should be available for individual aircraft or for all aircraft bound for specific sectors. The test bed implementation of the automatic TOC is limited and only allows all aircraft within a sector to be in 
automatic or manual mode. This limitation is a result of the complexity of implementing the full automatic TOC design into the NAS software. Nevertheless, the auto TOC was evaluated for its display attributes and how it works in conjunction with other NAS functions. The input action to enable or disable automatic Toc for all aircraft bound for an adjacent sector is as follows: Data Link Category Function Key (DL CAT KEY), DL SETTING CRD input, T, AUTO or MAN. This sets automatic or manual TOC for all aircraft in the sector. The controller team evaluated the automatic TOC function, and focused on how the automatic TOC worked in conjunction with the current NAS handoff function.

Four questions concerning the automatic TOC were asked. The questions and the comments are provided below.

a. What is your opinion of the DL CAT KEY, DL SETTING CRD INPUT, T, AUTO or MAN input? (See figure 5).

Controller Comments:

"A lot of buttons."

From figure 4, it seems that a few controllers would like to see an easier to remember input action. The comment above, "A lot of buttons," makes clear the current input sequence needs improvement. During debriefings, the ATDLVT felt that the Auto TOC inputs should be similar to those used for Auto Handoff.

b. What is your opinion of the TOC inhibit feature, i.e., SECTOR NUMBER, I, FLID? (See fiqure 6).

Controller Comments:

"Good."

"Worked with no problem."

"Didn't use."

"Inhibit is OK, but held status should also be displayed in the data block."

The two controllers that rated this function Acceptable with minor changes were new to the ATDLVT and either didn't use it or were more concerned with status in the FDB. After discussion with the team there was consensus that the above inputs were acceptable as they are currently implemented. 


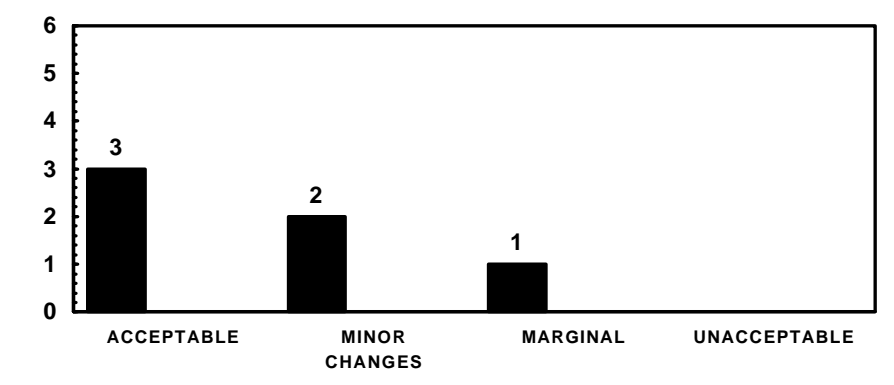

FIGURE 5. DL SETTING, T, AUTO OR MANUAL

CONTROLLER RESPONSES

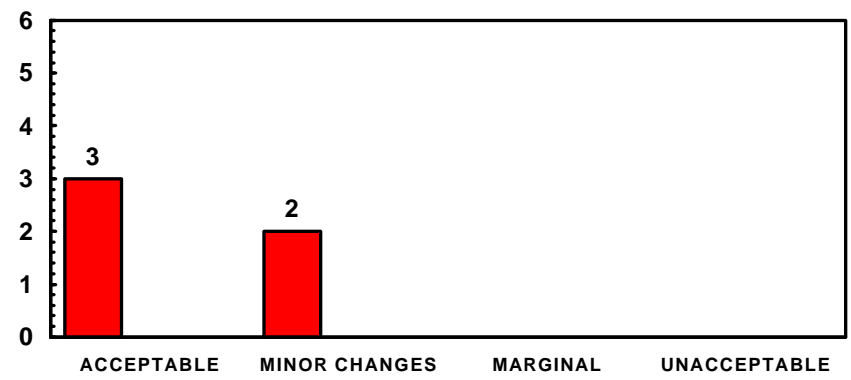

FIGURE 6. TOC INHIBIT FEATURE

c. How would you rate the status display at the top of the PVD? (See figure 7). What other symbology would you suggest?

Controller Comments:

"Data Link ON is good."

"DL ON; A or M for auto or manual TOC."

"None."

Originally, the team wanted a full data block (FDB) indication that an aircraft was, or was not, in automatic TOC mode. After trying to implement this feature, the software development team found that due to limitations imposed by the NAS display system, the FDB indication was not feasible. From figure 7, it is apparent that the proposed test bed displays were somewhat inadequate. During debriefings the controller team decided to display the Auto TOC status by sector in the computer readout device (CRD), similar to the CRD Auto Handoff displays. The CRD display would tell the controller which sectors are currently enabled for Auto TOC.

d. Other comments and suggestions for Automatic TOC. 


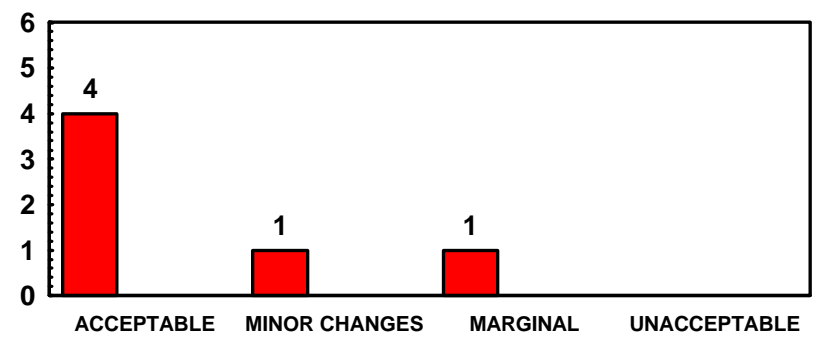

FIGURE 7. TOC STATUS DISPLAY

"I am not a proponent of auto TOC in the first place. It seems to work as advertised. When I handed off an aircraft and used $S$ with the handoff in auto mode, it made me do it over again. The $S$ should be allowed because you get used to it."

"It was easy to get used to. Changing to manual mode in the middle of the problem showed that even in a short time I got comfortable using Auto TOC. It seemed to slow me down with manual TOC during busy periods."

The controllers were divided on their opinion of the Auto TOC service. This seems to be attributed to the particular sector the controller normally works or the specific procedures unique to each controller's facility. The two comments above show the differing opinions of the controllers. It was agreed that if the capability would be beneficial to some sectors or facilities, then it should he included in the set of initial services.

Finally the controllers were asked to give an overall rating of the Automatic TOC. Figure 8 shows these results. The results indicate that overall the controllers reacted positively to the utility of an Auto TOC, although some details need further improvement.

CONTROLLER RESPONSES

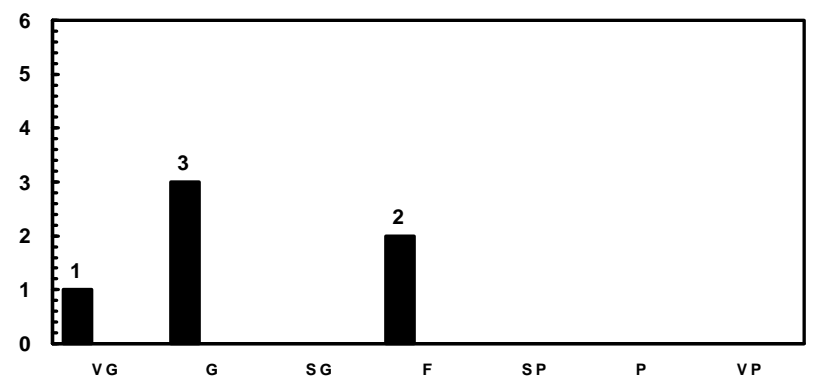

FIGURE 8. OVERALL TOC EVALUATION

\subsubsection{DL/OK With the S Option and DL/OK From Any Sector.}


During the May 1990 Micro Study, when Data Link eligibility was stolen using the /OK option with the $S$, the Data Link transaction was not displayed in the status list of the sector taking the /OK action. The current test bed implementation displays the transaction status in the status list of the sector taking the /OK action.

The controllers were asked "How would you rate the status list and Full Data Block displays?" They all agreed that the status list entry should be displayed at the sector taking the /OK action. But the controllers commented that the status list display may not be necessary unless the transaction Failed. This topic is covered in greater detail in the Data Link Service Display in the Status $\mathrm{T}$. i st section later in the Results.

The controllers were also asked if the /OK function should be available for all sectors who have had track control for an aircraft, but have handed that track control to another sector.

Controller Comments:

"No, just the last one."

"No, only sector working the aircraft."

"No, only the sector presently having track control."

"Should be able to /OK Data Link on an aircraft you have track control of."

"Yes, definitely."

"Yes."

This topic has been debated by the ATDLVT for many meetings. The "no" responses came mainly from controllers new to the team and the test bed. The "yes" answers are from the more experienced ATDLVT members. The more experienced members argue that the system should allow /OK for Data Link from any sector. Consensus was reached by all members, and they recommend that the system allow the /OK input from any sector, but controller coordination and Data Link procedures should govern how this Data Link function works when it is implemented in the field.

3.2.5 Held TOC Messages Not Bright.

During the last test bed exercise, the ATDLVT decided that Held TOC messages should not be displayed as double bright in the Data Link status list. During the current test, the controller team evaluated the display of the Held message without the double bright indication. The controllers were asked to rate the display of Held TOC messages which are given in figure 9. They were also asked "Can you find the Held TOC message in the status list to uplink?" 


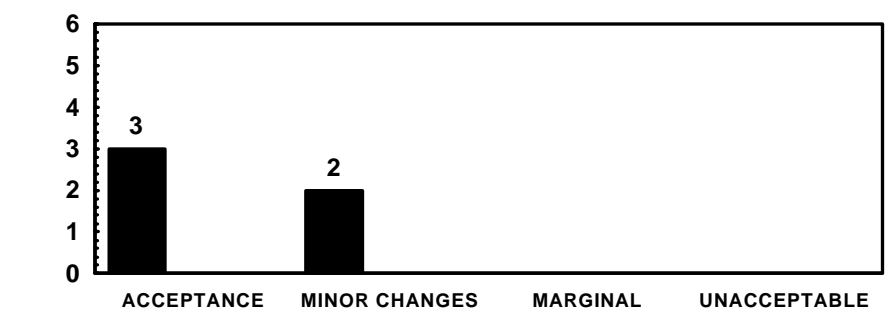

FIGURE 9. HELD TOC MESSAGES NOT BRIGHT

\section{Controller Comments:}

"Needs to be double bright (at least)."

"Better than before."

"Yes, maybe we also need something in the data block - single bright TOC's (Held) kept stacking up on me."

"No, Normal brightness is fine."

"I don't want the Held message showing up the same as Failed

messages. I had no trouble finding the Held messages."

"Yes, but again this is time-consuming and diverts the controllers attention away from duties."

"I don't like having to look in the status list for HLD TOC messages. I'd prefer to also have an indicator in the data block. The status list is too much of a distraction from my normal scan. It takes my attention away from other things I need to be doing.

It's too time consuming."

Again, the controllers were divided on their opinions of the display of the messages in the status list. After discussion, the controllers agreed that the Held TOC messages did not need to be double bright. The controllers agreed to this presupposing that normal (i.e., Sent, Delivered, WILCO) Data Link messages would not be displayed in the list, thus eliminating the clutter. A full

discussion of normal and full status list displays is covered later in the results.

\subsubsection{Sending Data Link Eligibility.}

Data Link eligibility may be sent to another sector. During the May 1990 tests, the ATDLVT suggested new inputs for uplinking or inhibiting the uplink of a TOC message when sector eligibility is sent to another sector. The inputs to send eligibility and uplink a TOC message with the specified sector's frequency in the uplink message is as follows: DL CAT KEY, Sector Number, Flight Identification (FLID). If the controller chooses not to uplink a TOC message to the aircraft, the following input sequence is used:

DL CAT KEY, Sector Number, I, FLID. The controller team evaluated the input sequences for validity and were in unanimous agreement that the input sequence was good. One controller felt that if the 
input sequence DL CAT KEY, Sector Number, S, FLID were entered, the computer should accept it and treat it the same as DL CAT KEY, Sector Number, FLID. The other controllers did not argue the point.

\subsubsection{Altitude Timeshare.}

The Data Link uplinked altitude and transaction status timeshare with the normal line 2 Full Data Block displays. The interval of the timeshare was set to 6 seconds during the last micro study and was found to be unacceptable. During this test, the controller team evaluated the timeshare interval at $1 / 2,1,1-1 / 2$, and 2 seconds. In addition to the controller evaluation, System Analysis and Recording (SAR) data were collected during the different time intervals to evaluate the impact the timeshare processing has on the Computer Display Channel (CDC). These data were compared to a test run without Data Link to determine the increased workload on the CDC. This information is needed by the En Route Software Development Support (ERSDS) contractor to aid in the implementation of the altitude service.

After reviewing the altitude timeshare intervals, the controllers were in unanimous agreement that the timeshare interval should be 1$1 / 2$ seconds.

Controller Comments:

"The 1-1/2 seconds was best."

"1-1/2 or 2 seconds."

"1-1/2 sec time share works best. It doesn't distract the controller, yet all the information is readily available." "Preferred the 1-1/2 second interval - seemed to be just right." "1$1 / 2$ second! Most acceptable."

\subsubsection{Full Data Block Failure Display Options.}

In the May 1990 controller evaluation, the entire FDB was displayed as double bright when a Data Link transaction Failed (i.e., No Pilot Response, Communications Failure, or Pilot Unable). The general consensus was that this Failure display method was unacceptable. The current test provides two new generic FDB failure indications: (1) the Data Link eligibility symbol is displayed as an oversized character, and (2) the entire AID field (i.e., the first line of the FDB) is displayed as oversized characters.

The controllers were asked which alternative they liked best and then asked to rate that alternative. None of the controllers liked the entire AID field oversized. They all picked the oversized eligibility indicator, but when asked to rate this display, figure 10, it only rated fair to somewhat good. The controllers and technical staff were both frustrated to come to a conclusion on a generic failure display in the FDB. The controllers have agreed in the past to double bright the status list entry when a transaction fails, but they could not come to a consensus for an FDB failure 
indication. It may be that the CDC does not provide enough display capability for this Data Link option.

CONTROLLER RESPONSES

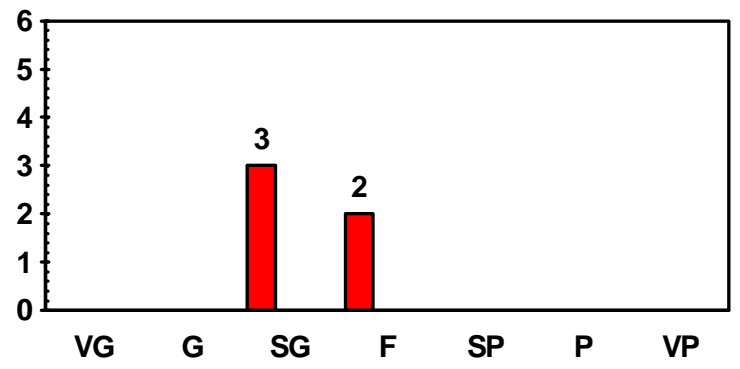

FIGURE 10. FDB FAILURE DISPLAY

\subsubsection{Menu Text Referent in the Status List.}

The menu text message referent and uplinked altitude data are displayed in the Data area of the Data Link status list. Each controller evaluated whether or not these data were displayed appropriately in the status list. The controllers were in unanimous agreement that the menu text referent in the status list was acceptable as is.

Controller Comments:

"With just the letter it is easier to scan the list." "Alphanumerics are acceptable."

They were also asked "Is the data sufficient?"

"Yes.

"Having the menu text referent in the status list is OK."

"Yes."

\subsubsection{Free Text Recall.}

The Free Text Recall capability was introduced in the May 1990 Micro Study. This capability was accepted by the ATDLVT, although the input format was changed to DL CAT KEY, $\mathrm{T}$, to recall the message in the CRD. To send the last entered message to an aircraft the input was changed to DL CAT KEY, T, FLID or ALL. When asked to rate the input to recall the message, once again the controllers were all in agreement that the input sequence was acceptable as is.

Controller Comments: 
"Good to have independent functionality for R \& D."

"Seemed fair to easy."

The controllers were also asked to rate the inputs to uplink the last free text message. Figure 11 gives the controller ratings. During the debriefing discussions, it was generally agreed that the inputs were acceptable as is.

The controllers were also asked if they thought the messages should be recallable at both the $\mathrm{R}$ and $\mathrm{D}$ positions. They all agreed that the free text should be recallable at both positions. They were also asked to give the Free Text Recall function an overall rating. Figure 12 shows that free text recall is rated as being somewhat good and will save typing when using the free text service.

CONTROLLER RESPONSES

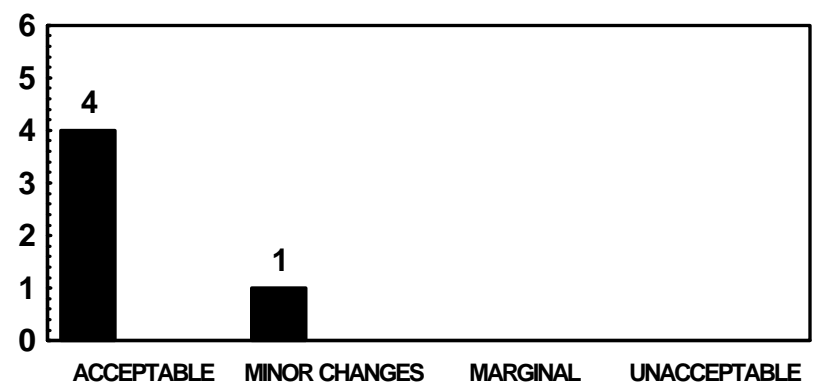

FIGURE 11. INPUT TO UPLINK LAST FREE TEXT MESSAGE

CONTROLLER RESPONSES

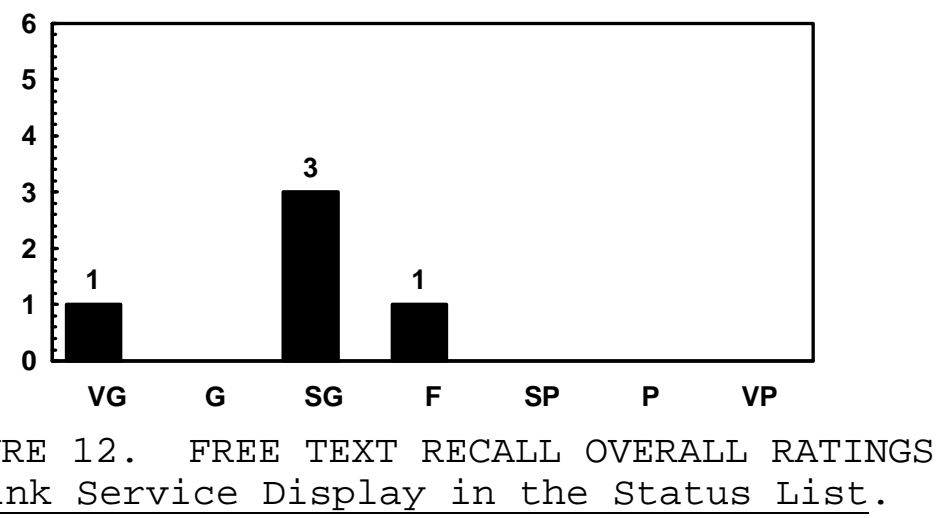

\subsubsection{Data Link Service Display in the Status List.}

The Functional Specification for Implementation of Data Link Services in the HCS (reference 4) provides the capability to display, or not display, each Data Link service in the status list. If the service is suppressed from display, normal (i.e., Sent, Delivered, and WILCO) 
status will not be displayed in the status list. However, if a Data Link message Fails, the display of the message is forced in the status list, even if the service is suppressed from the status list display.

The controllers were asked which services should be displayed. They reached agreement that the status list should have two display states, default and full. The default state would suppress all normal status list entries for TOC and altitude assignment. The purpose of this state is to reduce clutter in the status list and provide only those entries which the controller needs to see in the status list. The default state will display all Failures for all services. In addition, the default state will display all free text uplink messages, since there is no FDB display to indicate that a message has been uplinked. Lastly, the default state will display Held TOC messages. Held TOC messages are displayed because the controllers like the ability to slew the Held status list entry, which uplinks the Data Link TOC message to the aircraft.

The full state, selectable through controller input action, would display all Data Link transactions in the status list regardless of the transaction's status. This state would allow the controller to monitor all transactions via the status list. Some controllers suggested that all the Data Link transactions be contained in the status list despite the clutter.

Regardless of the default or full state of the status list, all the controllers agreed that any Data Link message which Fails should displayed as double bright in the status list.

\subsubsection{Communications Backup Downlink.}

The Communications Backup Downlink service was designed by the en route controller team in the seattle ATDLVT meeting. The design was reviewed by the team again in the May 1990 Micro study and implemented in the test bed software. This section of the testing focused the controller's attention on the Communications Backup Downlink service. All inputs and outputs of the service were exercised and evaluated by each controller. This section covers each aspect of the communications backup downlink service.

\subsubsection{D-CRD Acknowledgement Button and Alarm.}

The controllers were asked to rate the alerting mechanism and the response to display the downlink message on the D-CRD. Figure 13 provides the controller ratings of the alerting mechanisms. 


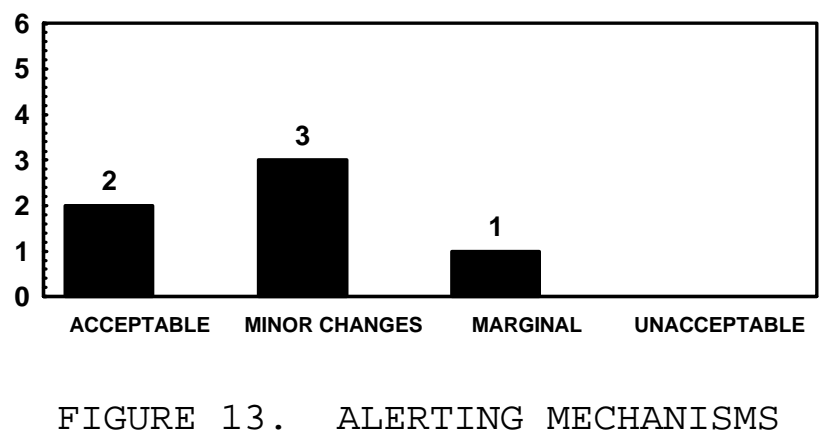

Controller Comments:

"Have the D-Position alarm ring with three bells; instead of the one ding we currently have."

"Printout should be when message is acknowledged."

"Alerts are fine, but when the bell rings the controller hits CRD ACK, which in this case, wipes out the message. This needs to be changed to display the message when the button is pushed."

The controller ratings and comments show that improvements are needed with this section of the downlink design. In the debriefings, the controllers recommended the following resolutions for the alerts and responses to display the message.

a. The downlink message is received by the Host and routed to the sector with Data Link eligibility. If there is a TOC in progress, the sector who last had Data Link eligibility will receive the message.

b. The D-alarm sounds and the D-CRD acknowledgement key is lit to alert the controller of the new incoming message.

c. The controller has a total of 2 minutes to respond (i.e., display response) to the downlink message (Timer 1). The response is generated by depressing the D-CRD acknowledgement key, which, in turn, displays the message in the D-CRD. If the controller does not respond within the first 1 minute, the D-alarm is sounded again to remind the controller of the pending downlink message.

d. If the controller does not respond within 2 minutes, the downlink message is considered to have timed-out. When this happens, no further responses to the downlink message are allowed and the downlink message is printed on the flight strip printer (FSP).

Since the D-CRD acknowledgement key is used for the dual purpose of displaying downlink messages and other NAS messages at the D-CRD, the controllers were asked "Is the use of the D-CRD acknowledgement key to display downlink messages acceptable? What if 
communications backup downlink message(s) are mixed with other messages sent to the D-position? Will this pose any potential problems?"

Controller Comments:

"No problem once controllers are used to it. ZAN gets mixed messages from ARINC (aircraft downlinks) and amendments from other sectors on the same D-position CRD."

"No, not after seasoning."

"Not as long as its printed out or retained somehow."

"No - controller input retrieves message."

"Acceptable."

"Busy periods will probably have numerous timeouts."

The D-CRD acknowledgement key was completely accepted by the controllers. They felt downlink messages worked similar to other messages at the D-position and were assured that all messages would work together.

\subsubsection{Downlink Messaae Display.}

The controllers were asked to rate the display of the downlink message on the D-CRD. Figure 14 provides the controller ratings of the display.

CONTROLLER RESPONSES

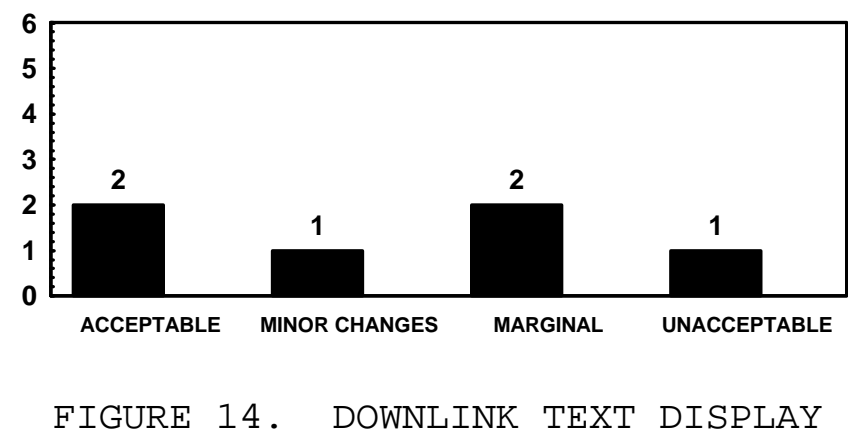

Controller Comments:

"Downlink message should work like other D-CRD acknowledgements. "Message shouldn't be displayed until after CRD- CK button is pushed."

"Message number looks like an aircraft CID."

"Message number needs to be associated with the message type. Otherwise it looks like a CID." 
"Messages are alright."

"Message number should not be three digits - too easy to confuse with CID."

During the debriefing session the controllers were in unanimous agreement to change the three digit message number to a two digit number. They were also asked "Is all the information that is currently displayed with the downlink message appropriate?"

Controller Comments:

"OK. "

"Yes."

"Yes."

"Yes."

"Appears to be."

"Yes."

From the controller responses, the data that appeared in the downlink message was relevant. They were then asked "Is there any additional information that needs to be included?"

Controller Comments:

"No."

"CID's of aircraft."

"No."

"Can't think of any."

"CID."

The controllers agreed that the CID needed to be added to the D-CRD information because the CID is widely used to identify the aircraft. Figure 15 provides the downlink data and its format in the D-CRD as suggested by the ATDLVT.

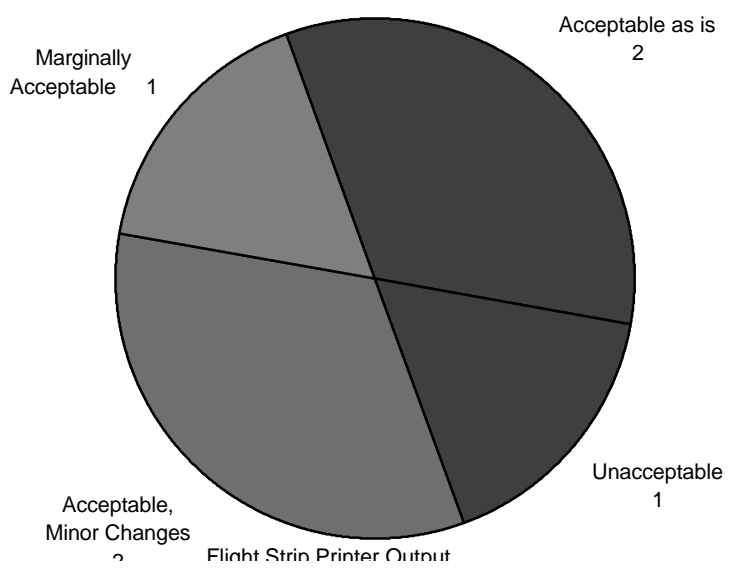

FIGURE 15. D-CRD DOWNLINK MESSAGE DISPLAY

3.2.11.3 Flight Strip Printer Data Display. 
As part of the communications backup downlink service, the ability to print the downlink message on the FSP was cited as a requirement by the ATDLVT. They felt that a hard copy of the downlink message was needed for future reference or as a backup in case the downlink message was inadvertently erased from the D-CRD. The controllers were asked to rate the FSP output (figure 16).

CONTROLLER RESPONSES

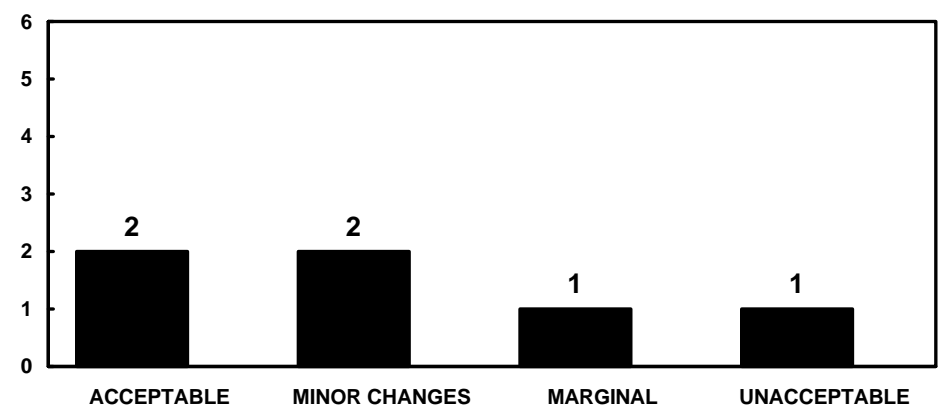

FIGURE 16. FLIGHT STRIP PRINTER OUTPUT

Controller Comments:

"Put CID in red on corner of strip."

"Need to have an input to force message to printer. Should only be automatic on timeout."

"Would prefer no output except when D-side CRD does not work properly."

"CID in red in lower left of strip. No three digit message ID.

The controllers were also asked the following questions. Is the data displayed in the proper field of the FSP? If not, which data should be displayed in which fields of the FSP output?

Controller Comments:

"OK."

"Did not see one."

"CID on strip."

"Data Link qualifier needs to be developed and displayed." "Probably."

"Red CID lower left of strip."

Will the flight strip printout be required as soon as the downlink message is received?

Controller Comments:

"No." 
"I think the D-side should answer CRD and receive message then take action on the message. Printing of message does not seem necessary. "As soon as it is acknowledged at D-position."

"No - should be forced by controller."

"No."

"No - when message is acknowledged."

Do all downlink message need to be printed out on the FSP?

Controller Comments:

"Not as long as the message doesn't show up in the D-position CRD until the CRD-ACK button is pushed."

"No."

"Yes or retained for recall somehow."

"No."

"No."

"Yes, as a backup if one is inadvertently removed from the CRD."

The controllers were not satisfied with the timing of the printout or the format of the printout. They recommended using the same format for the downlink message as is currently used for an altitude update message received at the D-position. Additionally, they decided to print the entire message in red. The controllers also recommended to optionally (set in adaptation) print the downlink message when the DCRD acknowledgement key is depressed to display the message. Also, if the downlink message times-out, the downlink message is printed.

3.2.11.4 Acknowledqement of the Downlink Messaqe.

After the downlink message is displayed in the D-CRD, the controller has one minute to read and respond to the message. The input for this action is; OTHER MSGS QAK, CZ, MESSAGE NUMBER, Optional Response (S - Standby, A - Approved, R - Roger, W - Wilco, U Unable), FLID. If the optional response is omitted, a default response of Roger is used as the response to the pilot. The controller ratings of the inputs are given in figure 17.

The controllers discussed the possibility of making the input format shorter, but could not come to a conclusion on what the input should be. They prefer a D-QAK which would take the place of the first two inputs above, but each center adapts the D-QAKs slightly different. Also, with each center's adaptation of D-QAKs, there usually aren't any spare QAKs. The team decided that if the center felt a D-QAK for communications backup downlink was needed over another QAK, then it could be adapted per site. Otherwise, the above input sequence holds. 


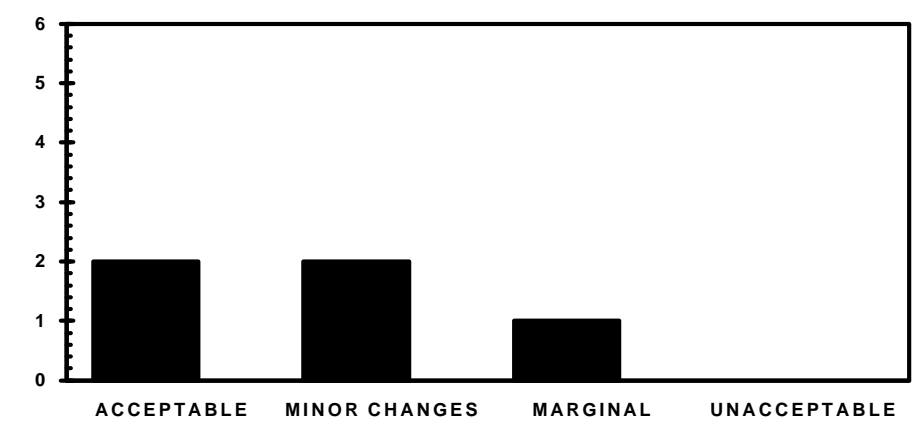

FIGURE 17. ACKNOWLEDGEMENT INPUT FORMAT

The controllers were also asked "Does the controller have to respond to a communications backup downlink message?"

Controller Comments:

"No, only if the nature of the message requires a response."

"No - system should send a standby."

"At least a standby."

"CRD ACK - should be sufficient - generate a Roger."

"Time may not permit a response."

The controllers were then asked "What should the default response to the downlink message be? Should there be additional allowable values for the response?"

Controller Comments:

"Message received and acknowledged (i.e., Roger).

"Stand-by."

"Standby default."

"Roger."

"Standby."

It was unclear from the controller comments and debriefings whether or not a response will be required. Also the type of default response was not clear, Roger will be the default at present. Further testing with pilot involvement is needed to resolve this issue.

The controllers were asked for their overall evaluation of the communications backup downlink service. Their ratings are given in figure 18. The overall opinion of the ATDLVT ranged from fair to slightly good. The controllers stated in the debriefings that they felt with the improvements stated in the results, the communications backup downlink service would be beneficial to the ATC system. 


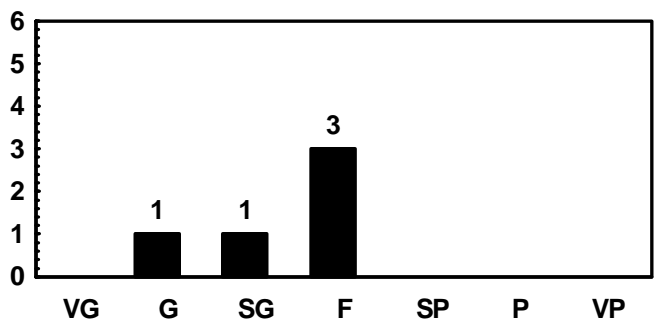

FIGURE 18. COMMUNICATIONS BACKUP OVERALL RATING

This was the first attempt at the communications backup downlink service. Many problems were identified and some solutions were reached. Further testing is needed in this area, especially with involvement from pilot groups. Finally, a logic flow chart, figure 19, shows the steps involved in the communications backup downlink design. This chart shows the sequence of events and resultant outputs that occur after a downlink message has been received by the Host computer.

\subsubsection{D-Position.}

In past ATDLVT meetings, the D-controller position has been cited as a potential candidate for performing a subset of the Data Link functions. In previous en route Data Link tests at the FAA Technical Center, the D-position has not been included as part of the evaluations. As a result of the current downlink design and the potential benefits of the D-position used in conjunction with Data Link, the use of the D-position was included in the November 1990 test. The purpose of the test was to solicit ideas from the ATDLVT about the use of the D- osition. Functions and responsibilities of the D-position and the potential workload reduction on the $\mathrm{R}$-position were the focus of this effort.

A starting point for the test was to define which Data Link functions the D-position could perform. The controllers were asked "Comment on the Data Link functions that can be performed at the D-position."

Controller Comments:

"Should be able to do free text and backup comm, Toc."

"Assigned altitude, interim altitude, free text, handoff, and TOC. Once inputs have been learned to do the above functions, the D-side can uplink as quickly as the R-side."

"D position is very necessary. It will increase safety and help out the R-controller. It reduces frequency congestion."

"Delete messages from the status list - needs to be included as a Dside function." 


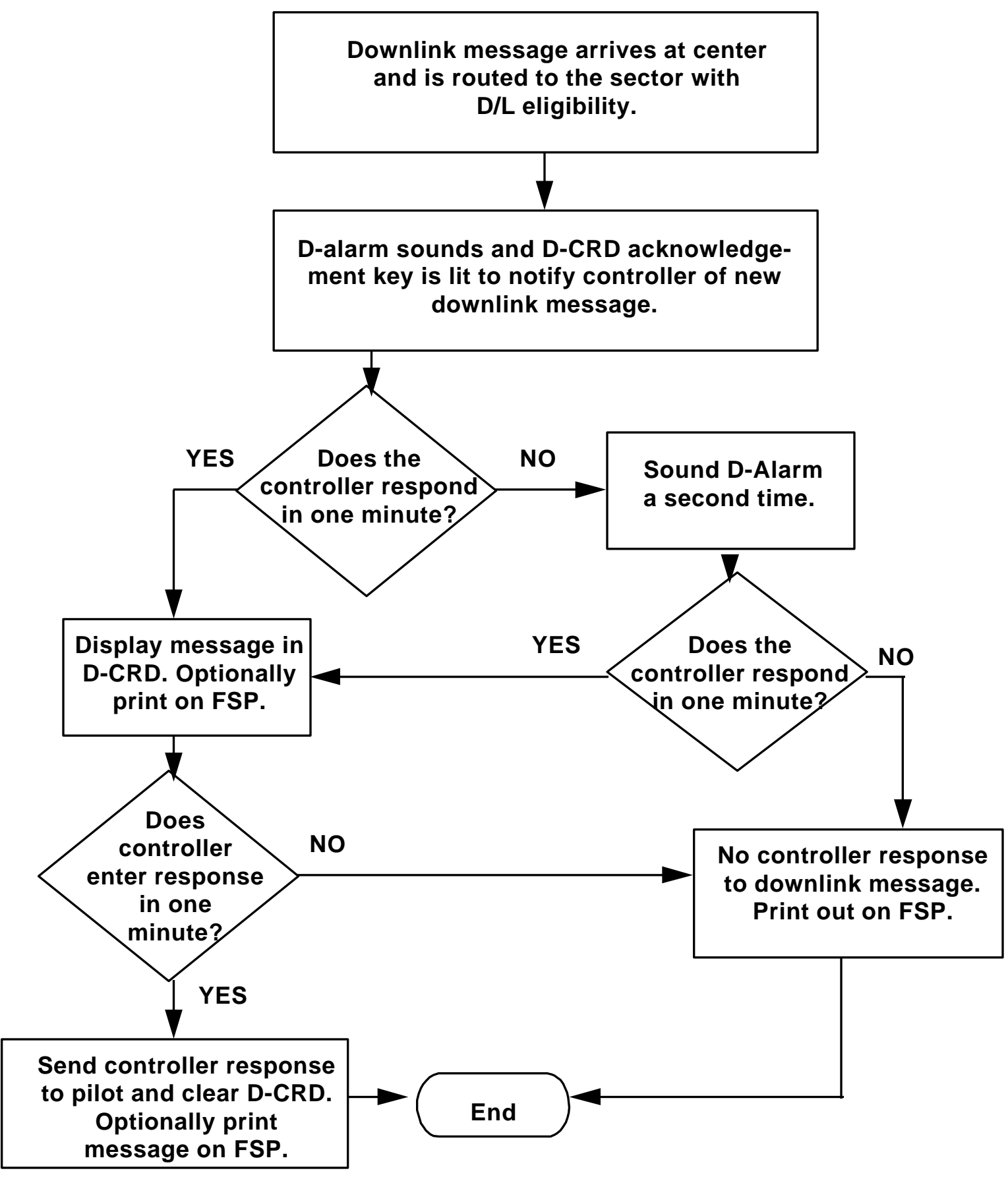

FIGURE 19. DOWNLINK LOGIC FLOW

From the comments and debriefings, the controllers felt that free text, backup communications, and handoffs/TOC would be the most likely candidates for D-position responsibility. Also cited as potential responsibilities were status list maintenance, monitoring for Data Link failures, and possibly assigned and interim altitudes, although the controllers felt that close coordination 
between the $\mathrm{R}$ - and D-positions would have to exist for altitude assignments.

Next, the controllers were asked to "Comment on how future Data Link testing could be conducted to help answer the questions of increasing a sector's efficiency and reducing workload on the R-position."

Controller Comments:

"Problems need to be developed which will completely saturate the Rcontroller and force the D-side to track from the manual position. This would indicate whether a busy sector could be worked mainly by Data Link and working relationship needed from the $\mathrm{R}$ and $\mathrm{D}$ sides when utilizing Data Link."

"Run the D-position just like we did until we figure out the problems. We may have to lock out certain functions if there are conflicts between the $\mathrm{R}$ and $\mathrm{D}$ sides."

"D-side has to be included on future tests and controllers need to be thoroughly familiar with the lab operation. (Proper sectors for coordination, etc). D-controller then needs to work with $\mathrm{R}-$ controller in order to use the TOC function."

The controllers expressed the concern that the subject controllers in future tests should be thoroughly familiar with the test bed airspace and any other items which are unique to the test bed. Sufficient training time will be required if sector efficiency is to be measured. Also, the controllers felt that high workload scenarios need to be developed to test the efficiency of a sector. Future testing using the en route Data Link test bed will need to be carefully planned to obtain valid results for measuring the increased sector efficiency using Data Link. From the ATDLVT input, high volume scenarios and controller training will play an important part of the test design.

\subsubsection{Data Link Procedures.}

The development and testing of the initial Data Link services and functions, to date, have not involved any substantival discussion on Data Link air traffic control (ATC) procedures based on ATC 7110.65 manual. The discussion of the Data Link ATC procedures was intended to simulated discussion on the subject and document procedures for testing purposes. The ATDLVT provided procedural guidelines to issues pertaining to sending messages to aircraft, failed messages, pilot check-in, and pilot responses to Data Link ATC message.

The discussion on rules for sending Data Link messages to aircraft resulted in several procedures:

a. A controller may send Data Link messages to more than one aircraft simultaneously.

b. A controller may send a message of the same service type to more than one aircraft simultaneously. 
c. A controller may send only one message per service type to a single aircraft.

d. A controller may not send messages of the same service type to a single aircraft while a message of that service type is outstanding for that aircraft with the exception of a free text message.

The issue of how a controller resolve a Failed Data Link message resulted in the following procedure:

a. If a Data Link message fails, use the radio or resend the message at the controller's discretion.

b. If the use of the radio is required, the controller phraseology will be at the controller's discretion.

The issue as to whether the pilot will be required to check-in with a controller upon switching to a new sector frequency resulted in the ATDLVT agreeing that the current check-in procedure must be adhered to, but the method (voice or Data Link) by which this will be accomplished will be discussed in a future meeting.

The discussion on what the pilot is expected to do if he/she responds with an Unable response resulted in the following procedure: The pilot must use voice to inform the controller as to why he/she cannot comply with the Data Link ATC instruction.

The ATDLVT also agreed that the pilot will be expected to respond to Data Link ATC instructions with a WILCO response. This issues must also be discussed with the pilot Data Link team.

The Data Link procedural issues discussed during the meeting are by no means conclusive and is only the beginning of issues that must be discussed and resolved by both the controller and pilot Data Link teams.

\subsection{ALTITUDE TIMESHARE DISPLAY: SYSTEM IMPACT.}

The test bed software provided timeshared display information during an Altitude Assignment transaction. To concurrently display both an uplinked altitude and the current altitude, the FDB altitude field (line 2) timeshared the displayed-altitude and conformance symbol with the uplinked-altitude and transaction status. The test bed Host computer generated the display timeshare by sending a new data block (Host to CDC Write Over message) each time the display alternated. These messages, which occurred only for data blocks executing an Altitude Assignment transaction, added to the messages normally sent for sector displays. The addition of the timeshare display for Data Link Altitude Assignments represented an additional quantity of FDB Write Over messages for those tracks executing an Altitude Assignment transaction. 
To investigate the system impact of the timeshare, data from two comparable test runs were collected. The tests are identified as run \#4; 11/6/90 (Timeshare alternation=1.5 seconds) (SAR= AC2130), and run \#4; 11/7/90 (Baseline) (SAR=AC2134). Clock time for both sets of data is 145900-152000.

\subsubsection{Analysis.}

For each sector, the total quantity of Write Over messages from the baseline run was compared with that from the Data Link run. The heavier traffic sample was used for both runs. For the analysis, increases in Write Over messages were assumed to result from the use of the Data Link Altitude Assignment function.

The two sets of data were collected on two different evenings, using the same scenario, but with differences in the operational tests. Controllers operating the positions had switched R/D sides so that different personnel made operational control decisions, and the operation at the ghost sector was modified in that more aircraft were accepted by an operating sector during the Baseline run than during the Data Link run.

The collected data included the total number of "flights handled" for each sector. Differences in flight distribution among sectors suggested that the operational characteristics of the two test runs varied and precluded detailed comparisons. On the other hand, the use of a common traffic sample and standard operational procedures for test conduct justified an overall comparison of Write Over message quantities.

\subsubsection{System Impact.}

Quantities of Write Over messages were compared to derive percentage changes between Baseline and Data Link test runs. The percentage changes of Write Over messages between the two data sets exhibited no significant statistical variation. The results suggest that no Data Link activity persisted long enough to result in significant increases of Write Over message generation.

In consideration of the Host/Data Link operational implementation time frame, it can be expected that multiple Altitude Assignments at one sector will not be performed. Further, pilot responses will occur within a 40-second time frame. Since the timeshare display will be used only occasionally, the increased data block message quantity will not significantly affect system throughput.

Since the test results are based on a small data sample, and represent a quick look at the total accumulated Write over message quantities, detailed analysis of display channel system impact was not warranted. Detailed interface analysis with real system data 
should be performed to generate peak display loads, and to assess the system impact. Display channel processing delays, if they occur, could increase the time or stability of the display alternation. Visual verification that the display will maintain the 1.5 second timeshare interval during periods of reasonably heavy display data transmission should be performed.

\subsection{SYSTEM DATA.}

NSSF Target Generation Programs performed the basic aircraft simulation functions which included target initialization, target update, navigation, holding, approach simulation, simulator pilot processing, radar processing, and data collection.

Data reduction and analysis routines provided a means of extracting and analyzing the data measures related to the concept under study. The reports provided such data as: lists of all violations of ATC separation standards including the position and motion characteristics of each aircraft at the start and end of the violation, duration of the violation, the horizontal and vertical separation of the closest point of approach, and a categorization of instructions (e.g., speed commands and vectors) issued to each aircraft.

The purpose of developing an initial set of performance measures was to determine the quality of measurement of system performance and statistical treatment that is possible and appropriate for assessing future simulations of Data Link services. It was not intended that they be used for a comparative evaluation of voice and Data Link in the present study. The major purpose of the present study was to obtain design information through controller feedback and was, therefore, not planned for the statistical treatment of the performance data.

The key NSSF performance measures that were collected for each run in this study included the following:

The number of aircraft handled for each sector.

The duration (in seconds) of aircraft handled.

The number of conflicts within each sector.

The duration (in seconds) of each conflict.

The number of between sector conflicts.

The duration (in seconds) of each conflict between sectors.

The maximum Aircraft Proximity Index (API). The purpose of this index is to provide a number that indicates the danger or seriousness of a confliction between two aircraft. It is based on the smallest vertical and horizontal separation during which a conflict existed. It is not based on the slant range miss distance.

The Closest Point of Approach (CPA). This measure is based on slant range miss distance.

The CPA less than a thousand feet.

The CPA less than 300 hundred feet.

The number of path changes. 
The average separation distance (in miles).

The standard deviation of separation distance.

The average time in sector (in seconds).

The standard deviation of time in sector.

The number of cancellations.

The number of completed flights.

The number of pilot messages.

\subsection{EN ROUTE-TERMINAL JOINT AIRSPACE DISCUSSION.}

During the initial ATDLVT evaluations of en route-terminal Data Link, numerous airspace deficiencies where noted. In an attempt to make Data Link simulation as realistic as possible, the controller team set forth to develop requirements for joint en route-terminal end-toend testing. This new test bed adaptation must be able to interface between the en route-terminal test beds and have real time flight simulators interfaced for aircrew Data Link evaluation and realism.

The ATDLVT controllers defined the following airspace requirements as a minimum for a realistic end-to-end test bed.

a. En route facility, preferable Washington Center.

b. Terminal ARTS IIIA at least level 4 or higher.

c. Multiple approaches (parallel and intersecting).

d. Satellite airports.

e. Four-corner post operation.

f. Four to five-sector operation.

g. Flight Plans consisting of arrivals, departures, and overflights for both the en route/terminal options.

4. CONCLUSIONS.

Conclusions derived from the results of the testing and debriefings presented in this report are provided below. Based on these conclusions, section 5 identifies recommendations for future testing as well as for additional functional development of the Data Link air traffic control (ATC) services identified herein.

\subsection{TEST BED ACTIVITIES.}

Controllers agreed that the test bed application of Washington Air Route Traffic Control Center (ARTCC) airspace provided a realistic operational problem. As a result of the operational complexity associated with the realism, a longer controller training period would have been desirable. In addition, controllers indicated that the test scenarios should be enhanced as follows:

a. A percentage of non-Data Link aircraft should be included.

b. Airspace in future testing should include airports and associated feeder sectors. In-trail spacing should be included as part of sector operations.

It was also concluded that Data Link operations for aircraft transitioning between facilities need to be investigated. Associated 
test bed requirements, scenarios, procedures and software functional requirements need to be developed for Transfer of Communications (TOC) between en route and terminal facilities.

\subsection{VOICE CHECK-IN/INITIAL CONTACT.}

Controllers identified pilot voice check-in as a significant, unresolved issue. The current TOC design includes no software mechanism for verifying a currently assigned altitude.

However, the participating controllers felt that voice check-in could be phased out, thus achieving the voiceless TOC, as controllers and pilots acquire Data Link field experience.

\subsection{AUTOMATIC TRANSFER OF COMMUNICATIONS.}

The controller opinion of the automatic TOC service was divided. Some controllers said that they would prefer to use the capability; others would not.

The tested automatic TOC is usable, although some details need further development. The input to establish the auto/manual setting for TOC was found to be complex. Controllers indicated that the automatic TOC inputs should be similar to those used for automatic Handoff.

The inputs to use the inhibit feature were found to be acceptable as they are currently implemented.

4.4 SECTOR DATA LINK DISPLAYS.

4.4.1 Plan View Display (PVD) Information.

The tested Full Data Block (FDB) displays for alerting to a Data Link transaction failure state were found to be unacceptable by the controllers. Although the oversized Data Link eligibility indicator was preferred over other techniques, no acceptable method that is technically feasible was identified.

The PVD header display, showing Data Link settings, should be changed to provide easy comprehension and reduce clutter. The ON/OFF indicator for Data Link system processing should be continuously displayed, while other setting information should be available upon request.

Held TOC messages need not be double bright, if the other states

(Held, Sent, Delivered, WILCO) are not displayed.

The status list should have two display states: Full and Default. The Full state would display all Data Link transactions in the status list regardless of the transaction's status. The Default state would suppress all normal status list entries for TOC and altitude assignment, display all failures for all services, display all Communications Backup uplink message transactions, and display Held TOC messages. 
Any Fail transactions, regardless of Default or Full status list operation, should be displayed as double bright in the status list.

4.4.2 Computer Readout Display (CRD) Information.

The automatic TOC status by sector should be indicated in the CRD in a manner similar to the CRD automatic Handoff displays.

The CRD display should indicate the sectors that are currently enabled for automatic TOC.

\subsection{DATA LINK ELIGIBILITY.}

The tested message format for sending eligibility and sending/inhibiting an uplink is satisfactory. Also, the use of "/OK" to acquire Data Link eligibility should be allowed from any sector.

\subsection{ALTITUDE TIMESHARE.}

The preferred alternation display interval for timesharing the uplinked altitude with the normally displayed altitude in the FDB is 1.5-seconds.

Summary counts of Host data blocks suggest that using the Write Over message to generate a display timeshare for altitude assignment transactions will not significantly affect the display channel interface in the near term.

Only four sectors were used and percentages were derived from a small data sample. More extensive and detailed testing is needed to assess the display timeshare's impact on the display channel processing.

\subsection{MENU TEXT REFERENT IN THE STATUS LIST.}

The menu text referent in the status list is acceptable as tested.

\subsection{FREE TEXT RECALL.}

The input message to recall the previously used free text is acceptable as tested. The recall capability should be provided independently at both the $\mathrm{R}-$ and $\mathrm{D}$-controller positions.

\subsection{COMMUNICATIONS BACKUP DOWNLINK.}

The controllers stated that, with the recommended improvements, (section 3.2.11) the Communications Backup Downlink service will benefit the ATC system by providing additional means of air/ground communications. 
The controllers indicated that the tested Communications Backup Downlink messages contained sufficient and necessary data.

The D-CRD Acknowledgement key was found to be suitable for controller use with downlink messages. The controller ratings and comments indicate that, for the D-CRD acknowledgement section of the design, two response time parameters are necessary. The controller should have 2 minutes to respond to the downlink message, by pressing the CRD Acknowledge key. If the controller does not respond within 1 minute, the audible alarm is again sounded to alert to the pending message. After the 2 minutes have expired, no response to the pending message should be allowed and the message should be printed on the flight strip printer (FSP).

Communications Backup Downlink messages should be referenced by use of a two-digit number.

The computer identification number (CID) for the aircraft should be added to the downlinked message display on the CRD.

The controllers recommended using the same format for the downlink message display as currently used for altitude update messages displayed at the D-position.

The received message should always be printed on the FSP. The format of the printout should be refined to include a Data Link equipment qualifier (when it becomes implemented) and red printing for the CID.

The FSP output of the received message should occur either when the message is acknowledged or displayed at the D-position by the controller, or when the message times out with no acknowledgement.

The input action to respond to a received Communications Backup Downlink message, when implemented, should require fewer keystrokes than the tested input action. A D-Controller Quick Action Key would be preferred over the two-character message type input. (It was recognized that spare QAKs are probably not available at field facilities.)

When the D-controller enters a message to respond to the received message, the default should be set to either "ROGER" or "STANDBY." Further testing with pilot involvement is necessary to identify and resolve this and other issues regarding the use of the Communications Backup Downlink service.

\subsection{D-POSITION OPERATIONS.}

Communications backup and handoff/TOC are the most likely candidates for D-controller responsibility. The controllers also suggested that the D-controller could perform status list maintenance and monitor for Data Link failures. D-controller inputs to enter Assigned and Interim altitude actions were considered as possibilities, but require further analysis and testing. 


\subsection{FUTURE TESTING FOR WORKLOAD REDUCTION.}

New test scenarios, developed to saturate the R-controller, are necessary to force operational impact at the D-controller. To successfully conduct a test with high workloads, controller familiarity is essential. Sufficient hands-on training periods will be necessary to enable test controllers to become completely familiar with the test bed airspace and any other items unique to the test bed.

\subsection{DATA LINK PROCEDURES.}

Discussions on rules for Data Link message transmissions resulted in several recommended procedures related to multiple uplinks, resolving failed transactions, and pilot check-in.

The procedures discussion was not conclusive, but identified a need for both controllers' and pilots' participation in the development of procedures and the resolution of issues.

\section{RECOMMENDATIONS.}

Listed below are the recommendations for future efforts under the Federal Aviation Administration (FAA) Data Link program. These recommendations are derived from the findings and conclusions stated herein.

\subsection{TEST BED ACTIVITIES.}

The Washington Air Route Traffic Control Center (ARTCC) adaptation, should continue to be used in the en route Data Link test bed. A Data Link test bed capable of interfacing computer systems from separate facilities should be established. Associated test bed technical requirements, scenarios, procedures, and software need to be developed to exercise Data Link functions for transitioning aircraft.

The airspace should include airports and feeder sectors. In-trail spacing should be included as part of the test conduct requirements. A percentage of non-Data Link equipped aircraft should be included.

\subsection{VOICE CHECK-IN/INITIAL CONTACT.}

An initial contact procedure to provide a voiceless transfer of communication (TOC) should be developed. Discussions and testing with pilots and controllers should be conducted to address the issue of voice check-in, and to define associated operational requirements.

\subsection{AUTOMATIC TRANSFER OF COMMUNICATIONS.}

An automatic TOC function should be implemented for future test bed activities, and should be incorporated in en route software to be subjected to operational test and evaluation. Use of the function 
should be optional at each sector position. Further, sector inputs to select the option should be similar to those used for selecting automatic Handoff.

\subsection{DATA LINK FAILURE DISPLAYS.}

A generic display technique for alerting to transaction failures should be developed and tested.

\subsection{ITEMS FOR OPERATIONAL TEST AND EVALUATION (OT\&E).}

En route software that will incorporate Data Link air traffic control (ATC) services should include the items listed below, which should be subjected to OT\&E.

a. The optional automatic TOC (sections 4.33 and 4.4.2).

b. The TOC Inhibit feature (section 4.3).

C. The detailed modifications to PVD and CRD displays identified herein (section 4.4).

d. The tested message formats and use of "/OK" for establishing Data Link eligibility (section 4.5).

e. The altitude timeshare display capability, with display interval set to 1.5 -seconds (section 4.6).

f. The tested use of the menu text referent in the status list (section 4.7 ).

g. The tested input message to recall previously used free text (section 4.8 ).

\subsection{COMMUNICATIONS BACKUP DOWNLINK.}

The functional design and use of the Communications Backup downlink should be pursued in accordance with the detailed modifications to the design identified herein (section 4.9). Further, pilots and controllers should participate in developing the default response messages and in developing procedures associated with the function.

\subsection{FUTURE TESTING.}

Recommendations for future Data Link testing are contained in the following subsections.

\subsubsection{Training Requirements.}

Testing in the future will involve heavy workload scenarios, as well as in-trail spacing requirements. Since participating controllers will require extensive training and hands on time, test facility 
scheduling and test planning should increase training times beyond that assiqned in the past.

\subsubsection{D-Position Responsibilities.}

Further testing should be conducted to develop the D-position capability in connection with Data Link. In support of that requirement, D-position operational responsibilities should be identified and tested, and new traffic scenarios should be developed to increase sector workloads.

\subsubsection{Altitude Timeshare Display Impact.}

Additional testing should be conducted to assess the effects of the Altitude Timeshare. A large scale test built from real operational data and run from simulation tapes should be assembled. The display channel should be tested to verify that the 1.5 second alternation is maintained during peak heavy loads.

\subsubsection{Data Link Procedures.}

Controllers and pilots should jointly develop procedures for using Data Link ATC services. The procedures should then be evaluated in the test bed. 
5.6 REFERENCES.

1. Talotta, Nicholas, et al., Operational Evaluation of Initial Data Link Air Traffic Control Services, Vols I and II, DOT/FAA/CT-90/1, I, II, February 1990 .

2. The MITRE Corporation, Plan for the Data Link Service Design Validation Micro Study, Report No. WP-90W00321, September 1990 .

3. The MITRE Corporation, Data Reduction and Analysis for the En Route Data Link Test Bed, Report No. WP-90W00206, June 1990.

4. The MITRE Corporation, Functional Specification for ATC Data Link Service Implementation in the Host Computer System, Report No. MTR90W00164, November 1990. 
APPENDIX A

CONTROLLER QUESTIONNAIRES 
The controller questionnaires are designed to obtain feedback from each controller participating in the laboratory test sessions. The areas covered by the questionnaires include the Washington Center Airspace, Test bed Software Validation, Communications Backup Downlink, and the D-Controller Position. The questionnaires contain a description of each of the areas to be covered in the test sessions. Included with each area are questions and comments to be filled out by each of the test participants. Please take time to read each question and provide the best answer possible. In some cases, a rating scale is used. Depending on the question, different rating scales will be used. The following shows the values for each of the choices in two of the rating scales used:

Rating Scale 1

1. Acceptable as is

2. Acceptable, minor changes desirable

3. Marginally Acceptable, major changes necessary

4. Unacceptable

Rating Scale 2

$$
\begin{aligned}
& \text { VG = Very Good } \\
& G=\text { Good } \\
& \text { SG = Slightly Good } \\
& F=\text { Fair } \\
& \text { SP = Slightly Poor } \\
& \text { P = Poor } \\
& \text { VP = Very Poor }
\end{aligned}
$$

Any other rating scales that are used will be explained with the question. If there are any questions on the ratings, ask the facilitator at your sector. If there are any further comments or issues which are not included, please write them down in the comment area provided. If there is insufficient space, use the back of the sheet on which the question appears.

Name

Date Sector 


$$
\mathrm{A}-1
$$

\section{WASHINGTON CENTER AIRSPACE COMMENT SHEET}

Four sectors from the Washington ARTCC have been implemented in the Data Link test bed to add realism to the Data Link simulation. During the first night of tests you will be expected to evaluate and comment on the Washington Center airspace. As the tests proceed on other nights, feel free to come back to the comment sheet and write down anything you feel will benefit the airspace implementation. Following the comment sheet are 8 pages for evaluation of each of the four new scenarios. Each sheet should be completed after the scenario has been run. The facilitator at you sector will instruct you when it is time to complete each scenario evaluation. Also, answer the question at the bottom of this page after the last night of testing.

Does the overall set of sceanrios present a sufficient range of operational problems to adequately excercise Data Link and test its effectivness? If not, what else is needed? 
A-2 


\section{SCENARIO \#1 EVALUATION}

1. Choose the number below which best describes how hard you were working during the test run.

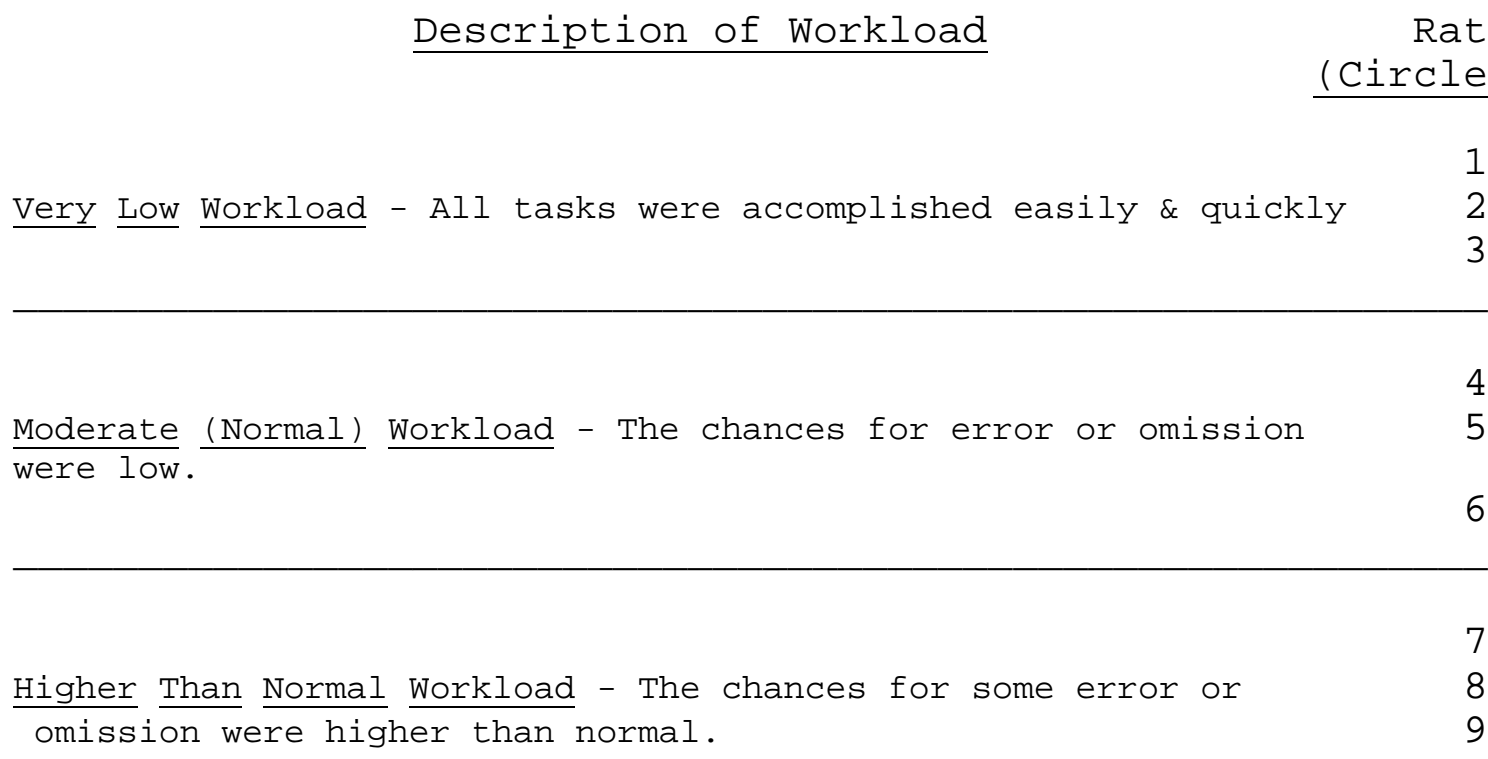

10

Very High Workload - It was barely possible to accomplish all 11

tasks properly. The chances for error or omission were high. 12

2. Rate your performance controlling traffic during the past hour. Circle the number which best describes how well you think you did.

$\begin{array}{lrlrrrrrr}1 & 2 & 3 & 4 & 5 & 6 & 7 & 8 & 9 \begin{array}{c}10 \\ \text { Poor }\end{array}\end{array}$

3. How busy were you during the period you were controlling traffic?

$\begin{array}{lccccccccc}1 & 2 & 3 & 4 & 5 & 6 & 7 & 8 & 9 & 10 \\ \text { Seldom Had } & & & & & & \text { Fully Occupied } \\ \text { Much To Do } & & & & & & \text { At All Times }\end{array}$

$A-3$ 
4. Rate the degree to which you found this control period stressful. Circle the number below which best describes how you felt.

$\begin{array}{llllllllll}1 & 2 & 3 & 4 & 5 & 6 & 7 & 8 & 9 & 10 \\ \text { Low } & & & & & & & & \text { High } \\ \text { Stress } & & & & & & & & \text { Stress }\end{array}$

5. What suggestions would you make to improve this scenario? 
A-4 


\section{SCENARIO \#2 EVALUATION}

1. Choose the number below which best describes how hard you were working during the test run.

$\begin{array}{ll}\text { Description of Workload } & \begin{array}{c}\text { Rating } \\ \text { (Circle One) }\end{array}\end{array}$

1

Very Low Workload - All tasks were accomplished easily \& quickly 2

Moderate (Normal) Workload - The chances for error or omission 5 were low.

\begin{tabular}{ll} 
Higher Than Normal $\frac{\text { Workload }}{\text { omission were higher than normal. }}$. The chances for some error or & 7 \\
& 9 \\
\hline
\end{tabular}

Very High Workload - It was barely possible to accomplish all 11 tasks properly. The chances for error or omission were high. 12

2. Rate your performance controlling traffic during the past hour. Circle the number which best describes how well you think you did.

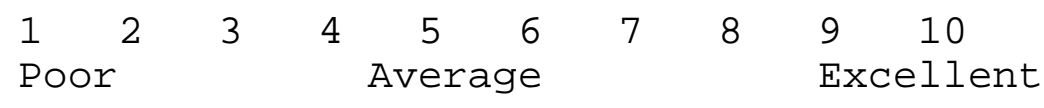

3. How busy were you during the period you were controlling traffic?

$\begin{array}{lccccccccc}1 & 2 & 3 & 4 & 5 & 6 & 7 & 8 & 9 & 10 \\ \text { Seldom Had } & & & & & & \text { Fully Occupied } \\ \text { Much To Do } & & & & & & \text { At All Times }\end{array}$


4. Rate the degree to which you found this control period stressful. Circle the number below which best describes how you felt.

$\begin{array}{llllllllll}1 & 2 & 3 & 4 & 5 & 6 & 7 & 8 & 9 & \begin{array}{l}10 \\ \text { High } \\ \text { Low } \\ \text { Stress }\end{array} \\ & & & & & & & & \\ \text { Stress }\end{array}$

5. What suggestions would you make to improve this scenario? 



\section{TEST BED SOFTWARE VALIDATION QUESTIONNAIRE}

1. Automatic Transfer of Communication(TOC) - During the spring testing, the ATDLVT suggested that auto TOC should be available for individual aircraft or for all aircraft bound for specific sectors. The test bed implementation of the auto TOC only allows all aircraft within a sector to be in auto or manual mode. This limitation is a result of the complexity of implementing the full auto TOC into the NAS software. Nevertheless, the auto TOC can be evaluated for its display attributes and general workings with other NAS functions. The input action to enable or disable auto TOC for all aircraft is as follows; DL CAT KEY, DL setting CRD input, $\mathrm{T}$, AUTO or MAN. This will enable automatic or manual mode TOC for all aircraft in the sector. In addition, when a sector is placed in the automatic TOC mode, an "A" will be displayed in the sector setup line at the top of the PVD to indicate Auto mode enabled for the sector. If the sector is in manual mode an "M" is displayed.

Also note: When Auto TOC is enabled, if the handoff of track control is initiated manually, the handoffinput action; sector Number, FLID will uplink the TOC message upon track control acceptance. If the input action; Sector Number, I, FLID (Inhibit) is used when TOC is in Auto mode, the TOC message will be placed in a Held status upon acceptance of handoff.

Questions:

What is your opinion of the DL CAT KEY, DL Setting CRD input, $T$, AUTO or MAN input?

1. Acceptable as is

2. Acceptable, minor changes desirable

3. Marginally Acceptable, major changes necessary

4. Unacceptable

Comments

What is your opinion of the TOC Inhibit feature, i.e., sector Number, I, FLID

1. Acceptable as is

2. Acceptable, minor changes desirable

3. Marginally Acceptable, major changes necessary

4. Unacceptable

Comments 
A-7 
How would you rate the status display at the top of the PVD?

1. Acceptable as is

2. Acceptable, minor changes desirable

3. Marginally Acceptable, major changes necessary

4. Unacceptable

What other symbology would you suggest?

Overall how would you rate the automatic TOC mode?

$\begin{array}{lllllll}\text { VP } & P & \text { SP } & \text { F } & \text { SG } & \text { G } & \text { VG }\end{array}$

Other comments and suggestions for Automatic TOC. 
2. DL IOK With the $S$ Option and DI IOK From Any Sector - During the spring testing, when a track was stolen using the /OK option with the $\mathrm{S}$ the status of the TOC message was not displayed at the stealing sector. Try stealing an aircraft from another sector with the Data Link /OK function. This will involve three sectors. Accept handoff for a track and hand that track to the next sector before the TOC has been sent at the sector with Data Link eligibility. Use the DL CAT KEY, /OK, S, FLID to steal eligibility. Observe that the TOC message status is displayed only at the stealing sector.

Questions:

How would you rate the status list and Full Data Block displays?

1. Acceptable as is

2. Acceptable, minor changes desirable

3. Marginally Acceptable, major changes necessary

4. Unacceptable

Comments

Should the /OK function be available for all sectors who have had track control for an aircraft but have handed that track control to another sector? 
3. Held TOC Messages Not Bright - Send a TOC message and observe that during the HELD state the message is not double bright in the status list.

Questions:

How would you rate the display of Held TOC messages?

1. Acceptable as is

2. Acceptable, minor changes desirable

3. Marginally Acceptable, major changes necessary

4. Unacceptable

Comments

Can you find the Held TOC message in the status list to uplink? Would it be better if the message were displayed as double bright?

$\mathrm{A}-10$ 
4. Sending Data Link Eligibility - Data Link eligibility may be sent to another sector. During the spring tests the ATDLVT suggested new inputs for uplinking or not uplinking a TOC message when the sector eligibility is sent to another sector. The inputs to send eligibility and uplink a TOC message with the specified sector's frequency in the uplink message is as follows; DL CAT KEY, Sector Number, FLID. If the controller chooses not to uplink a TOC message to the aircraft the following input sequence is used; DL CAT KEY, Sector Number, I, FLID. Try sending Data Link eligibility using both of these methods. Evaluate the input sequences for validity.

Questions:

The input sequence, DL CAT KEY, Sector Number, FLID will send eligibility and uplink a TOC message, while DL CAT KEY, Sector Number, I, FLID will send eligibility but inhibit the uplink. How would your rate these inputs:

1. Acceptable as is

2. Acceptable, minor changes desirable

3. Marginally Acceptable, major changes necessary

4. Unacceptable

Comments on sending eligibility. 
5. Altitude Timeshare - Observe the timeshare of the uplinked altitude data and the current altitude Full Data Block display. Three intervals will be tested, one half, one, and two seconds. Decide which time interval (if any) works best for timesharing the data.

$\underline{\text { Questions: }}$

How would you rate the altitude timeshare?

1. Acceptable as is

2. Acceptable, minor changes desirable

3. Marginally Acceptable, major changes necessary

4. Unacceptable

Comments

Which timeshare interval is preferred? $1 / 2,1$, or 2 seconds? Why? 
6. Full Data Block Failure Display Options - In the May, 1990 controller evaluation, the entire FDB was displayed as double bright when a Data Link transaction Failed (i.e., No Pilot Response, Communication Failure, or Pilot Unable). The general concensus was that this Failure display method was unacceptable. The current test provides two new generic FDB failure indications. 1) The Data Link eligibility symbol is displayed as an oversized character and 2) The whole AID field (1st line of the FDB) is displayed as oversized characters. Both of the above Failure methods are to be evaluated during the testing.

Questions:

Which of the alternatives (if any) are acceptable? Why or why not?

How would you rate the alternative you picked?

$\begin{array}{lllllll}\text { VP } & \text { P } & \text { SP } & \text { F } & \text { SG } & \text { G } & \text { VG }\end{array}$


7. Menu Text Referent in the Status List - The menu text message referent and uplinked altitude data are displayed in the Data area of the Data Link status list. Evaluate whether or not this data is displayed appropriately in the status list.

Questions:

How would you rate the display of the data in the status list?

1. Acceptable as is

2. Acceptable, minor changes desirable

3. Marginally Acceptable, major changes necessary

4. Unacceptable

Comments

Is the data suffieient? What else should be included? 
8. Free Text Recall - The input to recall the last entered free text message is; DL CAT KEY, T. To uplink the last entered free text message the inputs are; DL CAT KEY, T, FLID or ALL. Additionally, the $R$ and $D$ positions each have their own recallable messages. Evaluate the inputs for free text recall and use the capability at both the $\mathrm{R}$ and $\mathrm{D}$ controller positions.

Questions:

What is your opinion of the input DL CAT KEY, T to recall the message?

1. Acceptable as is

2. Acceptable, minor changes desirable

3. Marginally Acceptable, major changes necessary

4. Unacceptable

Comments

What is your opinion of the input DL CAT KEY, T, FLID or ALL, to uplink the last entered free text message?

1. Acceptable as is

2. Acceptable, minor changes desirable

3. Marginally Acceptable, major changes necessary

4. Unacceptable

Comments

Are recallable messages at both the $\mathrm{R}$ and $\mathrm{D}$ positions appropriate?

How would you rate the Free Text Recall Service?

$\begin{array}{lllllll}\text { VP } & \text { P } & \text { SP } & \text { F } & \text { SG } & \text { G } & \text { VG }\end{array}$


A-15 
9. Data Link Service Display in the Status List - The Functional Specification provides the choice to display or not display each Data Link service in the status list. If the service is suppressed from display, normal (i.e., Sent, Delivered, Wilco) status will not be displayed in the status list. However, if a Data Link message Fails, the display of the message will be forced in the status list, even if the service is suppressed from status list display. This test will try to determine which Data Link services must be displayed in the status list and which should not. The proposed setting will be: TOC - ON Altitude Assignment - OFF Free Text- OFF

Questions:

Which services should be displayed and which should not? Why?

Should messages that Fail always be displayed in the status list?

Should Held TOC messages always be included in the status list? 


\section{COMMUNICATIONS BACKUP DOWNLINK QUESTIONNAIRE}

1. D-CRD Acknowledgement Button and Alarm - Determine if the illumination of the D-position CRD Acknowledgement button and Dposition alarm are the appropriate mechanisms for alerting the controller to the incoming downlink message.

Questions:

Do the D-CRD Acknowledgement button and D-position alarm provide acceptable alerting mechanisms for the incoming downlink message? How would you rate the alerts?

1. Acceptable as is

2. Acceptable, minor changes desirable

3. Marginally Acceptable, major changes necessary

4. Unacceptable

Comments

2. Downlink Message Display - Evaluate the D-CRD acknowledgement button for displaying the communications backup downlink message. Determine if the message referent, time of receipt of the message, AID, and the downlink text are displayed properly in the D-position CRD.

Questions:

How would you rate the display of the downlink information?

1. Acceptable as is

2. Acceptable, minor changes desirable

3. Marginally Acceptable, major changes necessary

4. Unacceptable

Comments 
Is the use of the D-CRD Acknowledgement key to display downlink messages acceptable? What if the communications backup downlink message(s) are mixed with other messages sent to the D-position? Will this pose any potential problems?

Is all the information that is currently displayed with the downlink message appropriate?

Is there any additional information that needs to be included?

3. Flight Strip Printer (FSP) Data Display - Examine the display of the data on the flight strip printer. Comment on the FSP fields used for display of the downlink message and associated data.

Questions:

How would you rate the FSP output?

1. Acceptable as is

2. Acceptable, minor changes desirable

3. Marginally Acceptable, major changes necessary

4. Unacceptable

Comments

A-18 
Is the data displayed in the proper fields of the FSP? If not, which data should be displayed in which fields of the FSP output?

Should color be used to distinguish certain fields (i.e., Red or Black)?

Will the flight strip print-out be required as soon as the downlink message is received?

Do all downlink messages need to be printed out on the FSP?

4. Acknowledgement of the Downlink Message - Determine if the keyboard inputs required for response to the downlink message are appropriate. The input sequence to acknowledge the downlink message is; ACK QAK (new QAK at D-position), referent number, and optionally a response. If no response is included in the message, a default response (i.e., Standby) will be generated and sent to the pilot. Allowable values for the response are $S$ for Standby, $R$ for Roger, A for Approved, and U for Unable.

Questions;

A-19 
How would you rate the Acknowledgement input format?

1. Acceptable as is

2. Acceptable, minor changes desirable

3. Marginally Acceptable, major changes necessary

4. Unacceptable

Comments

Does the controller have to respond to a Communications Backup Downlink message?

What should the default response to the downlink message be? Should there be additional allowable values for the response?

\section{Overall Assessment}

How would you rate the Communications Backup Downlink service overall?

$\begin{array}{lllllll}\text { VP } & \text { P } & \text { SP } & \text { F } & \text { SG } & \text { G } & \text { VG }\end{array}$




\section{D-POSITION QUESTIONNAIRE}

The D-Controller position has been cited as a potential candidate for performing certain Data Link functions by the ATDLVT in the past. In previous Data Link tests the D-position has not been utilized. Now with the current downlink design and the potential benefits of the D-position used in conjunction with Data Link, the necessity for including the D-position has become apparent. The current exercise is intended to solicit ideas about the use of the D-position. Functions and responsibilities of the Dposition and the potential workload reduction on the R-position are the focus of this effort. Also the question of, Can the inclusion of the D-position increase an entire sector's capacity? should be asked.

During the 1 hour test, two controllers will be present at each sector position. They will take on the roles of the $\mathrm{R}$ and $\mathrm{D}-$ controllers. Half way through the test run the controllers should switch roles so each controller can give a proper evaluation of the Dposition issues.

A starting point for the test should be to define which Data Link functions the D-position can perform (e.g., Downlinks, Handoffs). Also, thought should be given as to how future evaluations should be conducted. Future tests will be conducted to answer the questions and issues raised above.

1. D-Position Functions - Comment on the Data Link functions that can be performed at the D-position. 
A-21 
2. Future Evaluations --Comment on how future Data Link testing could be conducted to help answer the questions of increasing a sector's efficiency and reducing workload on the R-position. 
APPENDIX B

CONTROLLER DISCUSSION ISSUES 
EN ROUTE CDIS

CDI \# : E1-091390

PRIORITY: HIGH

CTR REFERENCE \# :

TITLE: DOWNLINK NONRESPONSE TIMEOUT

SYSTEM: En Route

DESCRIPTION: If controller does not respond to a downlink should there be a timeout alert. The following are possible scenarios.

1. Pilot side times out giving some kind of alert. The pilot will resend or delete and call.

2. No pilot side timeout. It will remain steady, no alert.

3. Controller side will: a. Remain stable with no alert and no block of response. b. Show alert but with no block of uplinked response. c. Show alert and block uplinked response (since pilot side has timed out).

SUGGESTED SOLUTION :

RESOLUTION: The ATDLVT recommended at the the Nov 5-9 Technical Center Meeting that this issue be re-examined and this CDI discussed at a future design discussion meeting on downlinks. 
CDI \# : E2-091390

PRIORITY : HIGH

CTR REFERENCE \#:

\section{TITLE: NAKEd RESPONSES TO DOWNLINKS}

SYSTEM: En Route

DESCRIPTION: All downlinks need to be responded to by approve, disapprove, (watever). This constitutes an uplink which unfortunately can run afoul and get a negative acknowledgement (NAK) on the uplink. How will this be shown?

SUGGESTED SOLUTION: In the status list where it can be slewed for resending.

RESOLUTION: The ATDLVT concurred with the suggested solution above at the Nov 5-9 1990 Technical Center Meeting. The ATDLVT also stated that this issue should be re-examined at a future design discussion meeting on downlinks.

$\mathrm{B}-2$ 
EN ROUTE CDIS

CDI \#: E4-091390

PRIORITY : HIGH

CTR REFBRENCE \# :

TITLE: STEALING DL DELETES MESSAGES

SYSTEM: En Route

DESCRIPTION: Sometimes a controller need steal DL eligibility. Should this be allowed if a message is held, pending, failed, unabled, out? or a downlink is pending or with failed out? uplink response.

SUGGESTED SOLUTION :

RESOLUTION: The ATDLVT stated the following concerning this issue at the Nov 5-9 1990 Technical Center meeting:

1. A controller cannot steal data link eligibility without track control.

2. A controller cannot steal track control with data link messages pending.

3. A controller shall not hand off while a data link message is pending.

$$
\mathrm{B}-3
$$


CDI \# : E9-091390

PRIORITY: HIGH

CTR REFERENCE \# :

TITLE: DOWNLINK R AND D SIDE

SYSTEM: En Route

DESCRIPTION: On the bulletin board, Charles Scanlon indicates what pilots would like in terms of downlink. A copy is attached.

REROUTE downlink was especially liked. This is a host function for most facilities but DL can do it for ARTS also since it interfaces with host. AAS for sure. They will be looking at 4-D flight paths in future.

PREDEPARTURE CLEARANCE downlink was unanimously accepted.

AIRSPEED, HEADING, ALTITUDE and FREE TEXT requests were all unanimously wanted but were sometimes voiced instead by the pilots in their tests.

SUGGESTED SOLUTION: Pilot ideas suggest downlink is a general function not an emergency function and that downlinks should be treated just as importantly as pilot call by the $R$ side as well as D side.

RESOLUTION: The ATDLVT recommended at the Nov 5-9 1990 Technical Center meeting that this issue be re-examined and this CDI discussed at a future design discussion meeting on downlinks.

$$
B-4
$$




\section{EN ROUTE CDIS}

CDI \#: E10-091390

PRIORITY : $\quad$ HIGH

CTR REFERENCE \# :

TITLE: SPEEDS AND HEADINGS IN MENU

SYSTEM: En Route

DESCRIPTION: $\quad$ Suggest that en route have adaptable heading and speed menu messages like altitude. When sent, status indications would he like free text.

Heading and speed MT entries

To send MT message

DL, MT referent, FLID

To send MT \& change three digits DL, MT referent, nnn, FLID

To change \& retain MT three digits DL, MT enter

SUGGESTED SOLUTION :

RESOLUTION: The ATDLVT recommended at the Nov 5-9 1990

Technical Center meeting that this issue be re-examined and this CDI discussed at a future design discussion meeting.

B-5 


\section{EN ROUTE CDI}

CDI \# : E2-101890

PRIORITY: HIGH

CTR REFERENCB \# :

TITLE: MULTIPLE MESSAGES FROM MENU TEXT

SUPPLEMENTAL DATA: ORIGINATOR - EVAN DARBY

SYSTEM: HOST

DESCRIPTION: The controller should have the ability to send more than one menu text message to an aircraft. By combining messages the controller could be more efficient and Data Link will become even more powerful.

\section{SUGGESTED SOLUTION :}

Allow multiple Data Link menu text selections. These selections should be tied together to form one clearance and then sent to the aircraft. The pilot must either accept the entire clearance or the entire clearance is void. This eliminates the problem of partial clearances being used.

EX. "DL" A C F (CID)

$. \mathrm{A}+$ Climb and Maintain FL 230

- C Maintain 250 Kts

.F Fly Heading 060 Vectors for Spacing

RESOLUTION: The ATDLVT concurred with the above solution at the Nov 5-9 1990 Technical Center meeting. The ATDLVT stated emphatically that when more than one menu text message is sent to an aircraft, multiple messages of the same type may not be uplinked, i.e., multiple speeds, altitudes, etc. 


$$
\text { B- } 6
$$


EN ROUTE CDIS

CDI \#: E10-030990

PRIORITY: High

CTR REFERENCE \#: 90030602

TITLE: INTERFACILITY DL PROCESSING

SUPPLEMENTAL DATA: Problem Area: Design

SYSTEM: En Route

DESCRIPTION: The purpose of this CTR is to develop the functional processing requirements for Data Link interfacility processing, and to suggest that the approach in the Data Link functional specification be tested. That approach incorporates a new interfacility message, which will facilitate Data Link Transfer of Communications (TOC) for handoffs ARTCC/ARTCC and ARTCC/TRACON.

In that approach, presented herein, an interfacility Status Update (SU) message contains AID, a Reference Number, Transaction status and operation data such as radio frequency. This message will be generated by the sending computer and will be used to update transaction status in the receiving computer when a TOC involves more than one facility. Below, SU message applications to normal interfacility TOC, and to forcing and stealing Data Link eligibility are discussed.

\subsection{Normal Handoff and Transfer of Communication}

Figure 1 contains a diagram, which is referenced by the description of interfacility Data Link activity presented below. For an aircraft having Data Link session connectivity to the computers in both facilities, interfacility transfers of track control, radio frequency assignment and Data Link eligibility can be accomplished as follows:

- To initiate a transfer, Position A in facility A enters track handoff to position B in facility B. "H-xx" blinks in both data blocks. The full data block at $A$ indicates Data Link eligibility. The full data block at B indicates Data Linkcapability.

- When the Controller in B accepts handoff, and "O-xx" is displayed in both data blocks, a HELD Data Link message having B's radio frequency is generated and displayed in A's status list. Generation of this message initiates a TOC transaction. Full Data Block capability/eligibility symbols operate the same as with intrafacility TOC. An SU message is built and transmitted to B. The SU message
indicates HELD, the radio frequency and the unique transaction 
identifier (reference number). In $B$, this information is displayed the same as transaction information for intrafacility handoffs. B-7

The controller in $A$ uplinks the message to the aircraft. As Status changes to SENT, DELIVERED and WILCO, or FAIL, each status change is sent to B via an SU message.

When the status changes to WILCO, the B computer assigns Data Link eligibility to position $B$, in accordance with the requirements for granting Data Link eligibility. The Full Data Block symbol changes to indicate eligibility. At A, the A computer changes the Full Data Block symbol to indicate Data Link capability, not eligibility, in the same way as for intrafacility TOC.

The pilot changes frequency and calls B. First call and initial contact may be executed.

It should be noted that computer tables of radio frequencies must include all of those used for interfacility transfers.

2. Forcing Data Link Eligibility

When a track enters a facility and Data Link eligibility has not been established for a position within that facility, a process similar to track initiation should be used for forcing Data Link eligibility. In today's ATC system, an en route sector can force TRACK control by entering "/OK" and the track identification. For Data Link eligibility, the following procedure is sugqested.

The sector desiring Data Link eligibility for the aircraft must first acquire track control. This control is acquired by automatic track initiation, manual input action to initiate a track, or by using "/OK" to force a handoff to the entering sector.

After acquiring track control, the sector PVD will display the full data block with the Data Link-capability symbol indicating that a Data Link session is established for the aircraft. To acquire Data Link eligibility, the sector with track control should enter the Data Link Category/Function key and "/OK" for the aircraft ID. The computer would assign Data Link eligibility to the entering sector. If the operational "S" were entered, an uplink message would be built with that sector's radio frequency, and would be uplinked to the aircraft. The transaction status would be set to "SENT", and further processed according to Data Link requirements.

In the above example, no SU message is generated. The computer does not know which external facility, if any, previously had

Data Link eligibility. It is expected that operational coordination among facilities will ensure that only one controller issues operational directives to the pilot, as is the case in today's ATC facilities.

In the above approach, the SU message only updates transactions between facilities, and no messages are required to deal directly with eligibility assignments between facilities. 
3. Stealing Data Link Eligibility

To eliminate the possibility of a controller in one facility having

DL eligibility with an aircraft at the same time as a controller in $\mathrm{B}-8$

another facility, interfacility messages might be generated to be specifically used for eligibility. But, multiple eligibility is not clearly a problem. On the contrary, some advantage might accrue from providing an interface between a pilot and ATC in parallel with the control interface, e.g., for nonoperational information transfer.

A problem occurs if more than one controller issues an operational command to an aircraft.

If a controller uplinked an invalid command, any ability to steal DL eligibility from another controller enables this problem, regardless of interfacility computer messages that might be associated directly with eligibility. For a computer-based interfacility eligibility control mechanism to be effective, a "negotiation" process would be necessary, where a controller "requests" eligibility from some other facility

However, a negotiation process would be neither practical nor necessary. To execute a negotiation process, the stealing controller, or Host computer, must send a request.

A sector with DL eligibility could ignore or refuse the request. On what basis is that decision made? Would not there be a need to determine what that facility is requesting DL eligibility, and what they intend to do with it?

Why would interfacility messages be needed to request Data Link eligibility if subsequent coordination results anyway?

To summarize, using interfacility messages to ensure that only one controller maintains eligibility throughout all of the ATC facilities, who currently are capable of DL communications with an aircraft, would require a negotiation process. At this time, the need for such a process is not apparent.

It is therefore suggested that the test bed provide Host/ARTSIII interfacility testing as soon as possible, execute su message to keep both systems updated for interfacility TOCs, and that Data Link eligibility be assigned within a facility.

Both Host and ARTSIII software should therefore be modified to execute SU message generation and reception.

RESOLUTION: The ATDLVT recommended at the Nov 5-9 1990 Technical Center meeting that this issue be re-examined and this CDI discussed at a future design discussion meeting. 
B-9 


\section{EN ROUTE CDIS}

CDI \# : E3-091390

PRIORITY : MEDIUM

CTR RBFERENCE \# :

TITLE: FAILED DLP DOESN'T DELETE MSGS

SYSTEM: En Route

DESCRIPTION: If the Host fails, it should not delete status list messages. The controller might assume the msgs were delivered. Instead all messages should be given the status word "OUT" because they have been lost since the computer has failed.

SUGGESTED SOLUTION :

RESOLUTION: The ATDLVT recommended at the Nov 5-9 1990 Technical Center meeting that this CDI be closed and a new one opened entitled: Failed Recovery Data. 
CDI \# : E-091390

PRIORITY: MEDIUM

CTR REFERENCE \#:

TITLE: SECTOR FREQUENCY CHANGE

SYSTEM: En Route

DESCRIPTION: If a frequency goes bad, the controller may need to switch to another one. At the same time the controller needs to change the frequency associated to his sector in the computer table. I suggest menu item $F$ "change to my freq---.----" When sent to ALL, it changes the computer table. If sent to one flid, it does not change the table.

The initial services spec says that frequency changes for the TOC table can only be done by the supervisor.

SUGGESTED SOLUTION :

RESOLUTION: The ATDLVT stated at the Nov 5-9 1990 Technical Center meeting that frequency changes should only be done by the supervisor. 
CDI \#1: $E^{\star}-091390$

PRIORITY: LOW

CTR REFERENCE \#:

TITLE: QQ S FLID TO UPLINK REQUESTED

SYSTEM: En Route

DESCRIPTION: The entry $Q Q$ FLID overwrites the interim altitude in the FDB with the requested. The entry QQ S FLID seems like the logical entry to uplink it also. This is because QQ ddd FLID becomes uplinked by adding an S, eg. QQ ddd S FLID. However, the designed entry is DL R FLID. I suggest it be changed to QQ $S$ FLID because

1. It frees up $R$ to be used for "Roger" response to downlinks.

2. It shortens the menu text list.

3. It is consistent with " $S$ " design.

SUGGESTED SOLUTION: Use $Q Q \mathrm{~S}$ FLID to put requested in FDB and uplink it. 
RESOLUTION: The ATDLVT did not concur with this CDI at the Nov5-9 1990 Technical Center meeting. The ATDLVT stated that " $S$ " means send and the controllers want this to remain a clear fact.

EN ROUTE CDIs

CDI \# :- El-101890

PRIORITY : LOW

CTR REFERENCE \# :

TITLE: PRINT MENU TEXT MENU

SYSTEM: En Route

SUPPLEMENTAL DATA: ORIGINATOR - EVAN DARBY

DESCRIPTION :

For the most part controllers do not like to have listed displayed on their PVD's. Controllers must already watch their Metering list, Conflict alert list, MCI list and up to three optional lists.

There must be some other optional method for viewing or referring to data in the menu text list.

\section{SUGGESTED SOLUTION :}

Allow the controller to print the Data Link menu text list on the FSP.

Possible entry could be:

$$
\text { "DL" (FSP \#) (MT) (Enter) }
$$

RESOLUTION: The ATDLVT approved this CDI for test bed implementation at the Nov 5-9 1990 Technical Center meeting. 
B -13 


\section{EN ROUTE CDIS}

CDI \#: E3-101890

PRIORITY : LOW

CTR REFERENCE \#:

TITLE: ADDITIONAL DATA BLOCK INFORMATION

SUPPLEMENTAL DATA: ORIGINATOR - EVAN DARBY

SYSTEM: HOST

DESCRIPTION: During an altitude uplink there exists the possibility for information to reach the pilot and then either time out or be pilot unabled. In either case the controller needs to know that the pilot has the information available to him. The controller philosophy in the past has been all we need to know is did the message fail or not. This concept has some merit but is not entirely true. If the downlink of the WILCO message should fail for some reason the pilot may be complying with the clearance and the data block still reflects a FAIL status.

\section{SUGGESTED SOLUTION :}

Change the data block symbology to include the "D" for delivered. This would be displayed in the data block after the technical acknowledgement was received from the aircraft between the "S" for sent and the "W" for wilco. Now the controller would have information available on the status of the message not just the end result and could take appropriate actions.

RESOLUTION: The ATDLVT stated at the Nov 5-1990 Technical Center meeting that they do not want a "D" in the Data Block, they do want the "UNABLE" in the Data Block, and they want "NAKs" and "FAILs" in the status list. 
EN ROUTE CDIS

CDI \# : e7-091390

PRIORITY: LOW

CTR REFERENCE \# :

TITLE: $\quad$ STATUS LIST SUPPRESSION OVERRIDE

SYSTEM: En Route

DESCRIPTION: Even though the status list may be suppressed display NAKs, fails, unables, and held messages, since they need attention and can be slew entered from the list.

The initial en route spec has this feature but does not include held TOCs.

SUGGESTED SOLUTION :

\section{RESOLUTION :}

The ATDLVT stated at the Nov 5-9 1990 Technical Center meeting that NAKs, FAILs, UNABLEs, and HELD message displays should appear on the PVD even though the status list may be suppressed. 
APPENDIX C

SECTOR DESCRIPTIONS 


\section{Lessburg En-Route/Sim-Pilot Lab Pairings \\ Controller sectorPilot Lab ConsoleFreq.}

Pilot 1

Pilot2

Pilot 3

Pilot 4

Departure Ghost

Arrival Ghost
30

32

60

31

69

57
$34,35,36$

125.750

133.720

135.400

124.250

Intercom only

111.100

C-1 


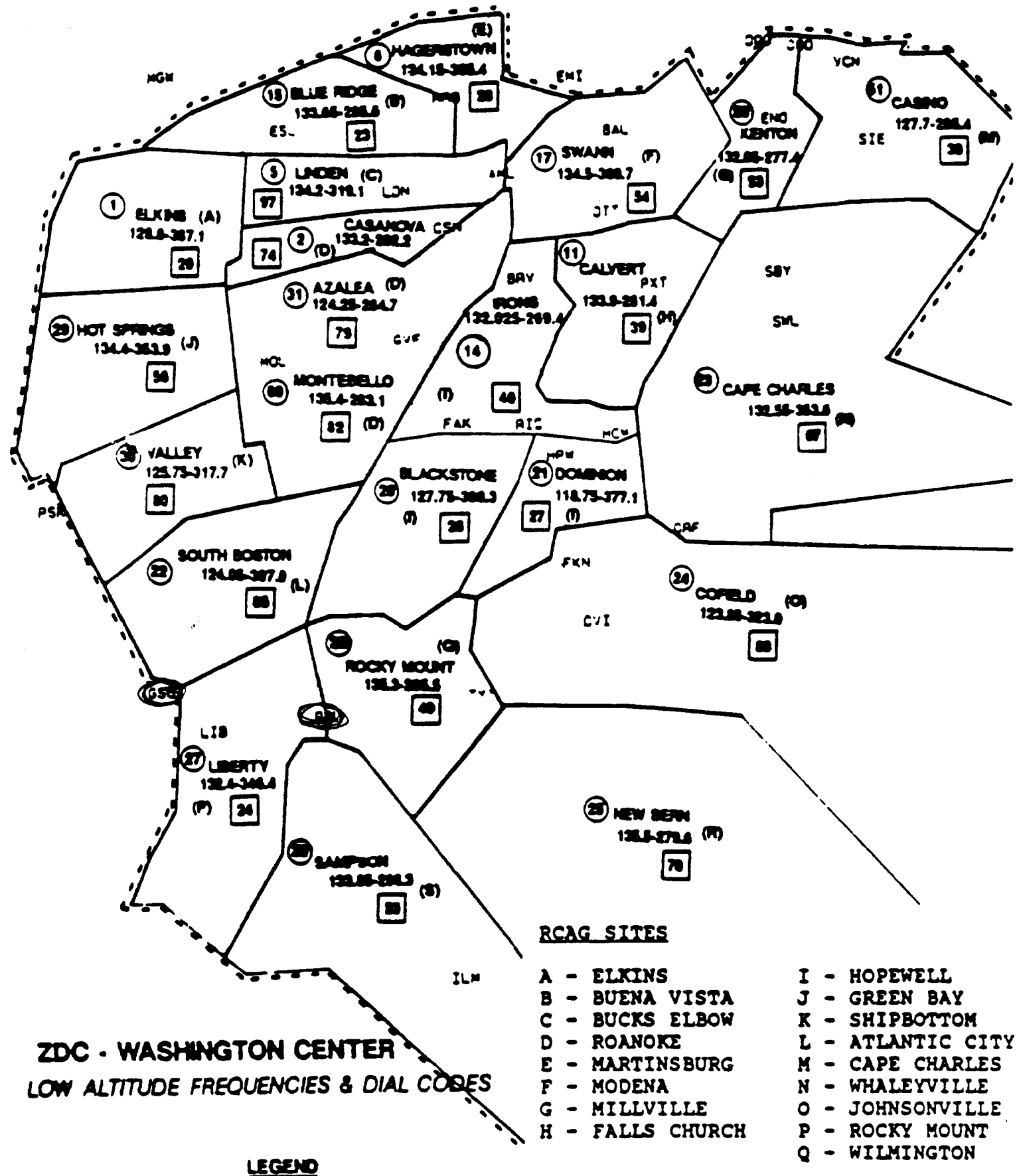

(12) secton menest

[2] sencous

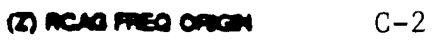




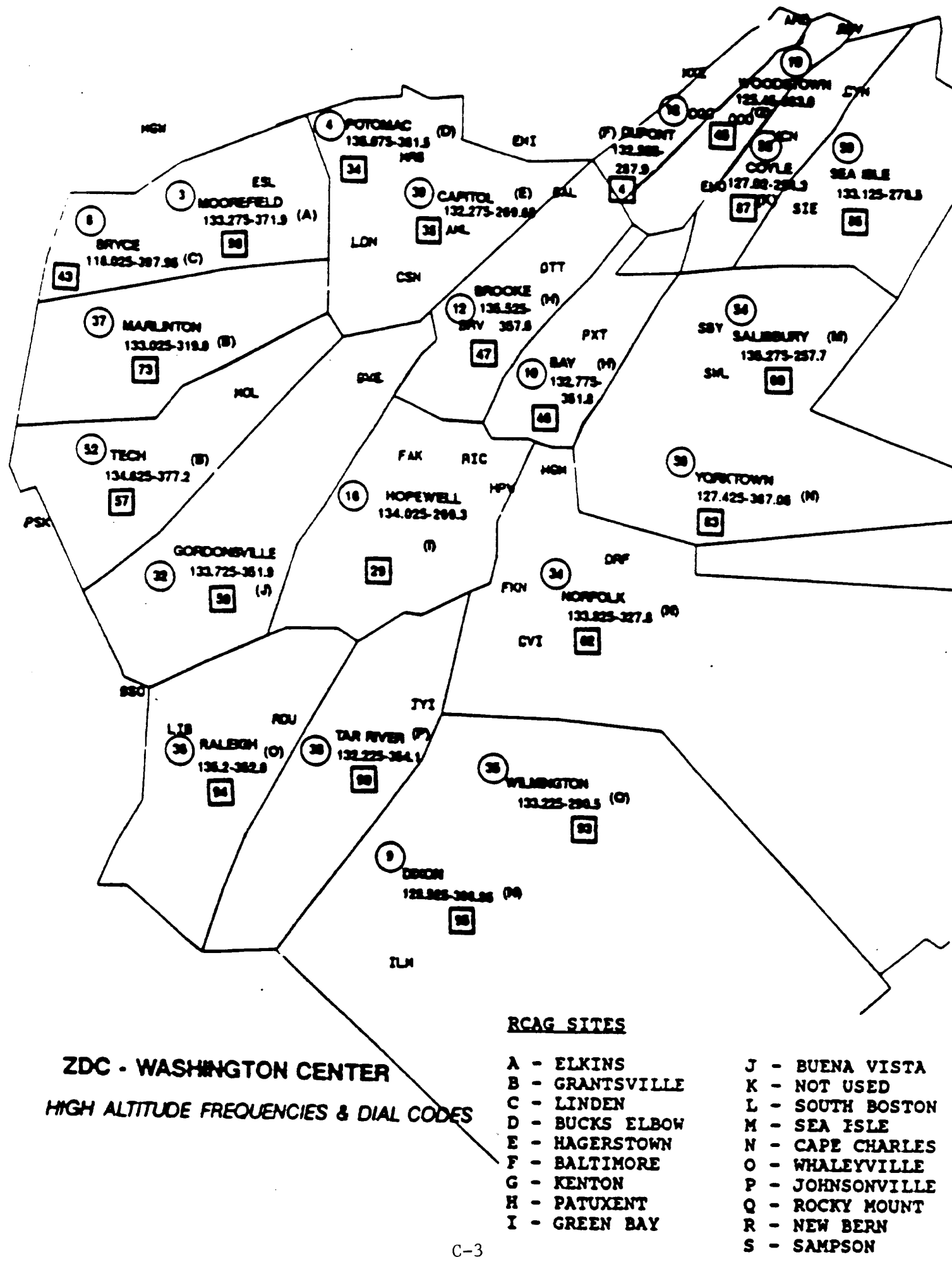




$\begin{array}{ll}\text { AAL } & \text { AMERICAN } \\ \text { ACA } & \text { AIR CANADA } \\ \text { AWI } & \text { AIR WISCONSIN } \\ \text { CDL } & \text { CAROLINA } \\ \text { CHQ } & \text { CHAUTAUQUA } \\ \text { COA } & \text { CONTINENTAL } \\ \text { COM } & \text { COMAIR } \\ \text { DAL } & \text { DELTA } \\ \text { EAL } & \text { EASTERN } \\ \text { HNA } & \text { HENSON } \\ \text { JIA } & \text { BLUE STREAK } \\ \text { MXA } & \text { MEXICANA } \\ \text { NAE } & \text { EAGLE FLIGHT } \\ \text { QKC } & \text { QUAKER CITY } \\ \text { R } & \text { ARMY } \\ \text { S } & \text { SAM } \\ \text { TWA } & \text { TWA } \\ \text { UAL } & \text { UNITED }\end{array}$




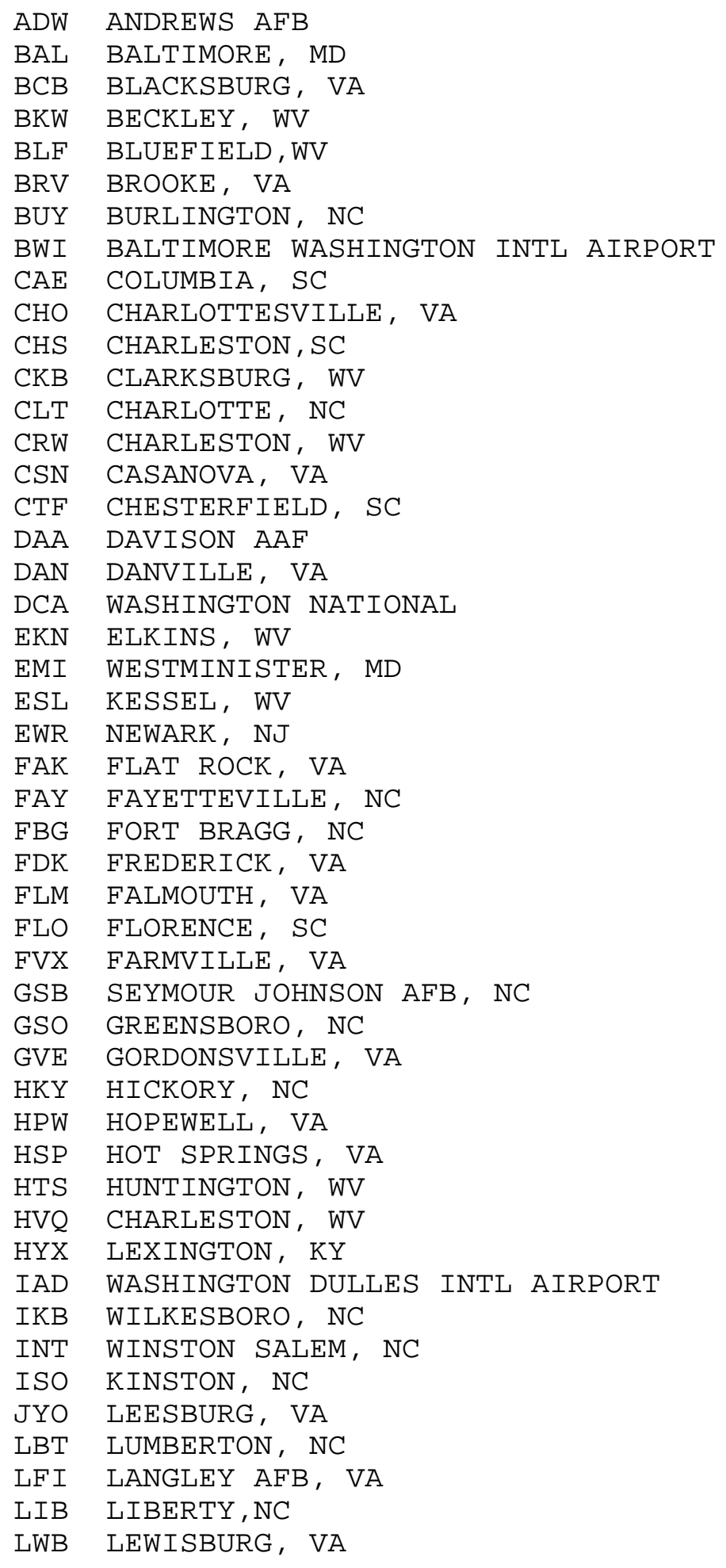




$\begin{array}{ll}\text { LYH } & \text { LYNCHBURG, VA } \\ \text { MGW } & \text { MORGANTOWN, WV } \\ \text { MOL } & \text { MONTEBELLO, VA } \\ \text { MRB } & \text { MARTINSBUR, WV } \\ \text { MTV } & \text { MARTINSVILLE, VA } \\ \text { ORF } & \text { NORFOLK, VA } \\ \text { OTT } & \text { NOTTINGHAM, MD } \\ \text { POB } & \text { POPE AFB, NC } \\ \text { PSK } & \text { DUBLIN, VA } \\ \text { PXT } & \text { PATUXENT RIVER NAS, MD } \\ \text { RDU } & \text { RALEIGH/DURHAM, NC } \\ \text { RIC } & \text { RICHMOND, VA } \\ \text { RNL } & \text { RAINELLE, WV } \\ \text { ROA } & \text { ROANOKE, VA } \\ \text { SBV } & \text { SOUTH BOSTON, VA } \\ \text { SBY } & \text { SALISBURY, MD } \\ \text { SDZ } & \text { SANDHILLS, NC } \\ \text { SHD } & \text { SHENANDOAH VALLEY ARPT, VA } \\ \text { SIF } & \text { REIDSVILLE, NC } \\ \text { SOP } & \text { SOUTHERN PINES NC } \\ \text { SPA } & \text { SPARTANBURG, SC } \\ \text { M40 } & \text { ABERDEEN/AMORY, MD } \\ \text { W10 } & \text { MANASSAS, VA } \\ \text { W13 } & \text { WAYNESBORO, VA } \\ \text { W16 } & \text { WINCHESTER, VA } \\ \text { W52 } & \text { CHAPEL HILL, NC } \\ \text { W54 } & \text { WESTMINSTER, MD } \\ \text { W78 } & \text { SOUTH BOSTON, VA } \\ \text { W93 } & \text { ORANGE CO., VA } \\ & \end{array}$





\section{Sector 30}

OT SPRINGS (HSP) 29/VALLEY SECTOR 30

1. General Description: The Valley Sector (R30) serves as a departure sector for two main airports in the middle western Virginia (Roanoke and Lynchburg). This sector will be combined with Hot springs for the purposes of our testing and serves as approach control for the Lewisburg/Hot Springs and Lynchburg, Airports. The basic altitudes are FL230 and below, with Roanoke approach owning 10,000 and below. The two primary very high frequency omnidirectional ranges (VOR's) are Roanoke (ROA) and Lynchburg (LYH) There are instrument approaches for all major airports in the sector. There are VFR towers at Lynchburg and Lewisburg, Virginia. Due to mountainous terrain, the minimum vectoring altitude is 6000 feet.

2. Radio Frequencies: For the purpose of this test, the frequencies for sector $29 / 30$ will be 123.000 .

\section{Procedures:}

A. Roanoke Approach

\section{Arrivals:}

a. Shall cross 25 miles from the Roanoke VOR level at 110 and $250 \mathrm{kts}$. Hand-offs shall be accomplished prior to the Aircraft crossing the approach boundary.

b. Roanoke arrivals operating at or below 10,000 feet shall be verbally coordinated with Roanoke approach prior to hand-off. All coordination involving facilities other than sectors 29/30, 31, 32 and 60 will be accomplished with sector (69 Ghost).

\section{Departures:}

a. All Roanoke departures will be climbing to 10,000 feet or their assigned altitude if less than 10,000 feet.

b. All roanoke departures will be established on their correct route of flight before being handed-off to center 
C- 7 
B. VER Towers:

1. Center Procedures:

a. All flight plans shall be issued to the tower at least 10 minutes prior to their departure times:

1. Aircraft Id.

2. Type A/C-Beacon Code

3. Route/Destination

4. Altitude to expect $10 \mathrm{~min}$. after Dept.

b. All inbound flight plans shall be given to the tower 15 minutes prior to Destination time:

1. Aircraft Id.

2. Type $A / C$.

3. Type of Approach

4. Arrival Time

issue:

c. When towers call for RLS of aircraft the center shall

1. Initial HDG.

2. Initial ALT.

2. Tower Procedures:

a. When towers call for RLS they shall provide the Active RWY.

b. Tower is responsible for the visual separation between arrivals and departures.

c. Tower shall call and advise the center when an A/C in insight landing assured.

C. Over Flight Procedures:

1. Raleigh-Durham arrival traffic shall enter South Boston Sector (69) Ghost at or below FL210.

2. Non-Jet arrival traffic to Baltimore, Washington, Richmond and satellites operating at or above 17,000 feet shall be handed-off to AZALEA (31) at or below 15,000 feet.

3. Arrivals to Raleigh Co. (BKW) shall be handed-off directly to Charleston approach (69 Ghost) at or below 10,000 as coordinated. 
4. Arrivals to Charleston, WV operating above 16,000 feet shall cross the common boundary at or below FL230 descending to 16,000 .

$$
\mathrm{C}-8
$$

\section{Sector 30 Facts sheet}

Roanoke Arrivals Roanoke Departures

Raleigh-Durham Arr

Non-Jet Traffis to
X 25 miles from ROA Q 110 and 250 Kts Climbing to 10,000 on corse

South Boston a or Below FL210

(a or below 15,000 (31 AZALEA)

\section{Baltimore (BWI) \\ Washington (DCA)/(IAD) \\ Richmond (RIC) \\ Satellites}

Raleigh Co. (BKW) Arr @ or below 10,000 (69 Ghost)

Charleston Arr

Decending to 16,000 (69 Ghost)

$\begin{array}{lll}\text { Valley } & \text { sector } 30 & 125.750 \\ \text { Azalea } & \text { sector 31 } & 124.250 \\ \text { Gordonsville } & \text { sector } 32 & 133.720 \\ \text { Montebello } & \text { sector } 60 & 135.400 \\ \text { Ghost Departures } & \text { sector } 57 & \\ \text { Arrival Ghost } & 69 & 111.100 \\ \text { Roanoke Approach } & 69 & 111.100 \\ \text { Lynchburg Tower } & & 111.100 \\ \text { All Towers } & & 111.100\end{array}$

Lynchburg Airport Elev - 938 feet MVA - 6000 RWY 36/18

All departures are using RWY 36.

Ingalls Field (HSP) Elev - 938 feet MVA - 6000 RWY 9/24

$\begin{array}{lllllll}\text { NDB } & \text { RWY } & 24 & 245 & \text { deg } & \text { IA } & 5400 \\ \text { ILS } & \text { RWY } & 24 & 245 & \text { deg } & \text { IA } & 5400\end{array}$


C-9 


\section{SECTOR 30 - VALLEY \\ LOW ALTITUDE SECTOR \\ (HOT SPRINGS(29)/VALLEY(30) COMBINED)}

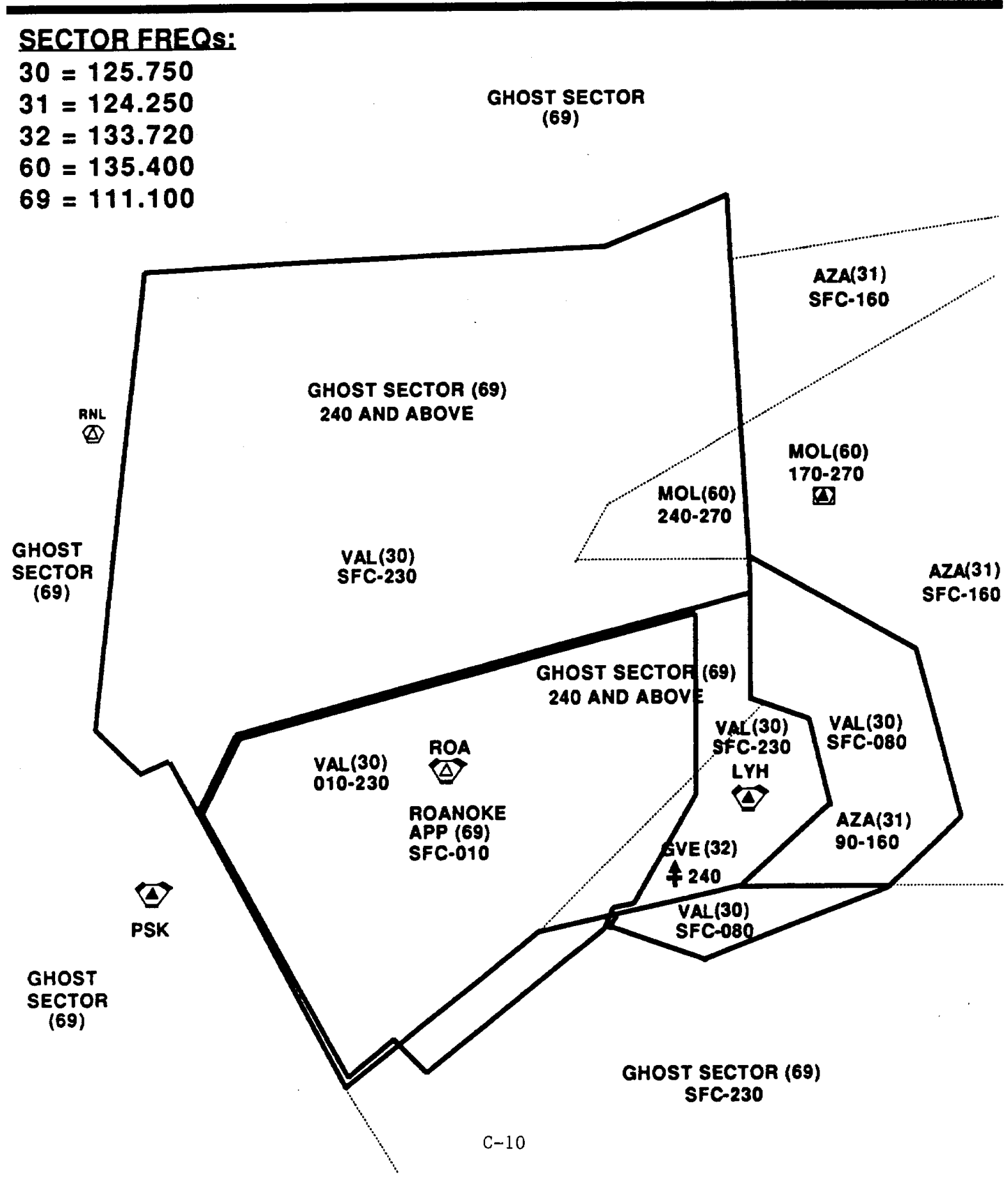




\section{SECTOR 30 - VALLEY LOW ALTITUDE SECTOR (HOT SPRINGS(29)/VALLEY(30) COMBINED)}

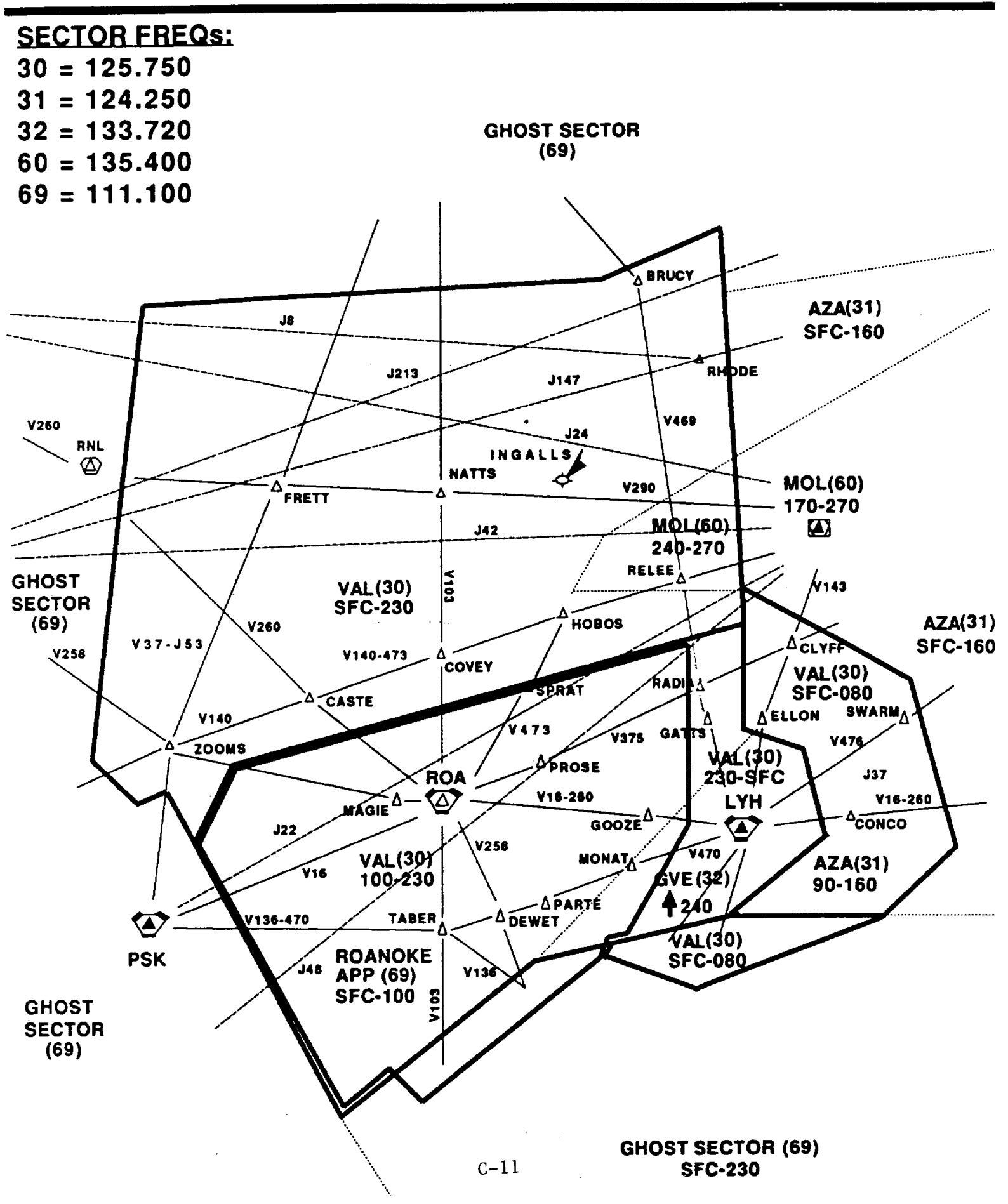




\section{SECTOR 30 - VALLEY \\ LOW ALTITUDE SECTOR \\ (HOT SPRINGS(29)/VALLEY(30) COMBINED)}

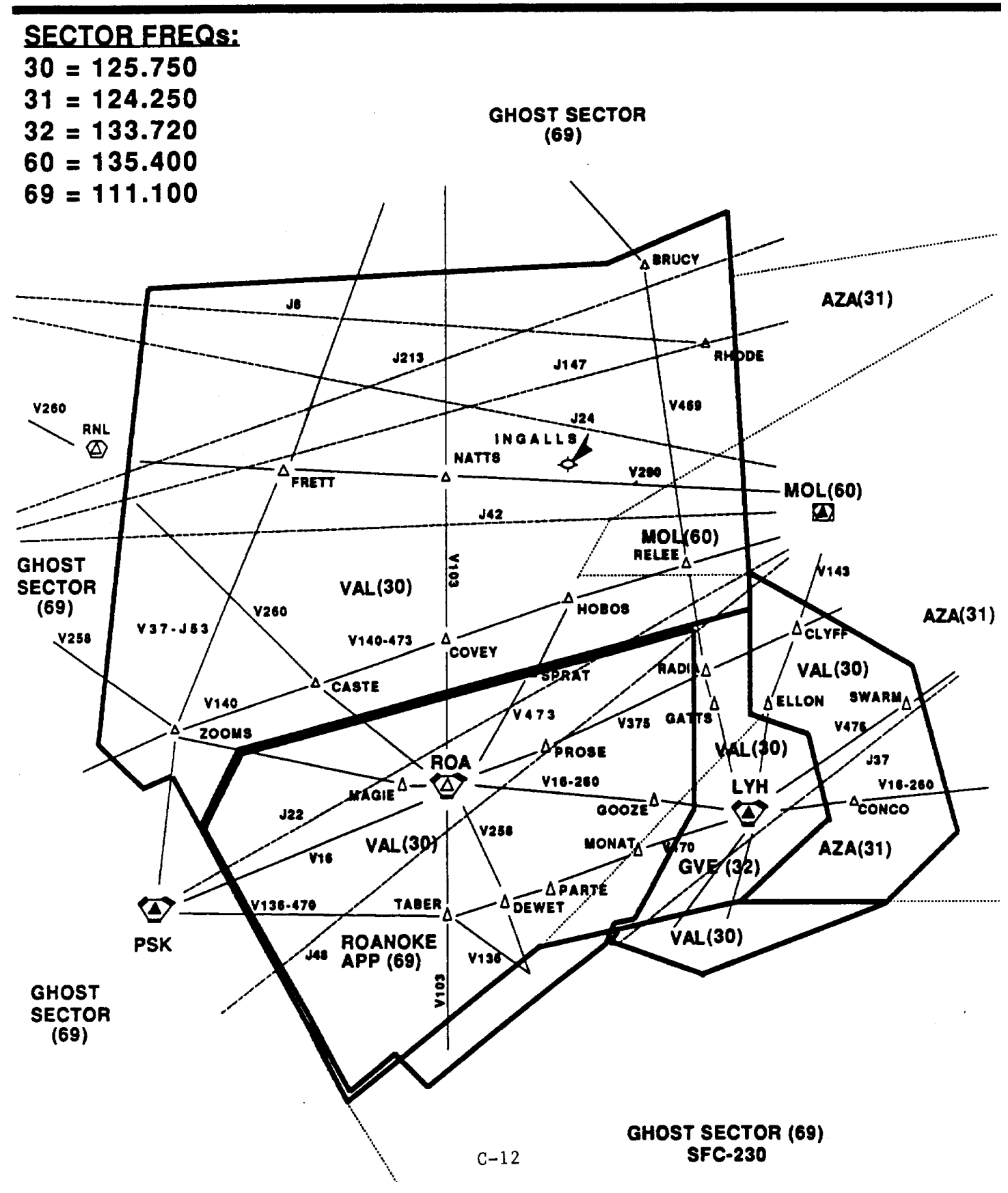






\section{Sector 31}

\section{AZALEA}

1. General Information: The Azalea sector 31 is a low altitude sector with a mixture of jet and general aviation traffic, serving central Virginia. The controller serves as approach control for Charlottesville, Harrisonburg/Staunton, Virginia with a VFR tower at Charlottesville. The sector is adjacent to approach control facilities to the east and north. The altitude limits are 16,000 feet and below, with shelves (see attached map). The two VOR's are Montebello (MOL) and Gordonsville (GVE). The minimum vectoring altitudes are 3,000 to the east rising 6,000 to the west.

2. Radio Frequencies: For the purpose of this test the frequency for the Azalea sector will be 124.250.

\section{Procedures:}

A. VFR Towers:

(1) Center Procedures:

a. All flight plans shall be issued to the tower at least 10 minutes prior to departure time:

1. Aircraft Id.

2. Type A/C-Beacon Code

3. Route/Destination

4. Altitude to expect $10 \mathrm{~min}$. after Dept.

b. All inbound flight plans shall be given to the tower 15 minutes prior to Destination time:

1. Aircraft Id.

2. Type A/C.

3. Type of Approach

4. Arrival Time

c. When towers call for RLS of aircraft the center shall issue:

1. Initial HDG.

2. Initial ALT.

(2) Tower Procedures:

a. When towers call for RLS they shall provide the active RWY. 
b. Tower is responsible for the visual separation between arrivals and departures.

$$
\mathrm{C}-13
$$

C. Tower shall call and advise the center when an A/C in insight landing assured.

\section{B. Sector Information:}

(1) Non-turbojet Baltimore, Washington, and satellite arrivals shall enter Casanova sector (69 Arrival Ghost) at or below 9000 feet established on Vl 43 .

(2) Aircraft landing $W 16$ and MRB shall enter Casanova sector (69 Arrival Ghost) at or below 9,000.

(3) Non-turbojet Dulles and Satellite arrivals shall be routed via V140 CSN and enter Dulles approach in-trail with constant or increasing separation or vertically separated with the faster aircraft at 90 and slower at 70 , or as coordinated.

(4) Dulles Tower over flight traffic shall be routed via V143 and handed off to Casanova (69 Arrival Ghost) at or below 10 000 .

C. Airspace Information:

(1) Shelves in sector as follows:

a. North of MOL (at and below 160) - CSN Lo owns 170-270 for metro inbounds (IDA, DCA, BWI) transitioning traffic.

b. North of GVE (at and below 130) - MOL-I - owns 140270 in order to keep IAD departures out of Azalea LO sector. 270 .

c. Over GVE and MOL (at and below 160) - MOL-I owns 170- 
C-14 


\section{Azalea Sector 31 Facts Sheet}

BWI, DCA and SAT. Arrivals Handed to Ghost sector (69) at or below 9,000 est. on V143

IAD Over flights shall be routed via V143 at or below 10,000 and handoff to Ghost (69)

$\begin{array}{lll}\text { Valley } & \text { sector } 30 & 125.750 \\ \text { Azalea } & \text { sector } 31 & 124.250 \\ \text { Gordonsville } & \text { sector } 32 & 133.720 \\ \text { Montebello } & \text { sector } 60 & 135.400 \\ \text { Ghost Departures } & \text { sector } 57 & \\ \text { Arrival Ghost } & 69 & 111.100 \\ \text { Roanoke Approach } & 69 & 111.100 \\ \text { Lynchburg Tower } & & 111.100 \\ \text { All Towers } & & 111.100\end{array}$

All VFR towers departing RWY 36. 


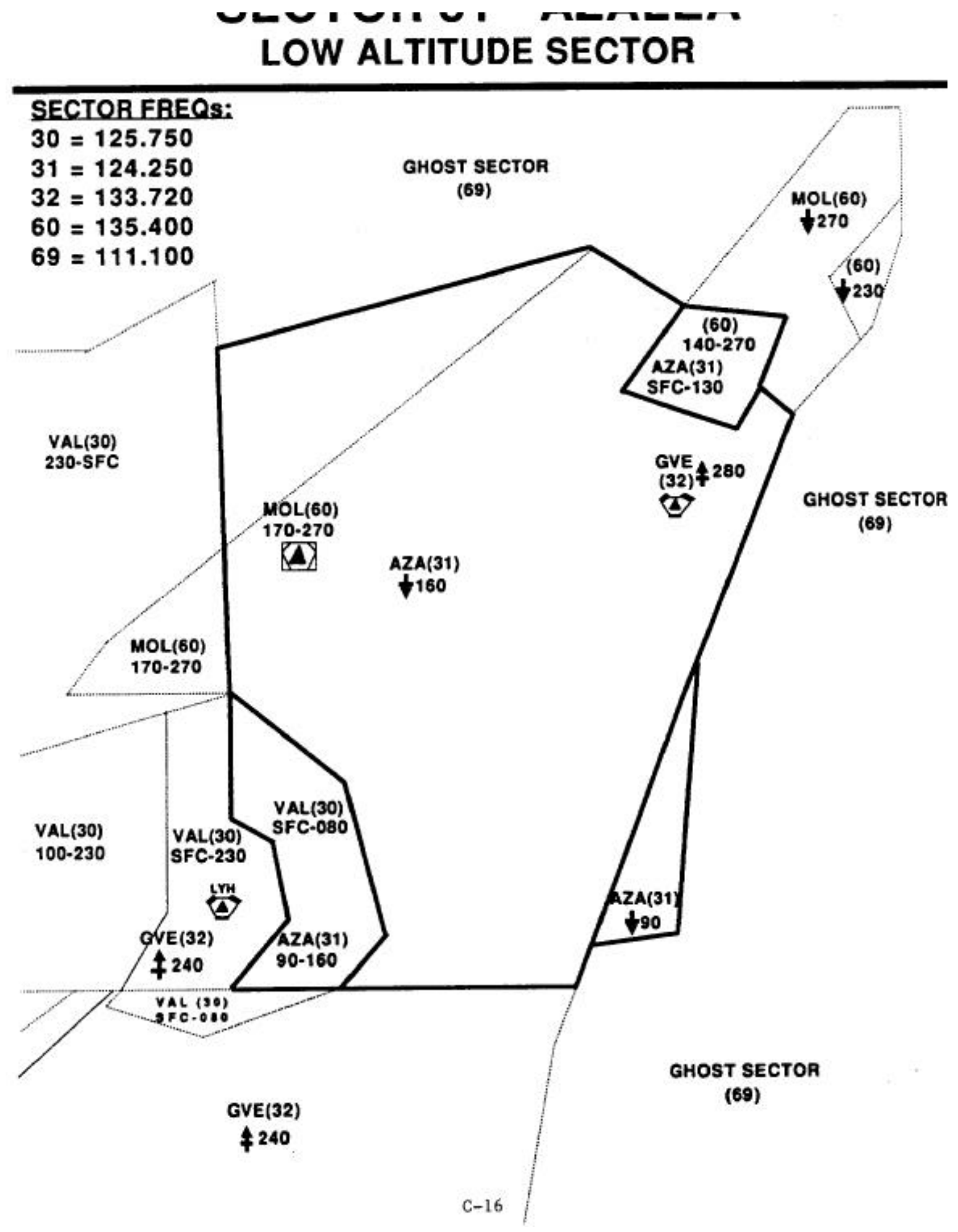




\section{SECTOR 31 - AZALEA \\ LOW ALTITUDE SECTOR}

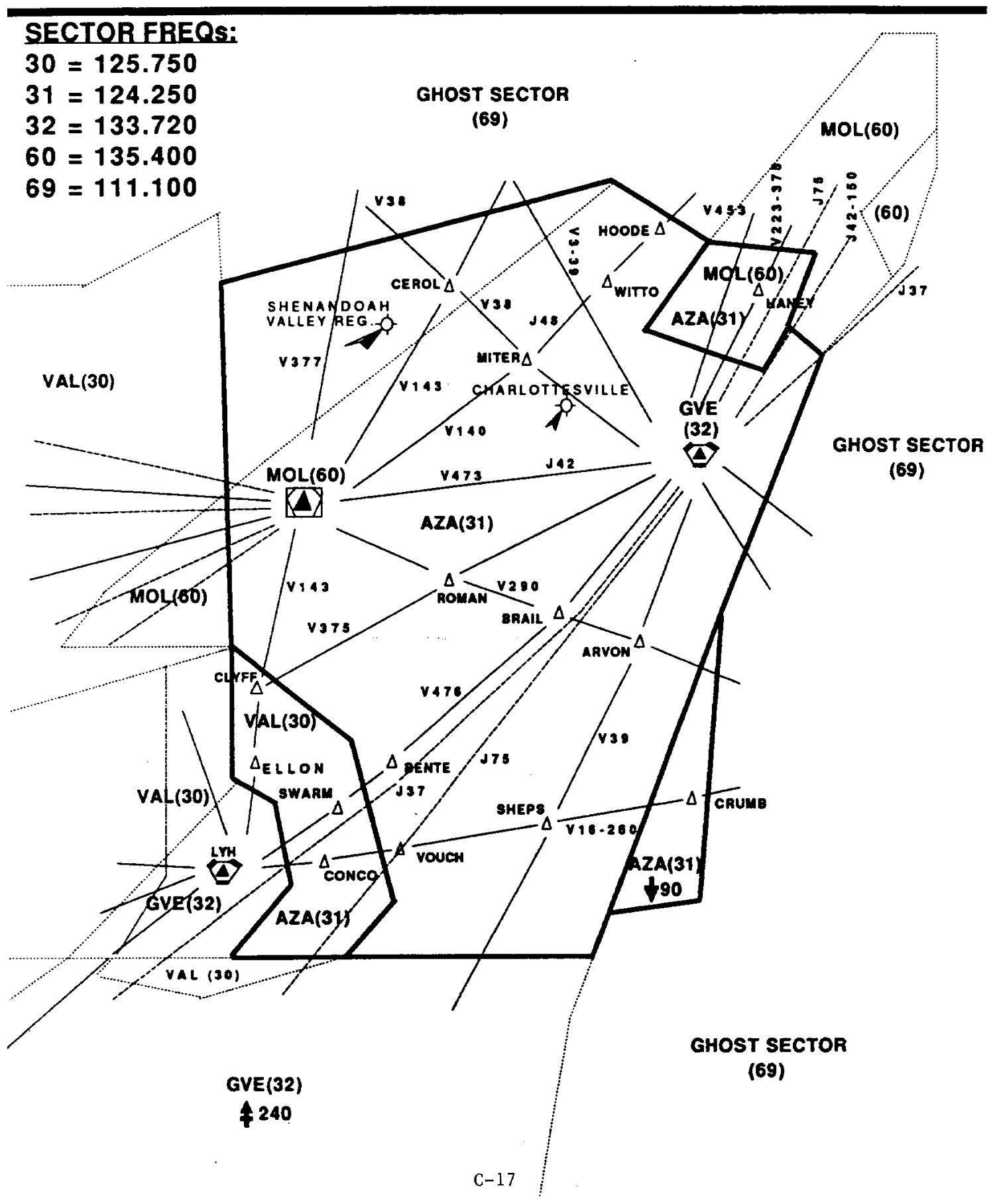




\section{SECTOR 31 - AZALEA \\ LOW ALTITUDE SECTOR}

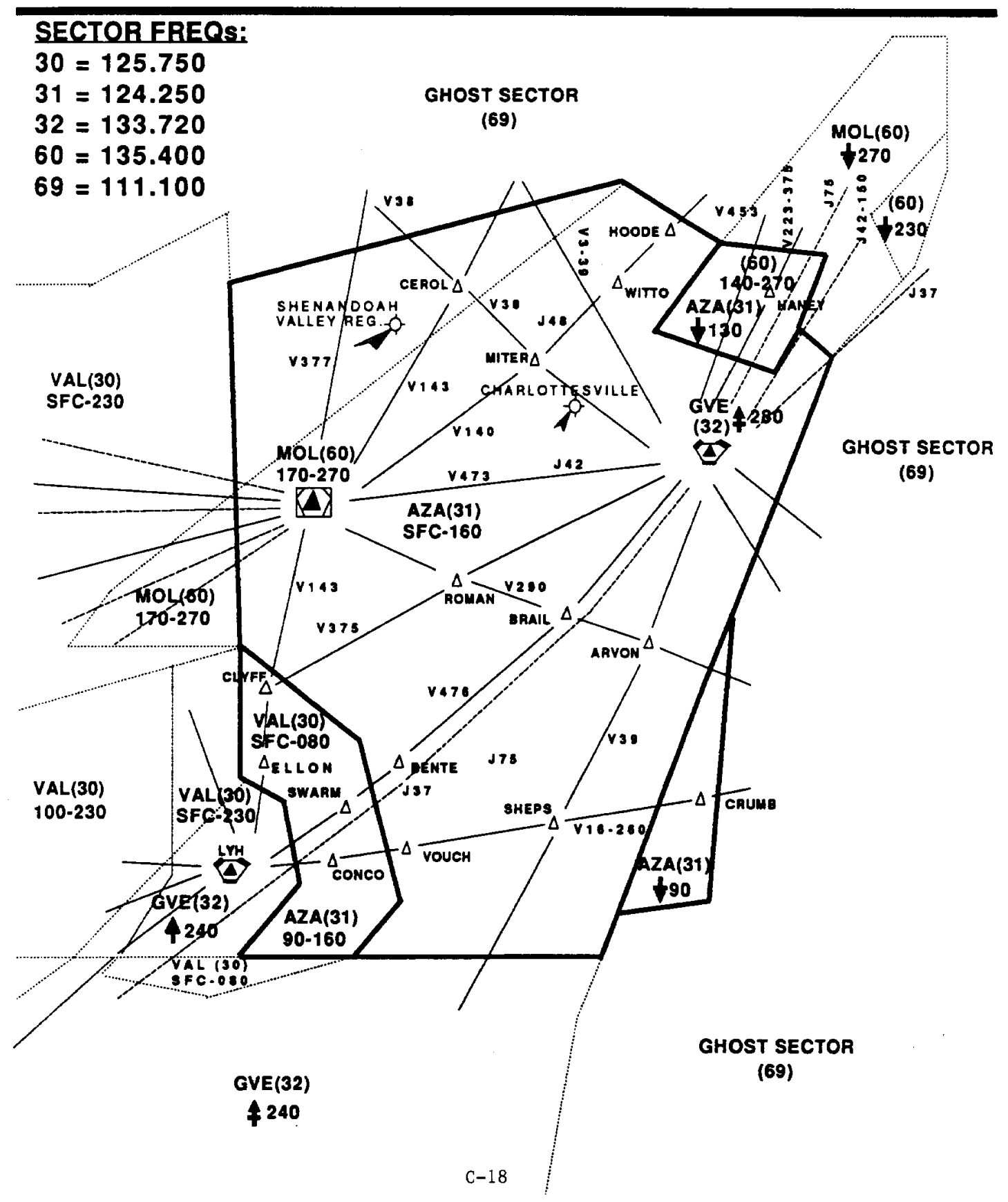




\section{Sector 32}

\section{Gordonsville High}

1. General Description: The Gordonsville sector (R32) is a high altitude en-route sector extending from western North Carolina to south of the Washington, D.C. area. The basic altitudes are FL240 and above, with two shelves (see attached map). The primary VOR's in the airspace are GVE (Gordonsville) and SBV (South Boston).

2. Radio Frequencies: For the purpose of this test, the frequency for sector 32 will be 133.720 .

\section{Procedures:}

A. Sector to sector.

(1) Raleigh-Durham and Greensboro arrival traffic shall be handed off directly to the South Boston Sector (Arrival Ghost 59).

(2) Philadelphia arrival traffic shall enter Brook Sector 12 (Arrival Ghost 69) at FL290 or below unless otherwise coordinated.

(3) Norfolk and satellite arrival traffic from over PSK shall be descended in sufficient time to comply with procedures listed under Montebello (60) sector (Aircraft must be handed off to sector 60 ASAP).

(4) Baltimore and satellite arrival traffic shall enter the Hopewell sector (arrival Ghost 69) at FL290 or below.

(5) Washington, Dulles, and satellite arrival traffic shall enter Blackstone Sector (Arrival Ghost 69) at or below FL250.

B. Sector airspace as follows:

(1) J24 and North (at and above FL280) - MOL-I (departure sector) owns airspace below GVE-H.

(2) South of J24 (at and above FL240).

(3) GSO shelf tat and above FL220). 
C-19 


\section{Sector 32 Facts Sheet}

PHL Arrivals at or below FL290 and handoff to Arrival Ghost 69 ORF Arrivals must start down early and handoff to sector 60

BWI Arrivals at or below FL290 and handoff to Arrival Ghost 69

IAD Arrivals at or below FL250 and handoff to Arrival Ghost 69

$\begin{array}{lll}\text { Valley } & \text { sector } 30 & 125.750 \\ \text { Azalea } & \text { sector } 31 & 124.250 \\ \text { Gordonsville } & \text { sector } 32 & 133.720 \\ \text { Montebello } & \text { sector } 60 & 135.400 \\ \text { Departure Ghost } & 57 & \\ \text { Arrival Ghost } & 69 & 111.100 \\ \text { All Towers } & & 111.100\end{array}$

$\mathrm{C}-20$ 


\section{SECTOR 32 - GORDONSVILLE HIGH ALTITUDE SECTOR}

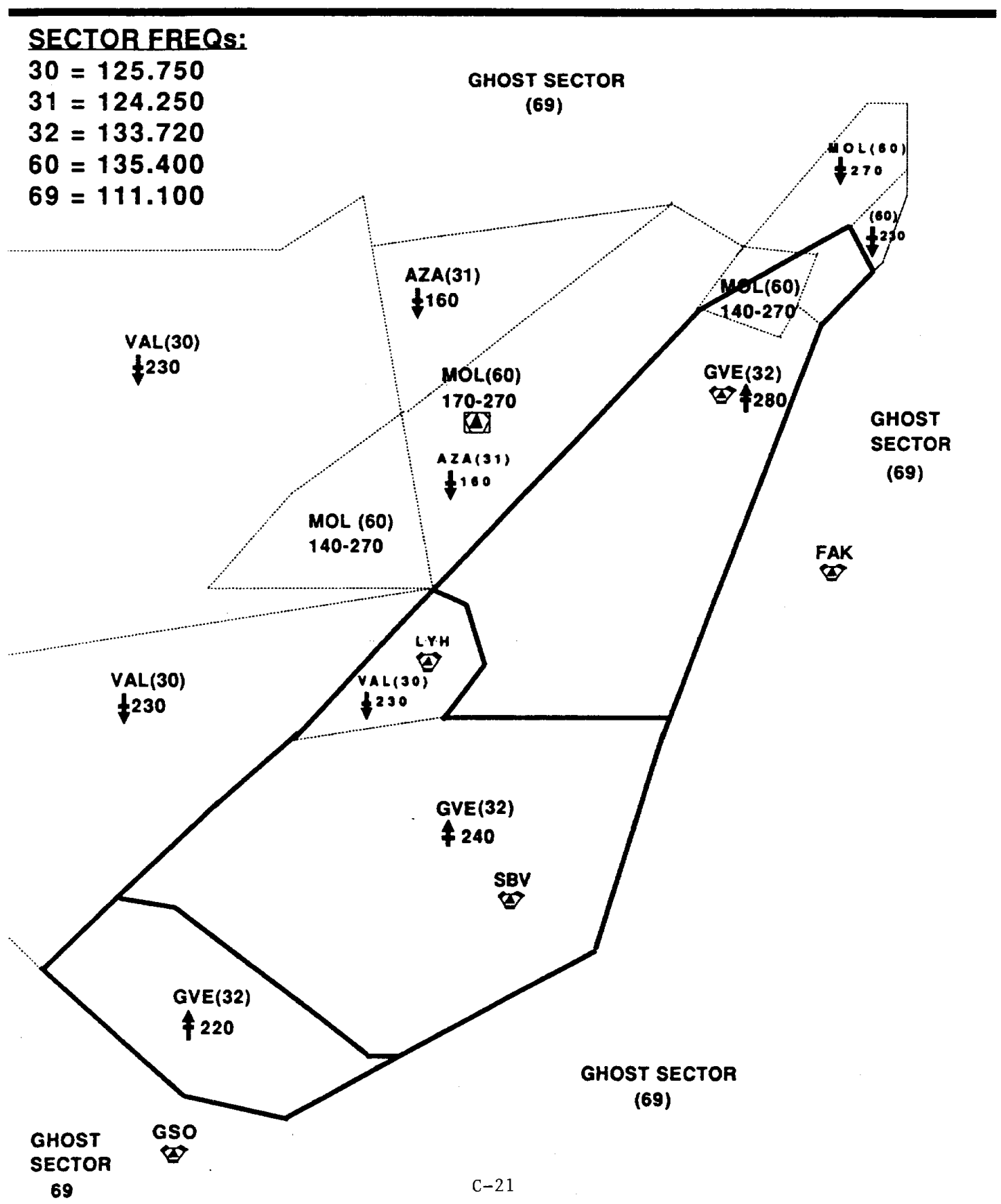




\section{SECTOR 32 - GORDONSVILLE HIGH ALTITUDE SECTOR}

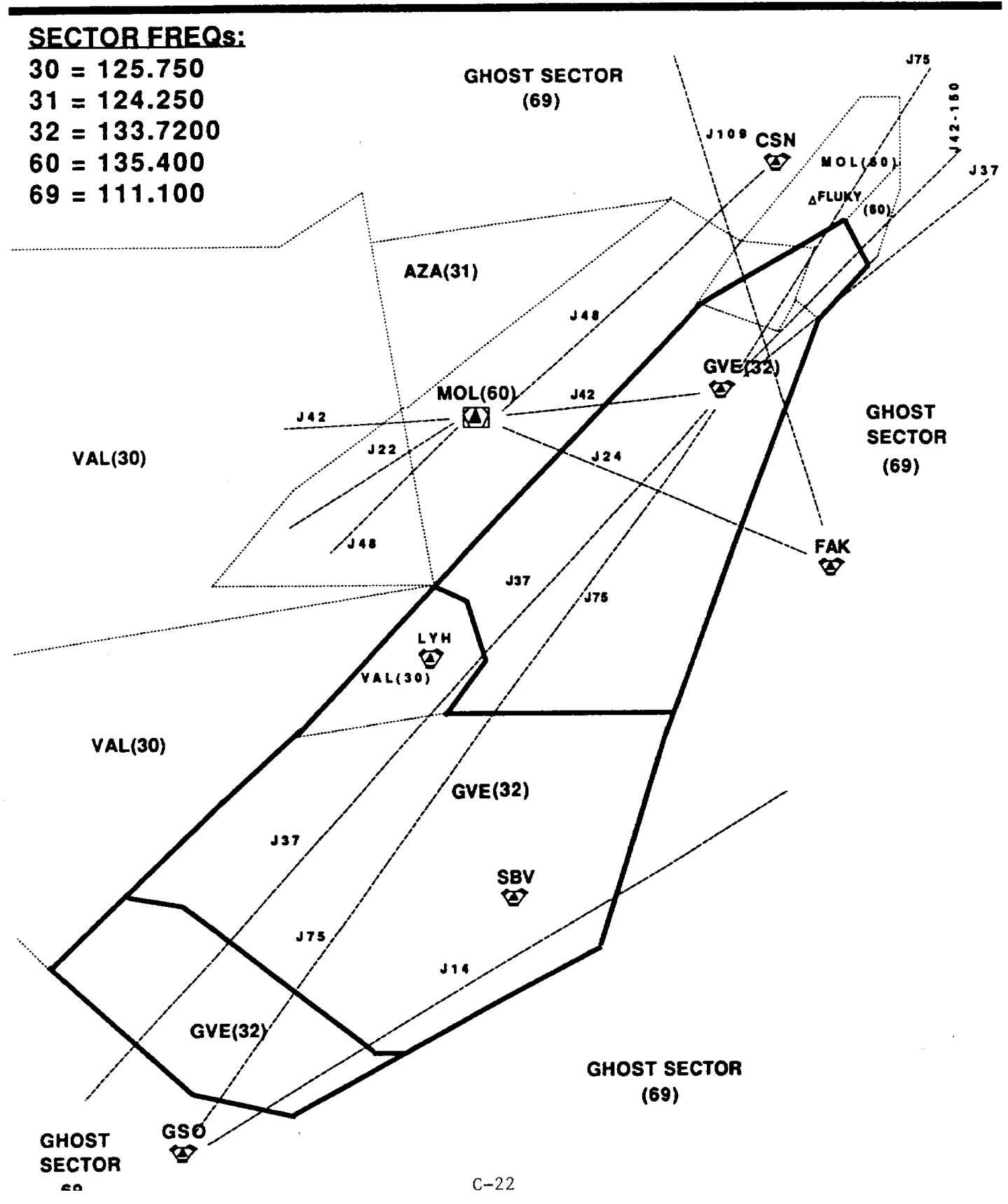




\section{SECTOR 32 - GORDONSVILLE HIGH ALTITUDE SECTOR}

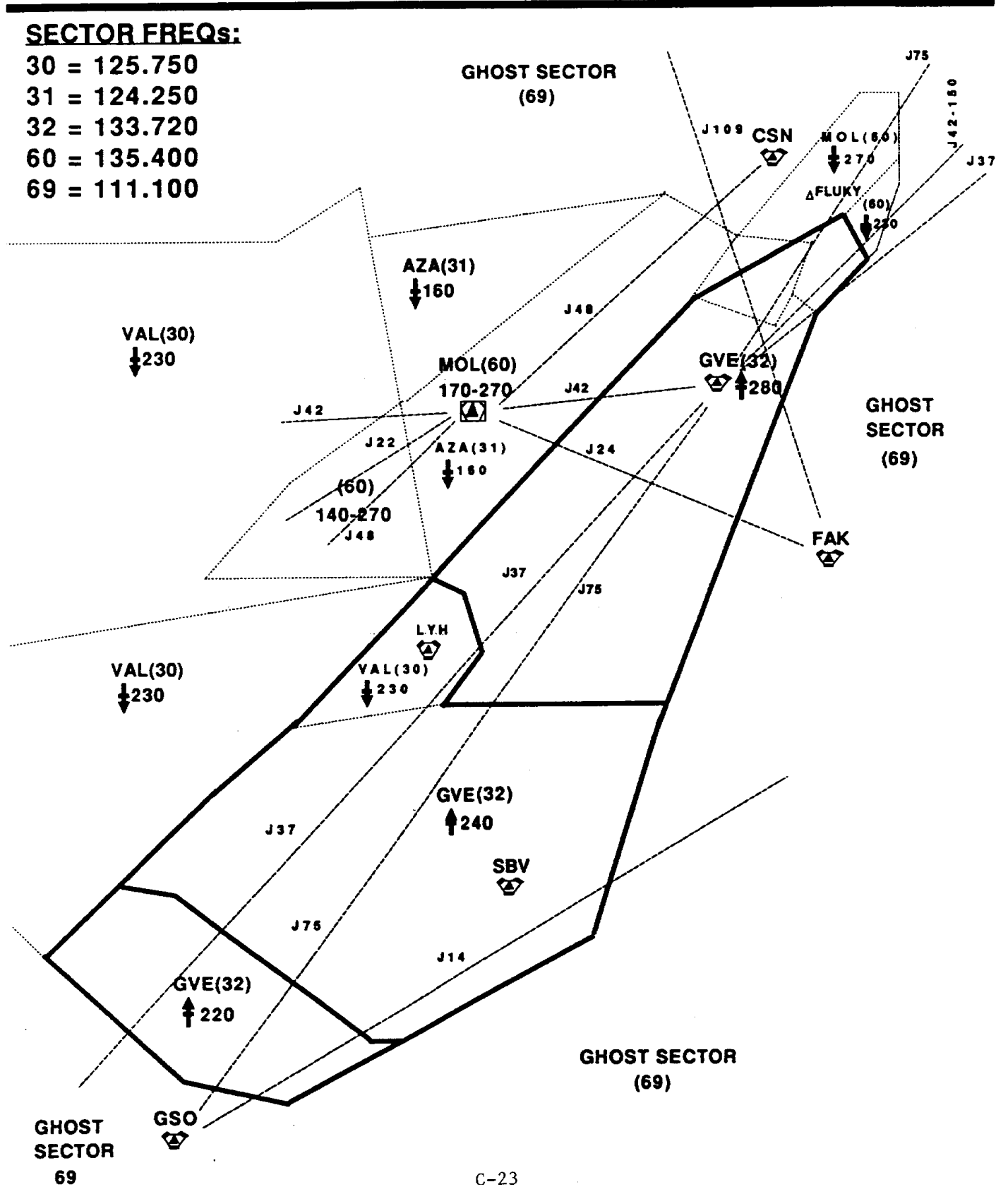


Sector 60

MONTEBELLO (60)

1. General Description: The Montebello sector (60) is primarily an intermediate departure sector serving the Washing, D.C. metropolitan area. The altitude limits are basically 17,000 FL270, with two shelves (see attached map). The two VOR's in the airspace are Montebello (MOL) and Gordonsville (GVE). Primarily a departure sector for IAD, DCA, BWI.

2. Radio Frequencies: For the purpose of this test, the frequency for sector 60 will be 135.400

\section{Procedures:}

A. Richmond and satellite arrival traffic shall be descended in sufficient time to comply with procedures listed under Azalea Sector 31 (Cross 20 west of FAK at 9,000).

B. Norfolk and satellite arrival traffic shall enter the Irons Sector 69 = Ghost at or below FL210.

C. Sector airspace is as follows:

(1) West of MOL (FL240-FL270) in order to keep TEC-H from working RIC arrivals for approximately 10 miles.

(2) NE of GVE (140-FL270) climb corridor for BWI departures.

(3) East of CSN (FL240-FL270) climb corridor for BWI departures.

(4) Remainder of sector FL170-FL270

D. Departure routes as follows:

(1) IAD, DCA, BWI - FLUKY GVE flight plan

- FLUKY MOL065R MOL flight plan

(2) ORF - ORF290R to join MOL130R MOL J24...

(3) RIC - RIC264R to Join MOL130R MOL J24...

E. Arrival altitude information:

(1) RIC arrivals enter MOL-I at or below FL250

(2) ORF arrivals Cross 20 West of FAK at FL210 
Note: IAD, DCA departures will be climbing to FL210: BWI departures will be climbing to FL230 and will be handed off to MOL-I (R60) by DCA approach (57)=Ghost, with in- Trail spacing between IAD and DCA Departures over the same fix (MOL or GVE).

$\mathrm{C}-24$

\section{Sector 60 Facts Sheet}

ORF and Sat. Arrivals 20 West of FAK at FL210.

IAD, DCA departures climbing to FL210.

BWI departures climbing to FL230.

Valley

Azalea

Gordonsville

Montebello

Ghost

Arrival Ghost

Roanoke Approach

sector 30

125.750

sector 31

124.250

sector 32

133.720

sector 60

sector 57

135.400

69

111.100

69

111.100

All Towers

111.100 



\section{SECTOR 60 - MONTEBELLO INTERMEDIATE ALTITUDE SECTOR}

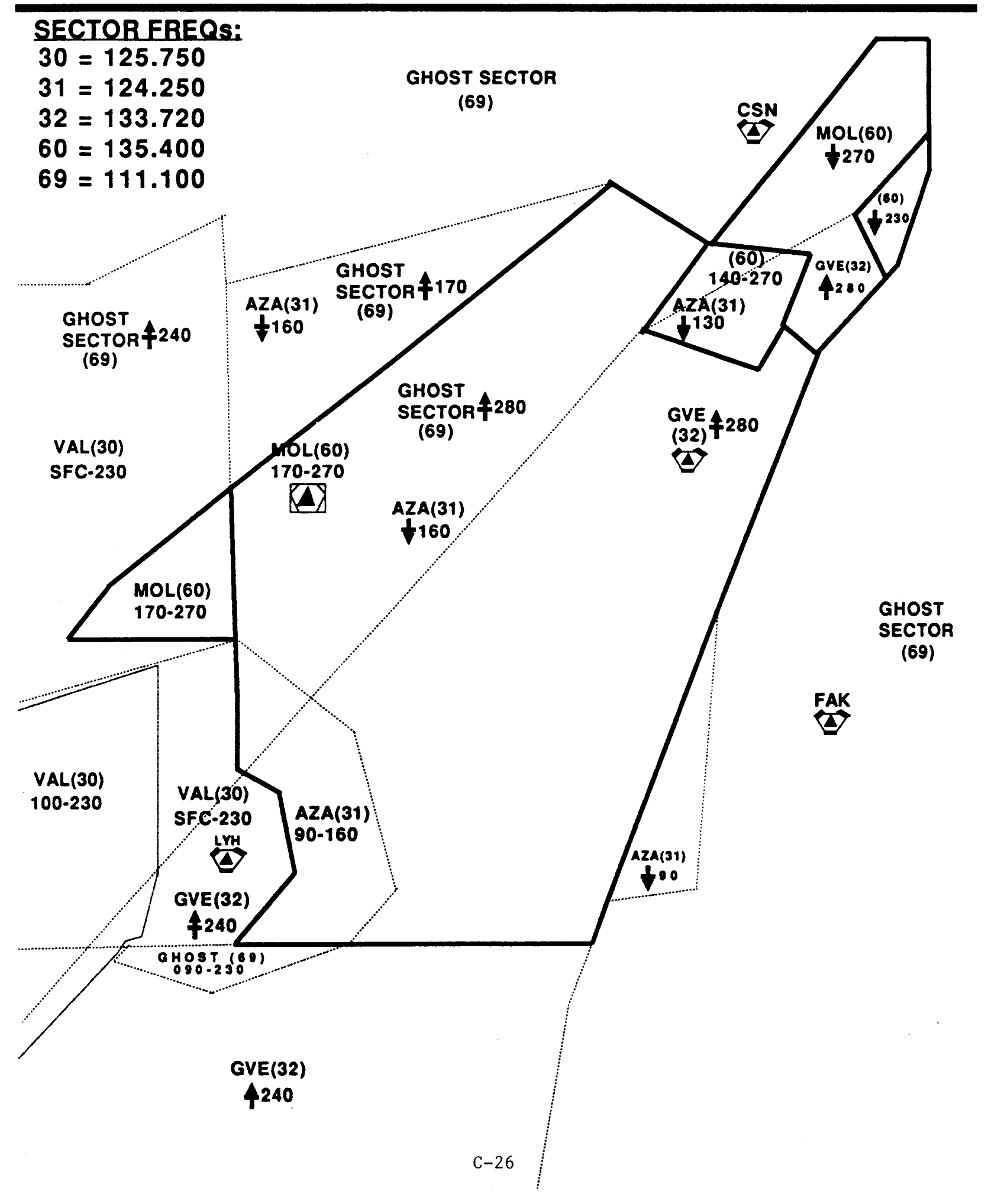




\section{SECTOR 60 - MONTEBELLO INTERMEDIATE ALTITUDE SECTOR}

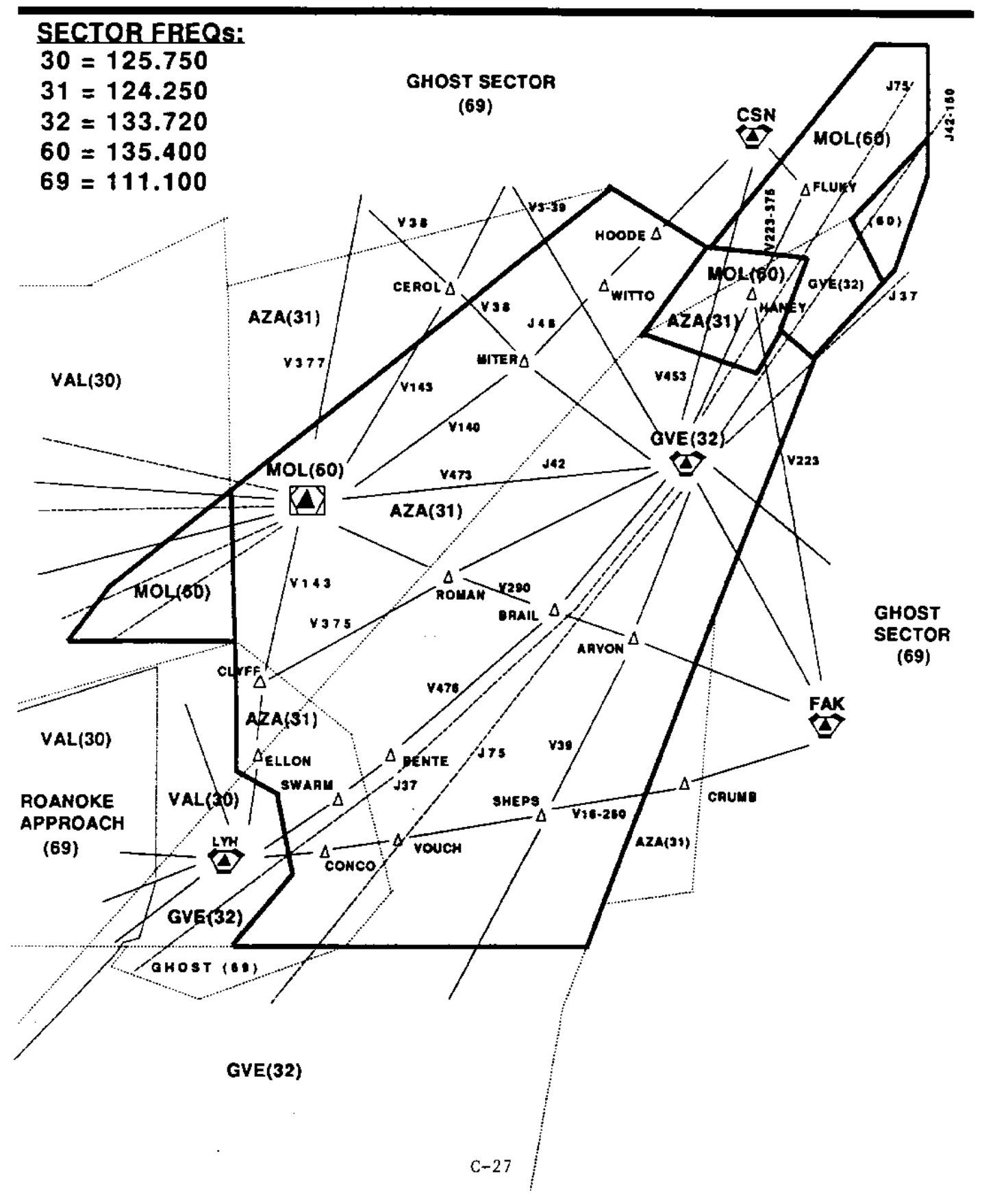




\section{SECTOR 60 - MONTEBELLO INTERMEDIATE ALTITUDE SECTOR}

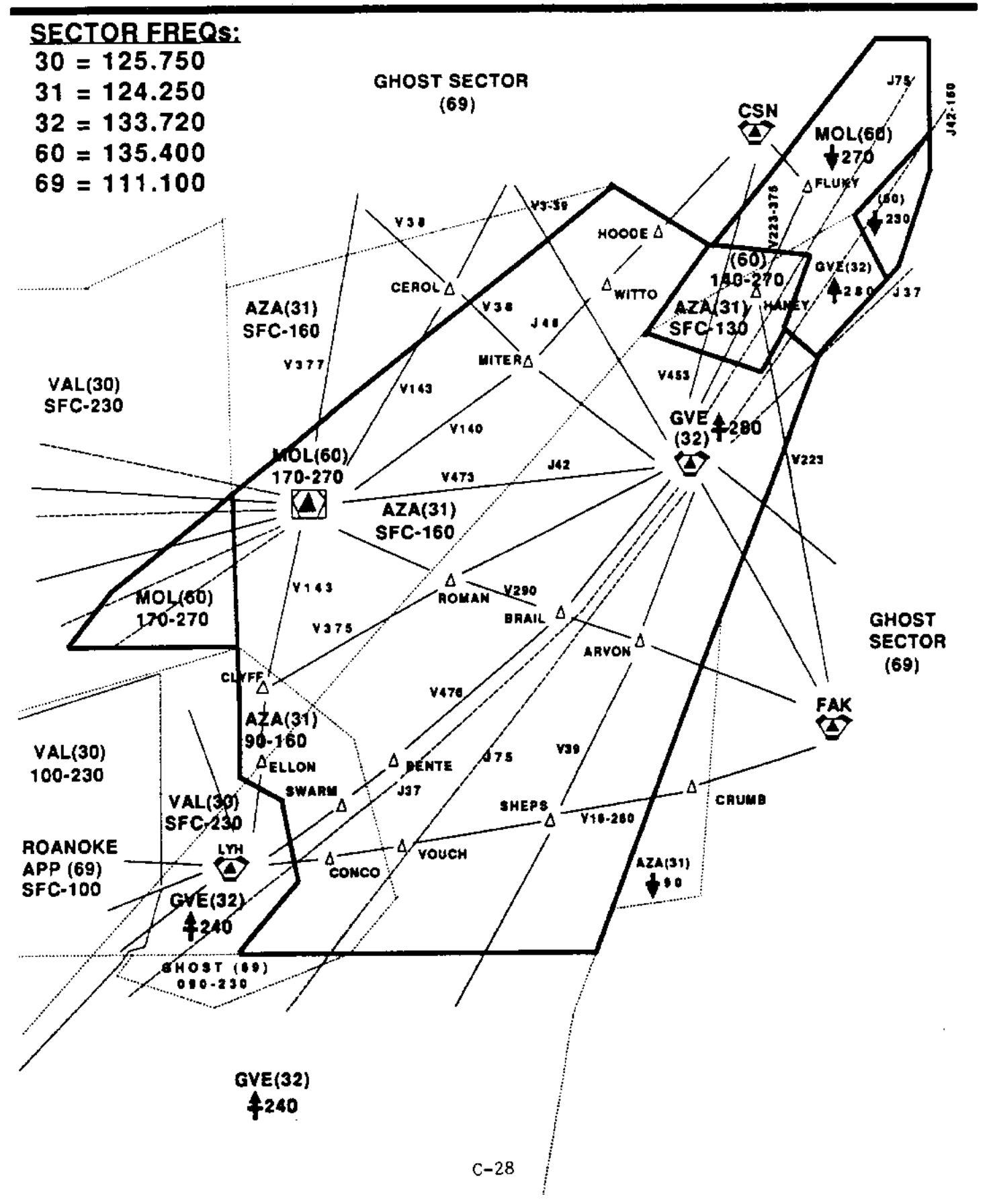



APPENDIX D

CONTROLLER CHART 
EN ROUTE RADAR CONTROLLER DATA IINK CHART

\begin{tabular}{|c|c|c|c|c|c|}
\hline PURPOSE & Q/A KEY & CAT KEY & FUNC KEY & FIELD CONTENT & COMMENTS \\
\hline$\frac{\text { Sector Set-Up Option }}{- \text { Service Active Mode }}$ & & $\mathrm{DL}$ & $\begin{array}{l}\text { DATALINK } \\
\text { SETTING }\end{array}$ & $\begin{array}{l}1 \text { or ON } \\
\text { o Or OFF }\end{array}$ & $\begin{array}{l}\text { ON will appear on PVD. } \\
\text { OFF deletes the DATALINK } \\
\text { set-up indicators from PVD. }\end{array}$ \\
\hline Status List Display & & $\mathrm{DL}$ & $\begin{array}{l}\text { DATALINK } \\
\text { SETTING }\end{array}$ & $\mathrm{P}$ or $\mathrm{N}$ & $\begin{array}{l}\mathrm{P}-\mathrm{ON} \quad(\text { Default }) \\
\mathrm{N}=\mathrm{OFF}\end{array}$ \\
\hline $\begin{array}{lll}\text { Full Data } & \text { Block } \\
\text { Data Link } & \text { Status }\end{array}$ & & $\mathrm{DL}$ & $\begin{array}{l}\text { DATALINK } \\
\text { SETTING }\end{array}$ & $\mathrm{F}$ or $\mathrm{S}$ & $\begin{array}{l}\mathrm{F}-\mathrm{ON} \text { (Default } \\
S-\mathrm{OFF}\end{array}$ \\
\hline $\begin{array}{l}\text { Automatic Transfer } \\
\text { of Communications }\end{array}$ & & $\mathrm{DL}$ & $\begin{array}{l}\text { DATALINK } \\
\text { SETTING }\end{array}$ & T AUTO OR T MAN & $\begin{array}{l}\text { T AUTO = ON } \\
\mathrm{T} \text { MAN = OFF (default) }\end{array}$ \\
\hline$\frac{\text { SERVICE }}{\frac{\text { Altitude Assignment }}{\text { Assigned Altitude }}}$ & $\begin{array}{c}\text { ADGD ALT } \\
(Q Z)\end{array}$ & & & ddd S FLID & $\begin{array}{l}\text { NAS \& Fdb updated upon } \\
\text { WILCO. }\end{array}$ \\
\hline Interim Altitude & $\begin{array}{c}\text { INTERIM ALT } \\
(Q Q) \\
\end{array}$ & & & ddd S FLID & FDB updated upon WILCO. \\
\hline$\frac{\text { Menu Text }}{\text { Interim Altitude }}$ & & $\begin{array}{l}\mathrm{DL} \\
----- \\
\mathrm{DL}\end{array}$ & $\begin{array}{l}\text { DATALINK } \\
\text { MLT TB }\end{array}$ & $\begin{array}{c}\text { a FLID } \\
----- \\
\text { Trackball a and } \\
\text { AC Track Symbol* }\end{array}$ & $\begin{array}{l}\text { a }=\text { Menu Text Referent } \\
\text { DataLink MLT Tb allows for } \\
\text { more than one trackball } \\
\text { input. *AID, CID, or } \\
\text { Beacon } \\
\text { may be used. }\end{array}$ \\
\hline $\begin{array}{ll}\text { R-Menu } & \text { Text } \\
\text { and } & \\
\text { Z-Menu } & \text { Text }\end{array}$ & & $\begin{array}{c}\mathrm{DL} \\
----- \\
\mathrm{DL}\end{array}$ & $\begin{array}{l}\text { DATALINK } \\
\text { MLT TB }\end{array}$ & $\begin{array}{c}\text { R or } \mathrm{Z} \text { FLID } \\
----- \\
\text { Trackball } \mathrm{R} \text { or } \mathrm{z} \\
\text { and AC Track } \\
\text { Symbol* }\end{array}$ & $\begin{array}{l}\text { R Menu Text removes INT ALT } \\
\text { if exists. } \\
\text { Z Menu Text uplinks } \\
\text { displayed ALT. } \\
\text { * See comment above. }\end{array}$ \\
\hline
\end{tabular}


EN ROUTE RADAR CONTROLLER DATA IINK CHART

(CONTINUED)

\begin{tabular}{|c|c|c|c|c|c|}
\hline PURPOSE & Q/A KEY & CAT KEY & FUNC KEY & FIELD CONTENT & COMMENTS \\
\hline $\begin{array}{l}\frac{\text { Communication Backup }}{\frac{\text { Uplink }}{\text { Send }}} \text { Message }\end{array}$ & & $\mathrm{DL}$ & & $\begin{array}{l}\text { T } 111 \text { FLID } \\
\text { or } \\
\text { T } 111 \text { ALL } \\
\end{array}$ & $\begin{array}{l}111 \text { = characters (up to 20) } \\
\text { ALL option sends message to } \\
\text { all AC under sector control }\end{array}$ \\
\hline Recall Message & & $\mathrm{DL}$ & & T FLID & $\begin{array}{l}\text { The Last Comm Backup Uplink } \\
\text { Message will be recalled }\end{array}$ \\
\hline $\begin{array}{l}\frac{\text { Communication Backup }}{\text { Downlink }} \\
\text { Respond to Message }\end{array}$ & & $\mathrm{DL}$ & $\begin{array}{c}\text { CD } \\
\text { RESPONSE }\end{array}$ & ddd $a$ & $\begin{array}{l}\text { ddd = message number } \\
\mathrm{a}=\text { uplink response: } \\
\mathrm{S}(\text { default), } \mathrm{R}, \mathrm{U}, \mathrm{A}\end{array}$ \\
\hline$\frac{\frac{\text { Transfer of }}{\text { Communications }}}{\text { Accept Handoff }}$ & $(\mathrm{QZ} / \mathrm{QN})$ & & & $\begin{array}{c}\text { FLID } \\
------ \\
\text { Trackball AC } \\
\text { Track Symbol }\end{array}$ & $\begin{array}{l}\text { Accept Handoff causes TOC } \\
\text { message to be in HELD state } \\
\text { or send to AC (if auto-TOC } \\
\text { ON). Only initiating } \\
\text { controller can send, } \\
\text { resend, or delete message. }\end{array}$ \\
\hline $\begin{array}{l}\text { Send HELD Transfer } \\
\text { of Communications }\end{array}$ & & $\begin{array}{c}\mathrm{DL} \\
------\end{array}$ & - & $\begin{array}{c}\text { FLID } \\
----- \\
\text { Trackball HELD } \\
\text { Status List } \\
\text { message }\end{array}$ & $\begin{array}{l}\text { Causes uplink of HELD } \\
\text { TOC message in status } \\
\text { List. }\end{array}$ \\
\hline $\begin{array}{l}\text { Resend Transfer of } \\
\text { Communications }\end{array}$ & & & $\begin{array}{l}\text { DL } \\
----- \\
\text { DL }\end{array}$ & $\begin{array}{c}\text { Trackball status } \\
\text { List message } \\
------- \\
\text { FLID } \\
------- \\
\text { Trackball Track }\end{array}$ & $\begin{array}{l}\text { Resends first failed TOC } \\
\text { message for the specified } \\
\text { AC. } \\
--------------------- \\
\text { Trackball AC Track Symbol }\end{array}$ \\
\hline
\end{tabular}


EN ROUTE RADAR CONTROLLER DATA LINK CHART

(CONTINUED)

\begin{tabular}{|c|c|c|c|c|c|}
\hline PURPOSE & Q/A KEY & CAT KEY & FUNC KEY & FIELD CONTENT & COMMENTS \\
\hline $\begin{array}{l}\frac{\text { Sector DataLink }}{\text { Eligibility Option }} \\
\text { Establish DataLink } \\
\text { Eligibility } \\
\end{array}$ & & DL & & /OK FLID & \\
\hline $\begin{array}{l}\text { Establish DataLink } \\
\text { Eligibility and Send } \\
\text { Sector's Frequency }\end{array}$ & & $\mathrm{DL}$ & & /OK S FLID & $\begin{array}{l}\text { "S" causes your sector's } \\
\text { frequency to be uplinked. }\end{array}$ \\
\hline $\begin{array}{l}\text { Give Datalink } \\
\text { Eligibility to } \\
\text { another Sector }\end{array}$ & & $\mathrm{DL}$ & & dd FLID & $\begin{array}{l}\text { dd }=\text { the other sector's } \\
\text { sector number }\end{array}$ \\
\hline $\begin{array}{l}\text { Give Datalink } \\
\text { Eligibility to } \\
\text { another Sector and } \\
\text { Send that Sector's } \\
\text { Frequency }\end{array}$ & & $\mathrm{DL}$ & & dd S FLID & $\begin{array}{l}\text { dd = the other sector's } \\
\text { sector number. } \\
\text { "S" causes your sector's } \\
\text { frequency to be uplinked. }\end{array}$ \\
\hline
\end{tabular}


EN ROUTE RADAR CONTROLLER DATA IINK CHART

(CONTINUED)

\begin{tabular}{|c|c|c|c|c|c|}
\hline PURPOSE & Q/A KEY & CAT KEY & FUNC KEY & FIELD CONTENT & COMMENTS \\
\hline $\begin{array}{l}\frac{\text { List Management }}{\text { Menu Text List }} \\
\text { Suppress Menu Text } \\
\text { List }\end{array}$ & & DL & $\begin{array}{l}\text { DataLink } \\
\text { Setting }\end{array}$ & I & $\begin{array}{l}\text { Causes suppression of } \\
\text { entire Menu Text List }\end{array}$ \\
\hline $\begin{array}{l}\text { Supress Menu Text } \\
\text { Entry }\end{array}$ & & $\mathrm{DL}$ & $\begin{array}{l}\text { DataLink } \\
\text { Setting }\end{array}$ & I a & $\begin{array}{l}\text { a }=\text { The Menu Text Referent } \\
\text { to be suppressed. }\end{array}$ \\
\hline $\begin{array}{l}\text { Display Menu Text } \\
\text { List }\end{array}$ & & $\mathrm{DL}$ & $\begin{array}{l}\text { DataLink } \\
\text { Setting }\end{array}$ & $\mathrm{D}$ & $\begin{array}{l}\text { Causes the Menu Text List } \\
\text { to be displayed in its } \\
\text { original state. }\end{array}$ \\
\hline $\begin{array}{l}\text { Display A Menu Text } \\
\text { Entry }\end{array}$ & & & & $\mathrm{D} a$ & $\begin{array}{l}a=\text { The Menu Text Referent } \\
\text { to be displayed. }\end{array}$ \\
\hline $\begin{array}{l}\text { Substitute a Menu } \\
\text { Text Entry }\end{array}$ & $\begin{array}{r}\text { INTERIM ALT } \\
(Q Q)\end{array}$ & & & a ddd FLID & $\begin{array}{l}\mathrm{a}=\text { Menu Text Referent } \\
\mathrm{w} / \mathrm{plus} \text { ddd = Altitutde data } \\
\text { Changes MT for a one uplink }\end{array}$ \\
\hline $\begin{array}{l}\text { Change a Menu Text } \\
\text { Entry }\end{array}$ & & $\overline{D L}$ & $\mathrm{MC}$ & A ddd & $\begin{array}{l}\mathrm{a}=\text { Menu Text Referent } \\
\mathrm{w} / \mathrm{plus} \text { ddd = Altitude data }\end{array}$ \\
\hline $\begin{array}{l}\text { Reposition Menu Text } \\
\text { List }\end{array}$ & $\begin{array}{l}\text { PVD } \\
(\mathrm{QP})\end{array}$ & & & A Trackball & $\begin{array}{l}\text { A }=\text { Menu Text List } \\
\text { designation } \\
\text { Trackball to desired PVD } \\
\text { area. }\end{array}$ \\
\hline
\end{tabular}


D-4

EN ROUTE RADAR CONTROLLER DATA LINK CHART

(CONCLUDED)

\begin{tabular}{|c|c|c|c|c|c|}
\hline PURPOSE & Q/A KEY & CAT KEY & FUNC KEY & FIELD CONTENT & COMMENTS \\
\hline $\begin{array}{l}\frac{\frac{\text { List Management }}{\text { (Concluded) }}}{\text { Status List }} \\
\text { Suppress Display of } \\
\text { Data Link SErvice }\end{array}$ & & DL & $\begin{array}{l}\text { DATALINK } \\
\text { SETTING }\end{array}$ & $11 \mathrm{~S}$ & $\begin{array}{l}11 \text { = The Service Type to be } \\
\text { suppressed. } \\
\text { Service Types:AA (Altitude) } \\
\text { TC (Transfer of Comm), \& } \\
\text { FT (Free Text) }\end{array}$ \\
\hline $\begin{array}{l}\text { Display Suppressed } \\
\text { Data Link service }\end{array}$ & & $\mathrm{DL}$ & $\begin{array}{l}\text { DATALINK } \\
\text { SETTING }\end{array}$ & $11 \mathrm{D}$ & $\begin{array}{l}11 \text { = The Service Type to be } \\
\text { suppressed. } \\
\text { Service Types:AA (Altitude) } \\
\text { TC (Transfer of Comm), \& } \\
\text { FT (Free Text) }\end{array}$ \\
\hline $\begin{array}{l}\text { Reposition Status } \\
\text { List }\end{array}$ & $\begin{array}{l}\text { PVD } \\
(\mathrm{QP})\end{array}$ & & & L Trackball & $\begin{array}{l}\mathrm{L}=\text { The Status List } \\
\text { designation. Trackball to } \\
\text { desired PVD area }\end{array}$ \\
\hline $\begin{array}{l}\text { Delete a Status List } \\
\text { Message }\end{array}$ & & & & D Trackball & $\begin{array}{l}\text { Trackball the Status List } \\
\text { message. Only HELD, FAILED, } \\
\text { NO TECH ACK, UNABLE msgs } \\
\text { can be deleted. }\end{array}$ \\
\hline $\begin{array}{l}\text { Resend a Non-Wilcoed } \\
\text { Message }\end{array}$ & & & & $\begin{array}{c}\text { Trackball } \\
----- \\
\text { (SVC ID) FLID }\end{array}$ & $\begin{array}{l}\text { Same message types as for } \\
\text { deleting. SVC ID }=\mathrm{DL} \\
\text { service type (two } \\
\text { characters-TC, AA, FT) if } \\
\text { omitted TC assumed. }\end{array}$ \\
\hline
\end{tabular}


